\title{
Belize coverage exercise study: Assessing the status to build a portfolio of targeted interventions for vulnerable girls
}

Joint UN Programme of Adolescent Girls

Follow this and additional works at: https://knowledgecommons.popcouncil.org/departments_sbsr-pgy

Part of the Demography, Population, and Ecology Commons, Family, Life Course, and Society Commons, and the Maternal and Child Health Commons How does access to this work benefit you? Let us know!

\section{Recommended Citation}

Joint UN Programme of Adolescent Girls. 2012. "Belize coverage exercise study: Assessing the status to build a portfolio of targeted interventions for vulnerable girls." New York: Joint UN Programme of Adolescent Girls. 


\section{JOINT UN PROGRAMME OF}

\section{ADOLESCENT GIRLS}

BELIZE COVERAGE EXERCISE STUDY: ASSESSING THE STATUS TO BUILD A PORTFOLIO OF TARGETED INTERVENTIONS FOR VULNERABLE GIRLS



JUNE 2012

REPORT 


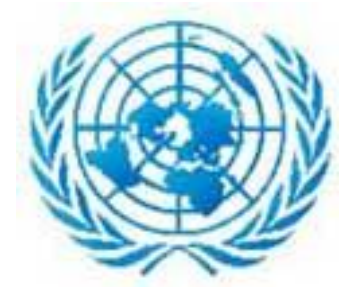

\section{Table of Contents}

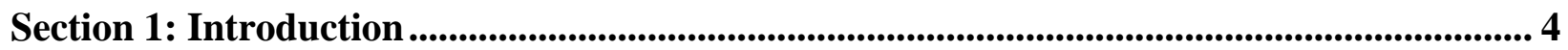

Background: Why Young People......................................................................................................................

Need for Holistic, Evidence-based Interventions..........................................................................................5

Youth \& Adolescents in Belize ......................................................................................................................

Section 2: Coverage Exercise Study ................................................................................... 18

Coverage Exercise Study - A Tool for Analyzing Service Provision .....................................................18

Methodology...........................................................................................................................................................21

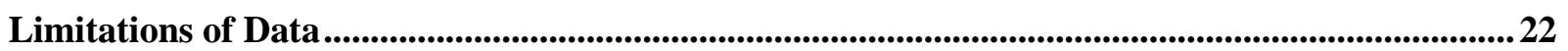

Section 3: Results of Belize Coverage Exercise Study ............................................................. 22

Demographic Characteristics of Respondents ..........................................................................................22

Marital Status ...............................................................................................................................................33

Parenthood ...........................................................................................................................................36

Education ...............................................................................................................................................

Work \& Volunteerism ...............................................................................................................................48

Service Provision.................................................................................................................................................50

Identifying Vulnerable Subgroups of Young Service Users ..................................................................58

Section 4: Conclusions \& Recommendations .................................................................65

Conclusions ..................................................................................................................................................65

Recommendations...........................................................................................................................66

References .......................................................................................................................................................................69

Section 5: Appendices .................................................................................................................... 70

Appendix 1: Participating Organizations Profiles................................................................................70

Appendix 2: Questionnaire .................................................................................................................... 71

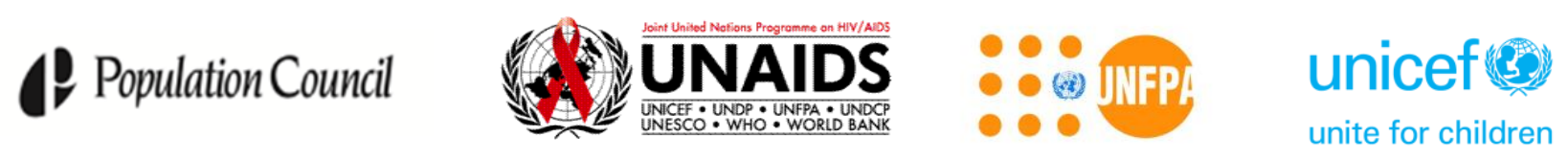




\section{SECTION 1: INTRODUCTION}

I n March 2011, the United Nation Children Fund (UNICEF), the United Nations Population Fund (UNFPA) and Population Council staff began collaborating on a number of activities to generate evidence on the lives and experiences of adolescent girls in Belize. The goal of the collaboration was to establish targeted, evidence-based policies and programs sensitive to the unique needs of girls. This document is the final report of the 2011 Belize Coverage Exercise Study, a data collection activity focusing on youth service providers that took place from November 15 to December 15, 2011 at select sites in three districts: Belize, Stann Creek and Toledo. The information presented is of particular interest to program planners, policy-makers and decision-makers from a wide range of institutions seeking to designate resources for programs and policies for vulnerable or marginalized subgroups of young people, particularly girls, in Belize. The report presents empirical evidence along with a substantive explanation of the indicators and issues of interest to youth and adolescents. This allows for the translation of the data and information into informed program design, policy analysis and resource allocation to reach the under-served young people whose well-being is so critical to achieving social and economic development in Belize.

The definition of "children," "adolescents" and "youth" affect many decisions and play an important role in the allocation of resources in a way that has serious budgetary implications for governments, NGOs, UN agencies, civil society groups and donors. For the purpose of this report, the authors use the definitions adopted by the United Nations. According to the UN's Department of Economic and Social Affairs, the term "youth" refers to persons between the ages of 15 and 24 while "adolescent" is defined as a person between the ages of 10 and 19 . The primary focus of the analysis presented in this report is on the age group of 10-24, encompassing both youth and adolescents, and they are referred to collectively as "young people" throughout this document. While these definitions may not correspond to those commonly used by government and civil society in Belize, it was important to select a standardized definition that is internationally comparable for the purposes of this report.

In order to make full use of available data on young people in Belize, the authors utilize data and empirical evidence from other sources that are cited at all times. Using other data sources allows the authors to triangulate the coverage exercise data - a supply-side focus to highlight trends in service delivery among participating organizations - with population-based data and other surveys to fill in gaps in empirical evidence. One data source in particular the authors utilized is the 2010 Belize Population and Housing Census. At times, the Main Results of 2010 Population and Housing Census (SIB 2010) report is utilized and at other times the authors' own analyses are the source. For the latter, the authors obtained a 10 percent sample of the 2010 Belize Population and Housing Census from the Statistical Institute of Belize and were able to run their own tabulations and descriptive statistics to support the analyses presented within. Whenever the census is cited it is the authors' analysis of the 10 percent sample unless otherwise noted. 


\section{Background: Why Young People}

Youth and adolescence are developmental stages define by rapid physical, social and emotional changes. During these phases, young people go through a number of formative experiences that require accurate information and reliable support to ensure they are safe and free from the pitfalls that can derail them for life. Some of these are: the onset of puberty; sexual initiation; marriage; childbearing; and the transition from school to work. In order to ensure that young people have a safe and healthy transition to adulthood they will need access to quality education, health services, job skills training and safe income-generating opportunities. It is the responsibility of government and civil society to provide the support mechanisms that allow young people to develop the human and social capital needed to become productive adult members of their communities.

Youth and adolescents are key drivers of change in every society. As a result, addressing their needs in a sensitive and relevant way is critical to achieving national development goals and those outlined in poverty reduction strategies. These include: breaking the intergenerational cycle of poverty, achieving universal primary education and increasing secondary school completion rates; reducing maternal and infant mortality; and halting the spread of HIV/AIDS. To do this successfully, decision-makers and planners must have a deep understanding of the youth and adolescent populations in their country in order to provide equitable access to scarce resources to all young people regardless of their age, sex, ethnicity or place of residence.

Two facts form the foundation of the lives of young people: 1) they are a highly diverse population, comprised of multiple subgroups each with its own unique needs based on the circumstances and characteristics of their daily lives; and 2) change occurs rapidly from one year to the next and can lead towards/away from vulnerability, significantly altering their lives for better or worse.

Young people's skills, knowledge and opportunities vary greatly depending on their age, sex, school attendance status, level of educational attainment, marital status, parental status, place of residence and household composition, among others. This diversity - in both their demographic and social characteristics as well as their access to opportunities - is regularly overlooked by policies and programs as evidenced by one-size-fits-all approaches that are not tailored to the specificities of their lives. A strong base of empirical evidence and the substantive understanding of the issues young people face are critical to developing targeted, evidence-based interventions that provide holistic approaches to building the social and human capital of those with the greatest needs and ensure that young people's rights to full development are achieved.

\section{Need for Holistic, Evidence-based Interventions}

If programs, services and other interventions do not reach the most vulnerable and marginalized subgroups of young people, national development goals and objectives will not be met in a timely manner. In fact, interventions not purposefully designed and based on reliable evidence 
may inadvertently increase disadvantage by delivering services to those who already have greater access to resources and opportunities, while excluding those who do not.

Population-based data used in conjunction with program-level data can help form the foundation of evidence to begin constructing a portfolio of targeted interventions designed to reach vulnerable girls and boys in ways that are relevant to their unique situations. These data can be used to identify and highlight critical points in the developmental path where a young person can move from being 'on track' to 'at risk.' They become the empirical information required for the design of interventions that address these specific vulnerabilities before they are likely to appear. For example, after young girls reach puberty at around age 12 or 13 , in many societies they begin to experience increased pressure to begin their sexual and reproductive lives by entering into sexual relationships or early marriage and childbearing. Interventions that are designed with consideration for this potential vulnerability can help to ensure that a girl of this age stays in school and avoids early sexual initiation while simultaneously building her capacity to be an informed and autonomous decision-maker.

The commonly used definitions for "children," "adolescents" and "youth" are used to define target populations for interventions. This means that certain age groups are likely to receive greater attention than others due to institutional priorities. Reproductive health services focusing on contraception are more likely to reach the "low-hanging fruit," or sexually active youth, usually age 15 and up, who experience fewer obstacles to accessing local programs. Many of these types of programs do not include parallel interventions that prepare younger adolescents age 10-14 to deal with the issues related to entering into sexual relations both within and outside of marriage. Job skills training and small business development programs usually targeted older adolescents ready to enter the labor force but rarely include a component to teach financial literacy and other related skills to younger adolescents to prepare them for entry into the work force. All age groups of young people have their specific needs and challenges, however policies and programs often overlook younger adolescents age 10-14 since they are in the developmental phase between "child" and "youth." Disaggregating data by characteristics and indicators relative to the local youth and adolescent population is the necessary first step for targeting scarce resources to services for disadvantaged and other vulnerable subgroups of young people.

Many young people, such as excluded young girls or ethnic minorities, experience asymmetries of power within their households and communities. To improve the lives of these vulnerable young people, sexual and reproductive health (SRH), poverty alleviation and education programs must empower the young beneficiaries otherwise they are likely to improve their lives and have lasting effects. 'Livelihoods' is broadly defined as the skills necessary to become economically productive as a means to increased autonomy and empowerment. A livelihoods approach to programming is one where service providers work to develop these specific skills. By integrating a livelihoods approach within, for example, a SRH intervention program planners acknowledge that issues such as HIV/AIDS, STIs, early marriage and pregnancy or sexual and gender-based 
violence are intricately linked with condition of vulnerability that arise from poverty, limited education and a poor understanding of one's rights.

The integration of a livelihoods approach within SRH programming recognizes that such problems as STIs/HIV, early pregnancy, early marriage, or sexual violence, are linked to circumstances of vulnerability related to poverty, lack of education, and limited understanding of one's rights. For example, in South Africa, girls and boys aged 14-19 who experienced nonconsensual sex were less likely to be enrolled in school than those who had not experienced nonconsensual sex (Hallman 2007). While identifying the actual causal pathway of this relationship would require additional research, these and other data are evidence of the linkages between sexual abuse or violence and education. In many settings, particularly those defined by poverty, young people can suffer multiple disadvantages. A livelihoods program for vulnerable youth and adolescents that includes SRH and general health information will serve as a bridge to preventive and treatment services for those who need them (Bruce 2007). Offering young girls and women safe and dignified livelihood and educational opportunities can help to decrease high-risk behavior and support them in developing the tools with which they can support themselves.

\section{Youth \& Adolescents In Belize}

According to the 2010 Belize Population and Housing Census, the population of Belize is approximately 303,000 (SIB 2011). Young people age 10-24 make up approximately $32 \%$ of the total population; young males and females are each approximately $16 \%$ of the entire population (Belize has an almost 1:1 female-to-male ratio). Among young people, $43 \%$ and $57 \%$ reside in urban and rural areas, respectively. These rates closely resemble the urban/rural distribution of the entire population ( $45 \%$ and $55 \%$, respectively).

The urban/rural distribution of males and females varies significantly from one district to the next. However females and males are distributed relatively similarly in urban and rural areas within each district. Table 1 shows the percent distribution of female and male youth by district.

Table 1: National percent distribution of young people according to 2010 Belize Census, by sex and district

\begin{tabular}{|c|c|c|c|c|c|c|}
\hline \multirow[b]{2}{*}{ District } & \multicolumn{3}{|c|}{ Females (10-24) } & \multicolumn{3}{|c|}{ Males (10-24) } \\
\hline & Rural & Urban & Total & Rural & Urban & Total \\
\hline Corozal & 79.2 & 20.8 & 100.0 & 77.3 & 22.7 & 100.0 \\
\hline Orange Walk & 72.4 & 27.6 & 100.0 & 70.4 & 29.6 & 100.0 \\
\hline Belize & 28.3 & 71.7 & 100.0 & 29.6 & 70.4 & 100.0 \\
\hline Cayo & 52.2 & 47.8 & 100.0 & 51.6 & 48.4 & 100.0 \\
\hline Stann Creek & 68.5 & 31.5 & 100.0 & 75.1 & 24.9 & 100.0 \\
\hline Toledo & 84.4 & 15.6 & 100.0 & 84.0 & 16.0 & 100.0 \\
\hline
\end{tabular}


TOTAL

56.6

43.4

100.0

57.1

42.9

100.0

Source: 2010 Belize Census (authors' analysis of 10\% sample)

Table 1 shows that only Belize District has an urban population of young people that is larger than its rural population (over 70\% urban for males and females). Cayo's rural and urban female and male populations are slightly more than $50 \%$ while Corozal's and Toledo's rural young population are approximately $78 \%$ and $84 \%$, respectively.

Education in Belize is mandatory from age 5 t0 14 years. Among females age 5-19, 85.9\% and $76.8 \%$ are attending school in urban and rural areas, respectively. Among males of the same age group, $85.9 \%$ and $77.8 \%$ are attending school in urban and rural areas, respectively. The gender parity index for school attendance (i.e., the ratio of females attending school to males attending school) at the national level for young people age 5-19 is 0.99, which means almost the exact same proportion of females are attending school as males. Figure 1 shows the school attendance rates of young people in urban and rural areas.

Figure 1: Percent of young people age 5-19 currently attending school according to 2010 Belize Census, by sex, age and area of residence



Source: 2010 Belize Census (authors' analysis of 10\% sample) 
Figure 1 shows that up until age 11, males and females in urban and rural areas attend school at a similar rate. After age 12, there is a sharp decline in the proportion of rural males and females attending school from year to year. In urban areas, the sharp decline begins after age 13. Table 2 below shows the school attendance rates for males and females age 12-19 in urban and rural areas to further highlight the differences seen between the areas of residence.

Table 2: Percent of young people age 12-19 currently attending school according to 2010 Belize Census, by sex, age and area of residence

\begin{tabular}{|cccc|ccc|}
\hline & \multicolumn{3}{c}{ Females } & \multicolumn{3}{c|}{ Males } \\
Age & Rural & Urban & Rural:Urban & Rural & Urban & Rural:Urban \\
\hline 12 & 91.9 & 97.1 & 0.95 & 97.0 & 98.7 & 0.98 \\
13 & 84.4 & 95.8 & 0.88 & 85.5 & 98.2 & 0.87 \\
14 & 76.5 & 90.8 & 0.84 & 73.9 & 91.1 & 0.81 \\
15 & 58.9 & 83.9 & 0.70 & 62.9 & 79.1 & 0.80 \\
16 & 47.2 & 83.0 & 0.57 & 50.3 & 75.4 & 0.67 \\
17 & 47.4 & 59.2 & 0.80 & 42.5 & 62.2 & 0.68 \\
18 & 35.7 & 52.1 & 0.69 & 27.3 & 44.2 & 0.62 \\
19 & 16.0 & 29.4 & 0.54 & 19.9 & 39.9 & 0.50 \\
\hline
\end{tabular}

Source: 2010 Belize Census (authors' analysis of $10 \%$ sample)

The proportional difference in school attendance rates between urban and rural young people is greatest (i.e., the lowest rural-to-urban ratio) among females at ages 16 and 19 where approximately half the proportion of rural females attend school than urban females. Among males, the proportional difference is greatest at ages 18 and 19 where approximately two-thirds and one-half the proportion of rural males attend school than urban males, respectively.

Despite the high rates of early school leaving in Belize, those who stay in school appear to keep on the expected track. Table 3 shows the percent of each age/sex cohort by the school level they are presently in among those currently attending school. Over $80 \%$ of 10-14-year old males and females are in primary school while over $70 \%$ of $15-19$-year old males and females are in secondary school, the school levels associated with those age groups. Among 15-19-year olds, over $20 \%$ of females and $16 \%$ of males are studying at the post-secondary or university levels, a trend that shows promising advances in education among this cohort. 
Table 3: Percent presently attending each school level among young people age 10-19 according to 2010 Belize Census, by age and sex

\begin{tabular}{|c|c|c|c|c|c|c|}
\hline Age & Primary & Secondary & $\begin{array}{c}\text { Post- } \\
\text { secondary }\end{array}$ & University & Other & Total \\
\hline \multicolumn{7}{|c|}{ Females } \\
\hline $10-14$ & 81.0 & 18.6 & 0.1 & 0.0 & 0.3 & 100 \\
\hline $15-19$ & 5.0 & 73.2 & 18.7 & 2.4 & 0.6 & 100 \\
\hline \multicolumn{7}{|c|}{ Males } \\
\hline $10-14$ & 86.0 & 13.4 & 0.1 & 0.0 & 0.6 & 100 \\
\hline $15-19$ & 10.1 & 72.6 & 14.8 & 1.5 & 0.9 & 100 \\
\hline
\end{tabular}

Source: 2010 Belize Census (authors' analysis of 10\% sample)

An additional indicator used for analyzing if young people are on track in school is their gradefor-age status. This indicator measures whether or not a young person is currently attending the grade or school level that corresponds with his/her age according to official definitions. For purposes of this report, the authors constructed a grade-for-age variable that allowed for a one year delay in starting school at the official age: For example, the official start age for Infant 1 is five years old in Belize. If an individual started Infant 1 between the ages of 5-6 and proceeded through the educational system without repeating a year then he/she would be considered at grade-for-age in whatever school level he/she was attending at the time of the census data collection. Below is a chart that shows the proportion of young people that are grade-for-age in urban and rural areas among all young people; those who are no longer attending school were classified as not being grade-for-age in order to analyze the data among the entire population from 10-18 years of age. 
Figure 2: Percent of all young people age 10-18 that are grade-for-age according to 2010 Belize Census, by age, sex and area of residence (Belize)

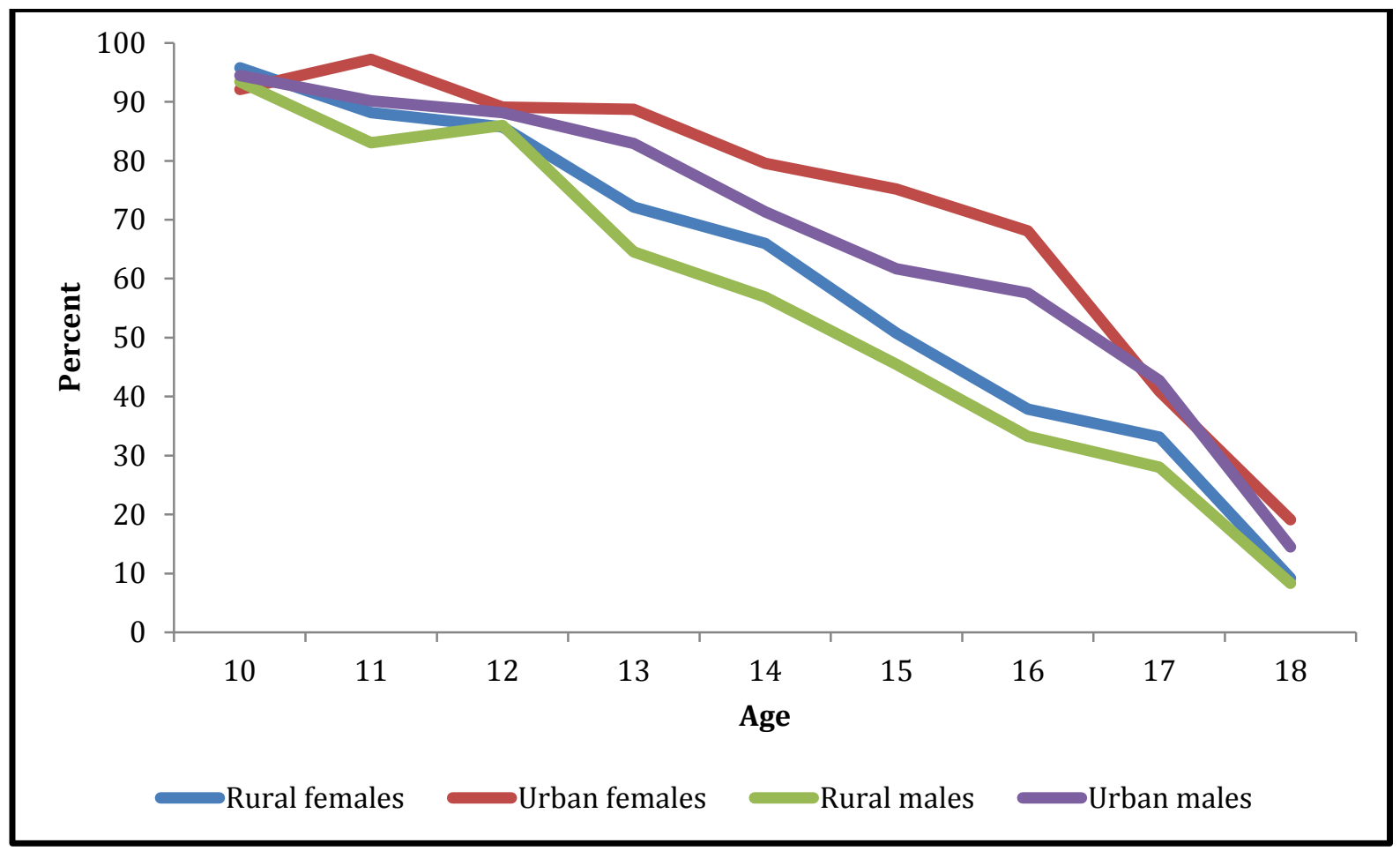

Source: 2010 Belize Census (authors' analysis of 10\% sample)

Figure 2 shows that a high proportion of males and females living in urban and rural areas are at grade-for-age from ages 10-12. This rate begins to steadily decrease thereafter with rural males showing the lowest levels overall. Females appear to be at grade-for-age at a higher rate than males in both urban and rural areas except at age 17 in urban areas and age 18 in rural areas, where the rates are almost equal. By the time young people reach age 18 , less than $10 \%$ of males and females in rural areas and less than $20 \%$ of urban females and less than $15 \%$ of urban males are still grade-for-age, according to the 2010 census.

The data on relationship status among young people age 15-19 show that over $70 \%$ of females and $85 \%$ of males nationally reported not being in any type of union. Of those who did report being in some type of union, over $50 \%$ of females $(12.8 \%$ out of $23.9 \%)$ reported being in a common-law relationship while over $60 \%$ of males $(7.3 \%$ out of $11.9 \%)$ reported being in a visiting partner relationship. Table 4 shows relationship status by district and urban/rural area of residence and highlights some of the differences seen in these geographic areas. For example, in Stann Creek, $20.2 \%$ of females age 15-19 are in common-law relationships while in the other districts the percent ranges from 10.5-15.0\%. In Belize district, almost 18\% of females age 15-19 are in visiting partner relationships compared to the other districts where $1.2-9.0 \%$ are in a similar situation. For both males and females, visiting partner relationships are more common in urban areas than in rural areas. 
Table 4: Relationship status among young people age 15-19 according to 2010 Belize Census, by sex, district and area of residence

\begin{tabular}{|c|c|c|c|c|c|c|}
\hline $\begin{array}{l}\text { Area of } \\
\text { residence }\end{array}$ & $\begin{array}{c}\text { Married } \\
\text { and living } \\
\text { with } \\
\text { spouse }\end{array}$ & $\begin{array}{c}\text { Common- } \\
\text { law }\end{array}$ & $\begin{array}{l}\text { Visiting } \\
\text { partner }\end{array}$ & $\begin{array}{c}\text { Not } \\
\text { in } \\
\text { union }\end{array}$ & $\begin{array}{c}\text { Not } \\
\text { reported }\end{array}$ & Total \\
\hline \multicolumn{7}{|c|}{ Females 15-19 } \\
\hline Corozal & 6.6 & 13.7 & 4.0 & 73.2 & 2.5 & 100.0 \\
\hline Orange Walk & 4.1 & 11.1 & 3.3 & 80.3 & 1.2 & 100.0 \\
\hline Belize & 1.1 & 10.5 & 17.7 & 69.4 & 1.3 & 100.0 \\
\hline Cayo & 2.3 & 12.0 & 4.2 & 80.2 & 1.3 & 100.0 \\
\hline Stann Creek & 3.3 & 20.2 & 9.0 & 66.9 & 0.6 & 100.0 \\
\hline Toledo & 4.3 & 15.0 & 1.2 & 78.9 & 0.6 & 100.0 \\
\hline RURAL & 4.3 & 14.9 & 4.5 & 75.6 & 0.7 & 100.0 \\
\hline URBAN & 1.5 & 10.3 & 12.5 & 73.7 & 2.1 & 100.0 \\
\hline TOTAL FEMALES & 3.0 & 12.8 & 8.1 & 74.7 & 1.3 & 100.0 \\
\hline \multicolumn{7}{|c|}{ Males 15-19 } \\
\hline Corozal & 1.2 & 5.5 & 2.2 & 88.3 & 2.8 & 100.0 \\
\hline Orange Walk & 0.5 & 2.3 & 2.8 & 92.7 & 1.8 & 100.0 \\
\hline Belize & 0.3 & 3.1 & 15.2 & 79.3 & 2.1 & 100.0 \\
\hline Cayo & 0.5 & 4.3 & 4.4 & 89.1 & 1.6 & 100.0 \\
\hline Stann Creek & 1.5 & 4.5 & 11.3 & 80.7 & 2.1 & 100.0 \\
\hline Toledo & 1.2 & 4.3 & 0.6 & 93.3 & 0.6 & 100.0 \\
\hline RURAL & 0.8 & 4.5 & 4.0 & 88.9 & 1.8 & 100.0 \\
\hline URBAN & 0.6 & 3.0 & 11.7 & 82.8 & 1.9 & 100.0 \\
\hline TOTAL MALES & 0.7 & 3.9 & 7.3 & 86.3 & 1.9 & 100.0 \\
\hline
\end{tabular}

Source: 2010 Belize Census (authors' analysis of 10\% sample)

Figure 3 below shows the percent of 15-19-year-old males and females who are married, in a common law relationship or visiting partner relationship (referred to here as "in union") by single years according to area of residence. Among all ages, females are in union at higher rates than males. Urban and rural females are in union at almost equal rates with only minor differences seen at ages 15 and 19. Rural males reported being in a union at the lowest rates. Rural females are two- to four-times as likely to be in union than their rural male counterparts while urban females are 1.2-2.5 times as likely to be in union than their urban male counterparts. 
Figure 3: Relationship status among young people age 15-19 according to 2010 Belize Census, by sex, single year and area of residence

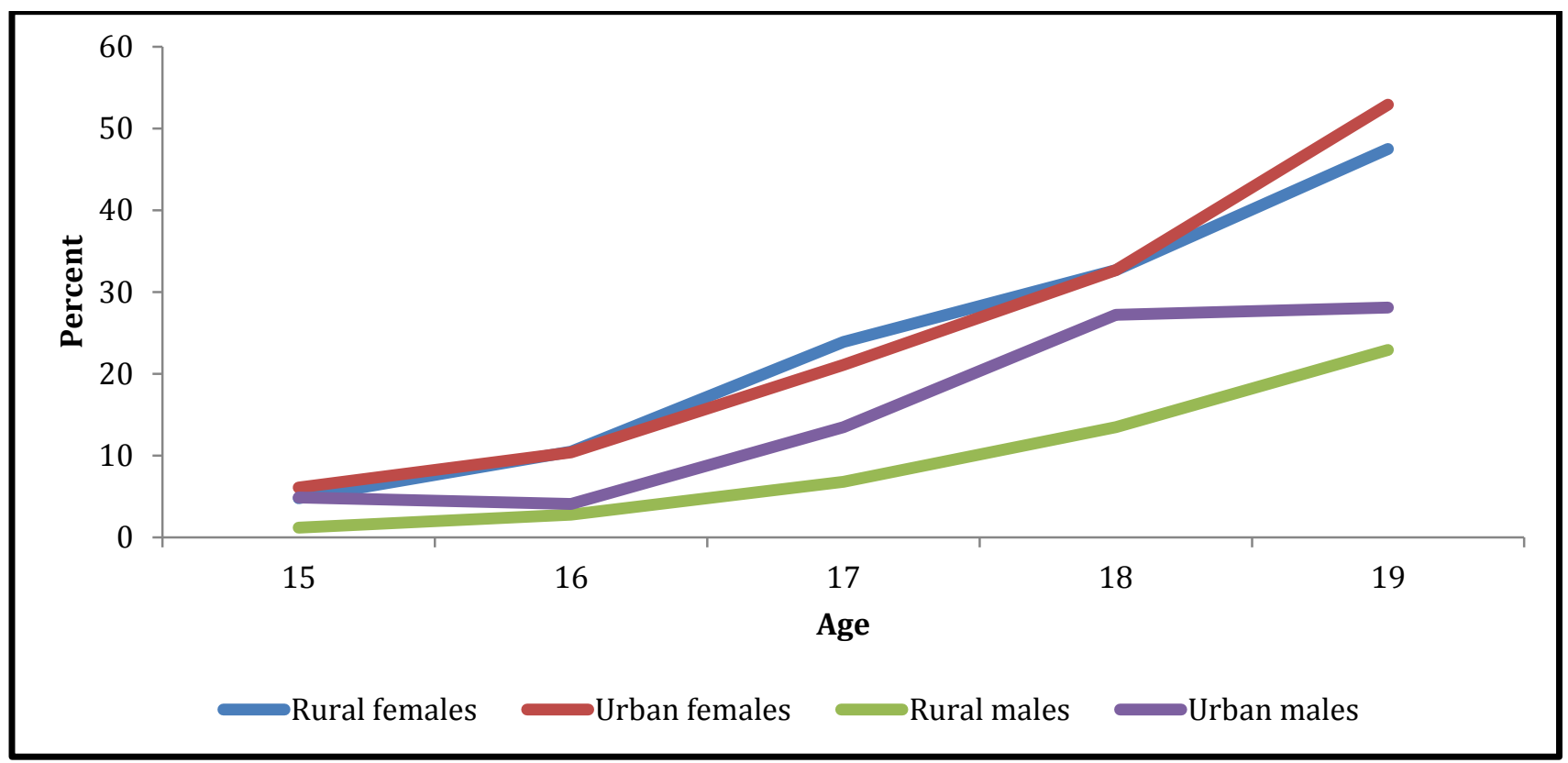

Source: 2010 Belize Census (authors' analysis of 10\% sample)

Early childbearing is an issue that can complicate the lives of young people in many ways. The need to support a child can lead to early school leaving in order to obtain the necessary employment to bring in the required income. Young females, particularly those who are still physiologically underdeveloped such as girls under the age of 15, are at high risk for complications during childbirth, which also threaten the well-being of their child; an issue that becomes even more acute when females are living in circumstances of poverty (Haberland et al 2003). According to the census, the median age at first birth among females age 15-19 is 17 and this varies only in Corozal district where the median age is 16 . The 2009 total fertility rate in Belize was 2.8 births per woman (World Bank 2012).

Figure 4 below shows the percent of urban and rural females who have ever given birth by single year. As expected, the proportion increases steadily with age. For females in urban areas, there is a sharp increase in childbearing after age 16 and for females in rural areas after age 17. These trends are very important to identify as it will help service providers to target interventions early enough in girls' lives to protect against teenage pregnancy. 
Figure 4: Percent of females age 15-19 who have ever given birth according to 2010 Belize Census, by single year and area of residence

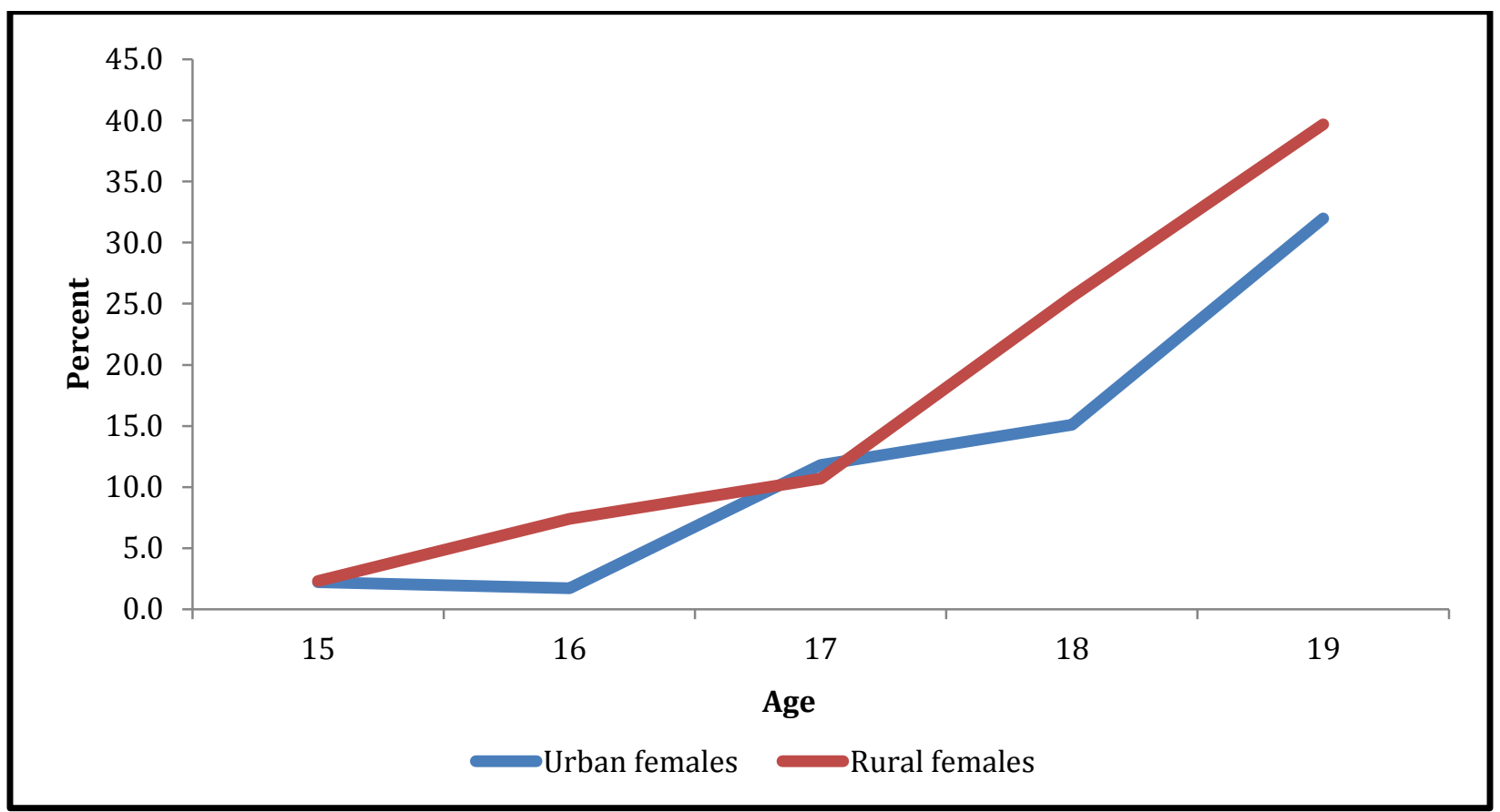

Source: 2010 Belize Census (authors' analysis of 10\% sample)

Table 5 shows rates of teen pregnancy in Belize among females age 18-24. In Stann Creek, over $16 \%$ of females age $18-24$ gave birth by age 15 and over $43 \%$ by age 18 . The former is more than twice the national average while the latter exceeds the national average by almost $10 \%$. In Toledo, almost $10 \%$ of females age $18-24$ gave birth by age 15 while almost $39 \%$ gave birth by age 18. These high rates of teen pregnancy are of particular concern, especially for girls giving birth before age 15 . 
Table 5: Percent of females age 18-24 who gave birth by ages 15 and 18 according to 2010 Belize Census, by district and area of residence

\begin{tabular}{|lcc|}
\hline Area of & $\begin{array}{c}\text { \% who } \\
\text { gave birth } \\
\text { before age } \\
\text { residence }\end{array}$ & $\begin{array}{c}\text { \% who } \\
\text { gave birth } \\
\text { before age } \\
15\end{array}$ \\
\hline Corozal & 4.2 & 30.5 \\
Orange Walk & 6.2 & 31.5 \\
Belize & 6.7 & 30.8 \\
Cayo & 7.1 & 36.0 \\
Stann Creek & 16.4 & 43.2 \\
Toledo & 9.6 & 38.5 \\
RURAL & 8.4 & 36.5 \\
URBAN & 7.1 & 31.1 \\
TOTAL & 7.9 & 34.4 \\
\hline
\end{tabular}

Source: 2010 Belize Census (authors' analysis of 10\% sample)

The transition from young person to adult involves many life-altering changes including the transition from school to work. According to the 2010 census, Belize's unemployment rate for the population age 14 and over was $23.1 \%$ (SIB 2011). Females experienced almost twice the rate of unemployment as males $-33.1 \%$ and $16.7 \%$, respectively (SIB 2011). Among young people age 15-24, both males and females, the unemployment rate is $28.4 \%$ (SIB 2011). This is the highest rate among all five-year age cohorts in Belize, second only to the 14-19-year olds (49.7\%) (SIB 2011).

Table 6 shows the labor force participation categories and rates for males and females age 15-19 in the different districts and urban/rural areas. Mirroring the data on unemployment cited above, females are employed at lower rates than males in all districts and areas of residence. Additionally, females are not in the labor force at much higher rates than males across all geographic areas, an issue that would require further research to more fully understand, but may be due to the gender differences seen in school attendance or the differential between the level of household responsibilities experienced by males and females. ${ }^{1}$

\footnotetext{
${ }^{1}$ According to the United Nations, the economically inactive population - or those not in the labor force - is comprised of those who are neither employed nor unemployed for any of the following reasons: attending an educational institution; performing unpaid household duties; retired or on pension; or other reasons such as those who are receiving private support or are disabled (United Nations 2007).
} 
Table 6: Labor force participation among young people age 15-19 according to 2010 Belize Census, by age, sex, district and area of residence

\begin{tabular}{|c|c|c|c|c|}
\hline $\begin{array}{l}\text { Area of } \\
\text { residence }\end{array}$ & Employed & Unemployed & $\begin{array}{c}\text { Not in } \\
\text { labor force }\end{array}$ & Total \\
\hline \multicolumn{5}{|c|}{ Females 15-19 } \\
\hline Corozal & 14.2 & 21.0 & 64.8 & 100.0 \\
\hline Orange Walk & 13.2 & 19.5 & 67.3 & 100.0 \\
\hline Belize & 12.5 & 23.0 & 64.5 & 100.0 \\
\hline Cayo & 11.8 & 26.3 & 61.9 & 100.0 \\
\hline Stann Creek & 14.0 & 14.1 & 71.9 & 100.0 \\
\hline Toledo & 13.5 & 23.0 & 63.5 & 100.0 \\
\hline RURAL & 15.1 & 23.3 & 61.6 & 100.0 \\
\hline URBAN & 10.1 & 20.6 & 69.3 & 100.0 \\
\hline TOTAL & 12.9 & 22.1 & 65.0 & 100.0 \\
\hline \multicolumn{5}{|c|}{ Males 15-19 } \\
\hline Corozal & 41.7 & 20.1 & 38.2 & 100.0 \\
\hline Orange Walk & 40.0 & 13.4 & 46.6 & 100.0 \\
\hline Belize & 24.3 & 21.3 & 54.4 & 100.0 \\
\hline Cayo & 30.9 & 24.8 & 44.3 & 100.0 \\
\hline Stann Creek & 32.9 & 15.2 & 51.9 & 100.0 \\
\hline Toledo & 34.8 & 16.9 & 48.3 & 100.0 \\
\hline RURAL & 38.4 & 20.2 & 41.4 & 100.0 \\
\hline URBAN & 24.1 & 19.2 & 56.7 & 100.0 \\
\hline TOTAL & 32.3 & 19.8 & 47.9 & 100.0 \\
\hline
\end{tabular}

Source: 2010 Belize Census (authors' analysis of 10\% sample)

In many societies, as girls age they experience a great deal of pressure to begin sexual relations, marry, bear child and take on household responsibilities. Each of these pressures, if not met with the skills and support necessary to make healthy and safe decisions, can derail a young female in ways that may be impossible to reverse. Although boys face similar pressures, gender norms create a situation where the balance of power is in their advantage. In Belize, the high rates of early childbearing, the relatively low rates of school attendance among older school-age girls and the very low employment rates highlight the circumstances with which girls must contend on a daily basis. The competing interests of school, work, marriage and family require empirical evidence to fully understand. Figures 5 and 6 show the different activities in which girls from rural and urban areas are engaged to highlight how these issues change over time. They show the proportion of each age that is engaged in the particular activity. 
Figure 5: Competing activities among girls age 10-19 in rural areas



Source: 2010 Belize Census (authors' analysis of 10\% sample)

Figure 6: Competing activities among girls age 10-19 in urban areas



Source: 2010 Belize Census (authors' analysis of 10\% sample) 
By presenting data on these topics in this way, it becomes clear that as girls age, schooling decreases steadily while childbearing, marriage and employment increase steadily, albeit at different rates in rural and urban areas. And while this is expected, it is important to see how early in the lives of the young females these circumstances arise and take hold, a message of critical importance to policy-makers and program planners seeking to deliver the services necessary to support young girls and women in Belize.

\section{SECTION 2: COVERAGE EXERCISE STUdy}

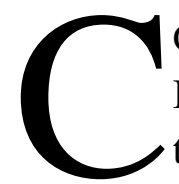

overage Exercise Study - A ToOl for Analyzing Service Provision

In recognition of the need for targeted, evidence-based programs and policies to reach

the most vulnerable and marginalized populations of young people, reliable data on a wide range of topics are required. In settings where large bodies of evidence are not publically available, researchers and analysts will need to conduct targeted data collection activities and triangulate the findings with other population-based data from censuses and surveys.

One such activity is the coverage exercise study (CE), a tool used to obtain data on the demographic, educational, work and other characteristics of the users and beneficiaries of youth services and programs - referred to as "respondents" in the sections below describing the results of the data analysis. It is a supply-side analysis that provides important information on what services are being used by which populations of young people. The CE is an important component of program monitoring activities, situation analyses and research on the lives of young people (Weiner 2011).

CE data are critical inputs for program staff, UN agencies, government ministries and other stakeholders to monitor the progress of interventions for young people in reaching the targeted population. They are also a key component for establishing a foundation of evidence for use in the design of national or regional campaigns to target resources at select subgroups within the youth and adolescent populations.

The CE process begins with a partnership between an organizing institution, such as a UN agency or government ministry, interested in establishing evidence on youth services and programs and an expert research group that has conducted CEs or similar activities to facilitate the data collection activities. Strategic planning sessions are used to define the geographic scope of the $\mathrm{CE}$, the timing of the data collection, the number and types of organizations that will participate in the data collection as well as the selection of a local technical agency that will organize and manage the fieldwork.

Data collection often occurs over a four to six week period and entails collecting data at various service delivery points (SDP) on the age, sex, marital status, childbearing history, educational background, work status and types of services utilized, among other characteristics. The

$\mathbf{1 8} \mid \mathrm{P}$ a g e 
technical team facilitates various meetings and workshops with the participating organizations, youth groups and the organizing institution(s) as part of an iterative process to elicit feedback on the topics covered in the $\mathrm{CE}$ questionnaire and the types of wording used. Additional topics covered by the $\mathrm{CE}$ have included ethnicity; language spoken at home; household composition or living arrangements; time or distance traveled to the SDP; type of and cost of transportation used to arrive at the SDP; perceived safety of the route traveled to reach the SDP; and participation in other activities or programs.

Analysts utilize the data from the $\mathrm{CE}$ to establish a profile of the users of services and program participants. This involves conducting data analyses to develop descriptive statistics on a wide range of characteristics in order to more fully understand which subgroups of young people are being served and which are not.

CE data are one type of information in a host of data sources that complement one another. Data such as censuses, household surveys, policy or situation analyses, coverage exercise studies, and program evaluations, complement one another by filling substantive and temporal gaps. For example, by triangulating CE data with census or household surveys such as the Demographic and Health Surveys (DHS) and Multiple Indicator Cluster Surveys (MICS), analysts can identify vulnerable populations of young people who are in need of targeted interventions.

Figure 7 below shows common sources of data that can potentially be collected at each administrative level (Uganda is shown as an example). Given the limitations of each, no one data source can answer every question one might have about youth and adolescents. For example, when planning a coverage exercise, there is a tension between depth and breadth. This is similar to other sources such as the census, which covers all individuals and households in a population but on a limited number of topics.

Large-scale sources of data, such as censuses and nationally representative household surveys, provide information on a range of geographic levels and are key inputs for the design of policies and programs and in determining resource allocation. National surveys, such as the DHS, MICS and labor force surveys are typically not designed to be representative below the regional level, however they are conducted fairly frequently, more so than the census, and are therefore valuable complementary sources of data. The other data collection tools listed in the Figure 7 are valuable to a wide range of stakeholders and can strengthen the empirical evidence available on the lives of young people as well as the availability of and access to services and programs. 
Figure 7: Data that inform policies and programs for adolescents

\begin{tabular}{|c|c|c|c|c|c|c|c|c|}
\hline & Cross-National & National & Sub-National Region & District & Sub-County & Parish & Community & \\
\hline National Census & O & 0 & O & O & O & O & O & \\
\hline National Survey & O & O & O & & & & & \\
\hline Policy Analysis & ○ & ○ & ○ & ○ & & & & \\
\hline Program Scan & O & O & O & ○ & 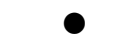 & $\bullet$ & 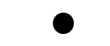 & \\
\hline Coverage Exercise & O & O & O & $\bullet$ & $\bullet$ & $\bullet$ & $\bullet$ & $\bullet$ \\
\hline Sub-National Survey & & & & $\bullet$ & $\bullet$ &  & ○ & $\bullet$ \\
\hline Outcome Evaluation $\dagger$ & & & & & & & & $\bullet$ \\
\hline Process Evaluation $\dagger$ & & & & & & & & ○ \\
\hline Participatory Mapping & & & & $\bullet$ & $\bullet$ & $\bullet$ & $\bullet$ & $\bullet$ \\
\hline
\end{tabular}

Note: Most likely to organize data collection at specified level (not necessarily representative)

$\bigcirc$ Population-based data collection would require significant resources

$\dagger$ Programs (and policies) can be evaluated across administrative/geographic units

Source: From the desk of E. Philip Green, Population Council

To date, coverage exercise studies have been conducted in the following countries as part of collaborations between UNFPA and/or UNICEF and the Population Council:

1. Ethiopia

2. Mauritania

3. Guinea Bissau

4. Burkina Faso

5. Liberia

6. Malawi

7. Guatemala

8. Nicaragua

9. El Salvador

10. Pakistan 
The results of these CEs show that a number of subgroups of young people are regularly underrepresented in the youth programs and services surveyed during the CE. Some examples are:

1. Out-of-school school-age males and females

2. Very young adolescents (age 10-14)

3. Married girls

4. Single mothers (except at reproductive health clinical services)

5. Rural males and females (except where services are delivered in rural areas)

6. Ethnic or linguistic minorities

The CE is a tool that is designed to be easily adapted to any set of circumstances. This permits interested stakeholders to design a CE methodology that fits in with the research and data collection goals and objectives of campaigns and projects for which evidence are required. CEs can be conducted for specific types of programs (such as youth livelihoods or reproductive health), programs/services within a target geographic area or for a donor's portfolio of programs. Any of these designs will allow for the use of the data to help improve overall service delivery in a way that ensures more effective and efficient use of resources.

\section{Methodology}

The goal of the 2011 Belize Coverage Exercise Study was to collect data at select sites in three districts (Belize, Stann Creek, and Toledo) to determine the extent to which adolescent girls are accessing services and participating in programs at those service delivery points. ${ }^{2}$ The data and information that resulted from the field work was meant to serve as a guide for: 1) establishing a broad evidence base on the experiences of girls in Belize; 2) designing new, or re-orienting existing, interventions among the participating organizations in order to include a greater number of girls; and 3) launching advocacy campaigns to expand services for girls and establish evidence-based programs and policies.

Site selection began over the summer of 2011 and the roster of participating organizations was finalized in November 2011. In total, 25 sites, including 10 polyclinics, representing 13 different organizations in the four districts collected data for four weeks from late November to late December 2011. Questionnaires were collected periodically during this time and data were cleaned and entered into Microsoft Access (and later transferred to STATA for the purposes of this report). A total of 3550 questionnaires were filled out and entered into the database.

The CE questionnaire was finalized after a vetting process that included meetings with the UNFPA Youth Advisory Group; two workshops, one each in Belize and Stann Creek, with

\footnotetext{
${ }^{2}$ Originally the study was designed for Belize, Stann Creek and Toledo districts however two participating organizations were strategically selected from Cayo and added to the roster shortly before data collection began. Due to the small number of respondents in Cayo during the CE, the data are not included in the tables with district disaggregated figures so as to avoid possible misrepresentation of the population included in the study.
} 
representatives from the participating organizations and other key stakeholders; and site visits to select partners to elicit feedback on the topics and wording used for the questions.

Enumerators were used to facilitate data collection in each site. They were selected based on recommendations from the participating organizations because of their familiarity with the local communities and their skills related to data collection. They were trained prior to the commencement of data collection during a series of workshops and site visits and, upon finalizing the training, were given copies of the questionnaire.

\section{Limitations of Data}

While the coverage exercise methodology does allow for obtaining data that are representative at the institutional or regional levels, none of those conducted thus far have done so. To do so, researchers and planners would need to design a sample frame based on a program/service delivery inventory in the geographic area of interest. Given time and resource constraints as well as the fact CEs were used primarily as either a rapid assessment of programs or part of a larger situation analysis, the decision was made not to make the data representative. As a result, endusers of CE data must avoid making generalized statements about service provision in a given country or district based on the CE data and clearly communicate that the data are based on those who were surveyed (i.e., the "respondents") during the data collection period. Data are not representative of young people in Belize or of all youth services in Belize.

\section{SeCtion 3: Results of Belize Coverage EXercise Study}

\section{DEMOGRAPHIC CHARACTERISTICS OF RESPONDENTS}

Age and Sex Distribution

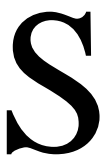

ex and age are the two topics most often cross-examined with other characteristics. Variations by sex and age occur across almost all of the common indicators used in youth and adolescent studies, such as education, marital status, fertility and labor force participation, among others. Data disaggregated by sex are necessary for analyzing gender dimensions while data disaggregated by age help draw out the rapid changes taking place during the different stages of a young person's life. By defining appropriate sex and age cohorts during the data analysis planning phase and subsequently disaggregating all data by these groups, it is possible to construct an evidence-base that reflects the reality of the lives of boys and girls, young men and women for the design and implementation of policies and programs.

The Belize CE participating organizations each have their own target populations for the variety of programs surveyed during the data collection period. Some, such as the polyclinics, are open to anyone in need of services while others are designed for more specific age/sex cohorts, such as out-of-school 12-17 year old females. As a result, age and sex distribution of the respondents 
is not representative of the population of Belize. Below is a population pyramid for the respondents:

Figure 8: Age and sex distribution of Belize CE respondents

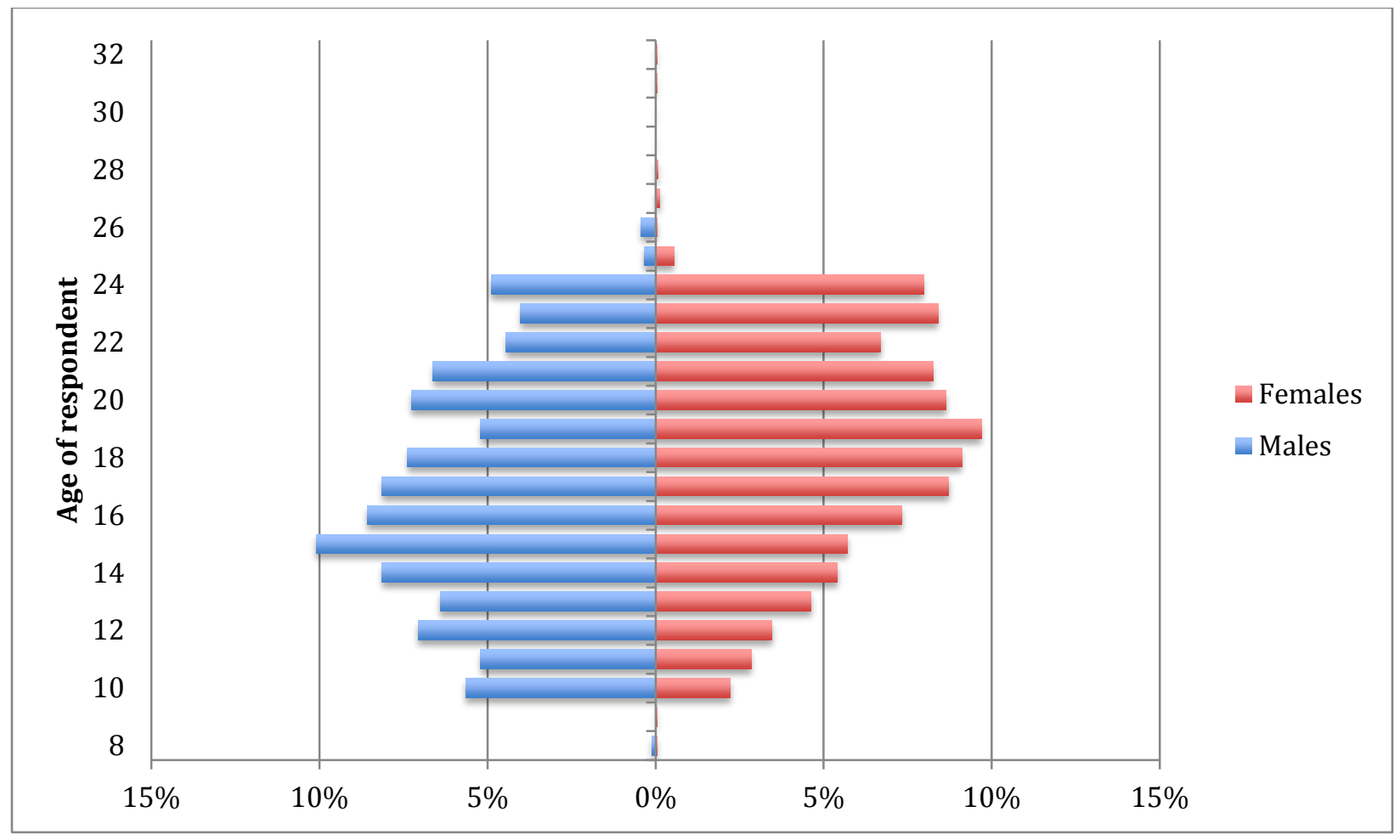

Figure 8 shows that 19-year-old females make up the largest percentile of the female respondents (9.7\% of all females) while 15-year-old males make up the largest percentile of the male respondents $(10.2 \%$ of all males).

Female respondents range in age from 8-32 while male respondents range from 8-26. The median age of females and males are 19 and 15, respectively. According to an analysis of the 2010 census, the median age of the young population (age 10-24) is 16 for both males and females.

Many issues and challenges begin when young people enter into puberty. School leaving, sexual initiation, early childbearing and marriage are among the numerous issues that arise during this time and require highly specified efforts to mitigate. As a result, service providers will want to begin working with young people earlier in their life before the problems arise; this means between the ages of 10 and 12 for both boys and girls. Figure 8 above shows that the participating service providers are reaching males at a younger age than females. In order to ensure the beneficiaries of programs are on track for a healthy transition from school to work and from youth to adulthood, service providers need to target services at the young adolescents in the 10-14-year-old age cohort. If young people in this age group are not utilizing the available 
services then program planners must devise strategies to reach them in other ways, such as visiting them in their communities and talking with their parents/guardians to better understand the obstacles they may face in accessing services.

Young people are often categorized by the developmental stage in which they fall according to their age, a classification that has important policy and programmatic implications. For the purposes of this report, the following development stage classifications are used:

1. Pre-adolescent: Less than 10

2. Young adolescent: $10-14$

3. Adolescent: $15-19$

4. Older youth: $20-24$

5. Young adult: Greater than 24

Table 7 shows the distribution of the respondents from the Belize CE according to development stages. Among females, the largest group represented among the respondents is the older youth (20-24). Among males, the largest group is the adolescents (15-19). However males are almost evenly distributed between the development stages representing 10-24 year olds while females show greater variation between the three groups.

Table 7: Percent distribution of respondents of the 2011 Belize Coverage Exercise, by sex and development stage

\begin{tabular}{|lcccccccc|}
\hline & $\begin{array}{c}\text { Pre- } \\
\text { Adolescents } \\
\text { (less than 10) }\end{array}$ & $\begin{array}{c}\text { Young } \\
\text { Adolescents } \\
(10-14)\end{array}$ & $\begin{array}{c}\text { Adolescents } \\
(15-19)\end{array}$ & $\begin{array}{c}\text { Older } \\
\text { Youth } \\
(20-24)\end{array}$ & $\begin{array}{c}\text { Young } \\
\text { Adults } \\
(25+)\end{array}$ & Total & N \\
\hline Male & 0.1 & 32.2 & 33.9 & 32.2 & 1.6 & 100.0 & 929 \\
Female & 0.1 & 18.5 & 30.8 & 49.5 & 1.2 & 100.0 & 2,579 \\
Not Reported & 0.0 & 21.4 & 26.2 & 50.0 & 2.4 & 100.0 & 42 \\
TOTAL & 0.1 & 22.1 & 31.5 & 45.0 & 1.3 & 100.0 & 3,550 \\
\hline
\end{tabular}

According to Figure 9, in all districts older youth (20-24) were the largest group of females served. Young adolescents (10-14), a population of great importance for targeting in order to reduce rates of teen pregnancy and early school dropout, make up between $12.8 \%$ and $50 \%$ of females served in the districts. In Toledo, Belize and Stann Creek districts, program planners may want to target resources at reaching 10-14-year-old girls given how important prevention programs are to this age group. Figure 10 shows that among males, programs and services appear to reach a larger proportion of young adolescents (10-14) than among females - between $21.3 \%$ and $37.2 \%$ of males served in the districts. 
Figure 9: Percent distribution of female respondents of the 2011 Belize Coverage Exercise in the district where services were delivered, by development stage

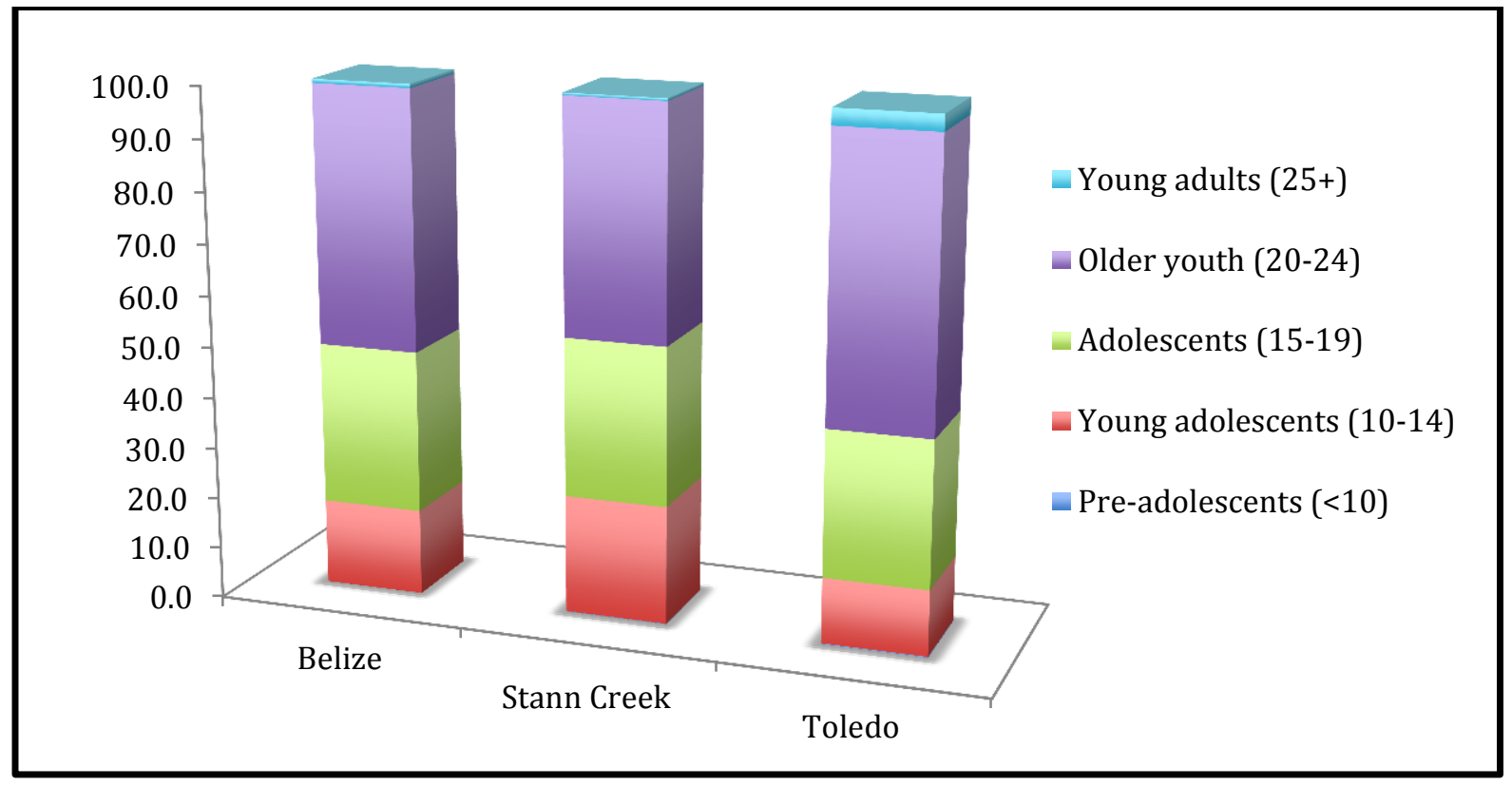

Figure 10: Percent distribution of male respondents of the 2011 Belize Coverage Exercise in the district where services were delivered, by development stage

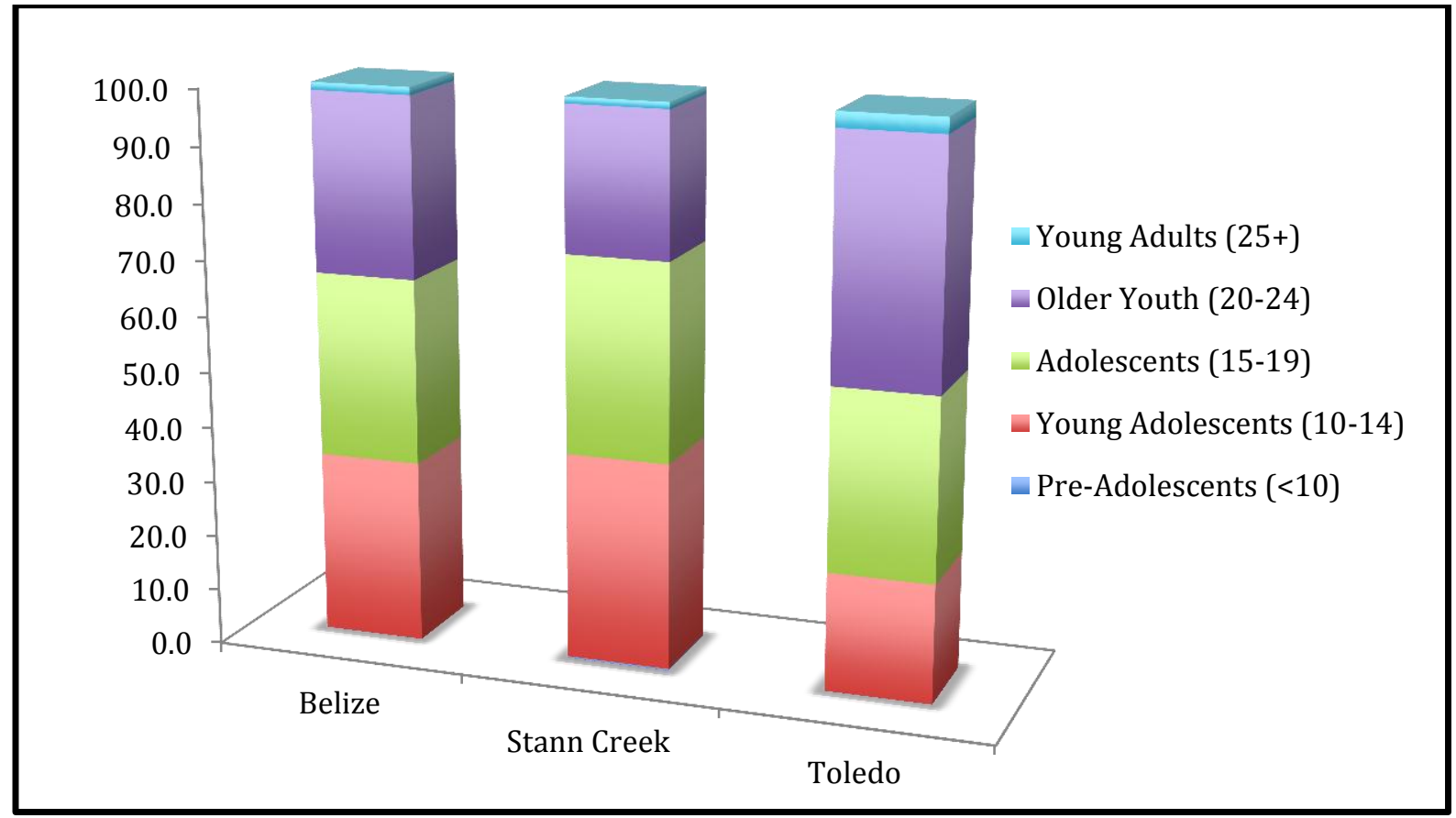




\section{Ethnicity and Language Spoken at Home}

Social and demographic characteristics and outcomes often show great variation among people from different ethnic or linguistic groups. The socio-economic status of an individual and his/her household is linked to their level of access to resources and opportunities, which in turn are linked through a complex web of causal relationships to the values and norms unique to the different ethnic and linguistic groups as well as those of the dominant society. Data on the ethnic and linguistic groups are necessary to ensure equity in access to basic services and rights.

Although the globalized structures that govern the world's social and economic institutions have brought a greater awareness and appreciation for ethnic and cultural diversity, they have also created barriers to inclusion and participation, particularly for indigenous peoples. For example, in Guatemala, 2.5 times as many indigenous females age 15 and above are illiterate than nonindigenous females of the same age: $60 \%$ and 24\%, respectively (ECLAC 2005). In Mexico, a country where $13 \%$ of the population (approximately 12.7 million people) self-identify as indigenous, the poverty rate is almost twice that among indigenous people than non-indigenous peoples (UNHCR 2012).

In Belize, the 2010 census shows variations in school attendance by ethnicity among 10-19 year olds. Figure 11 below shows that among females age 15-19, Mayans have the lowest rate of school attendance $(34.6 \%)$ followed by Mestizos and those classified as Other $(46.4 \%$ and $48.1 \%$, respectively). Garifuna young people have the highest rates of school attendance among the four sex-age cohorts represented in the chart.

Figure 11: Percent currently attending school among 10-19-year-olds in Belize, by age, sex and ethnicity 


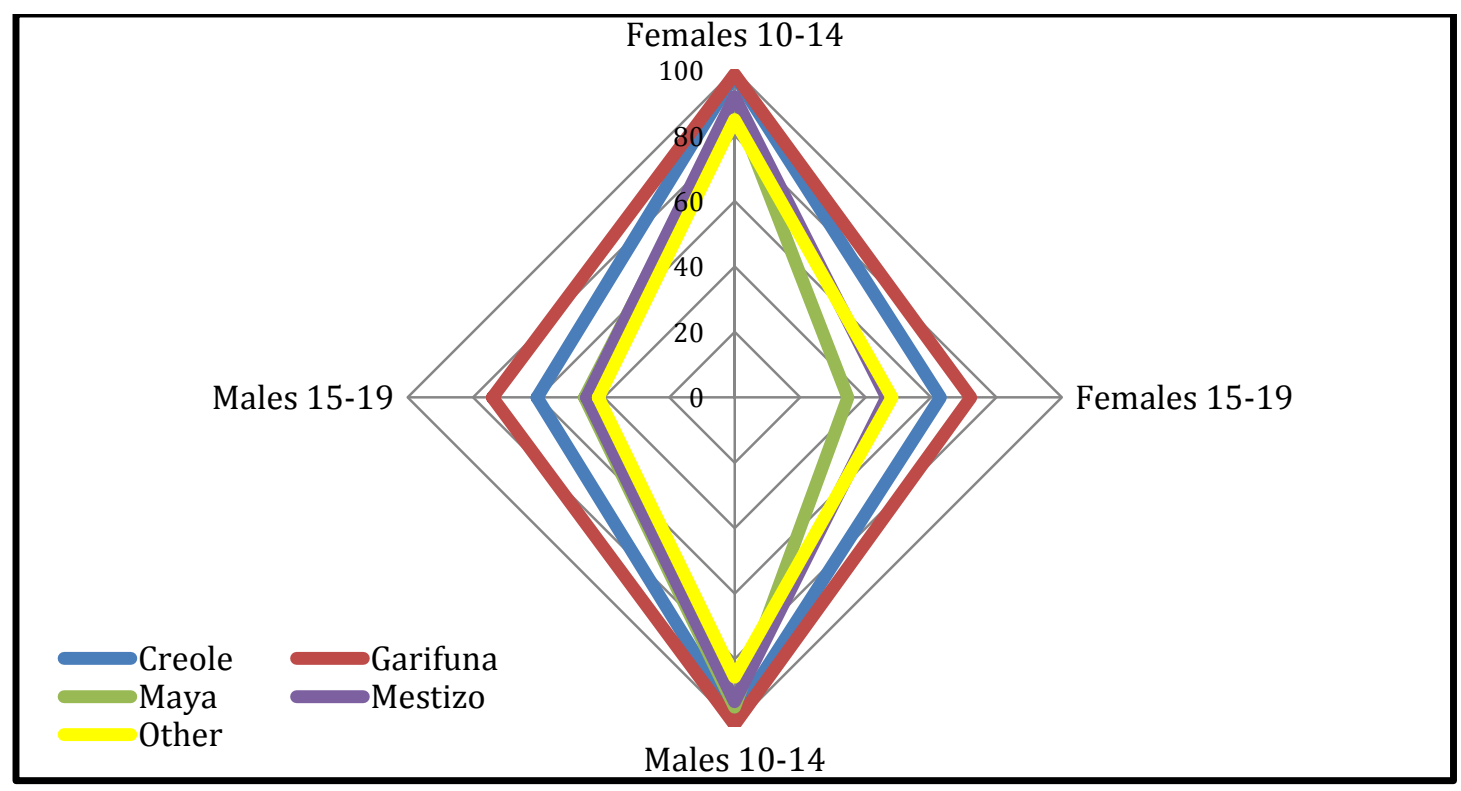

Source: 2010 Belize Census (authors' analysis of 10\% sample)

Figures 12 and 13 below show the distribution of male and female respondents age 10-24 by ethnicity. The data show little variation in the ethnic breakdown between male and female respondents. For both sexes, Creole young people make up the majority followed by Garifuna and Maya.

Figure 12: Distribution of male respondents of the 2011 Belize Coverage Exercise age 10-24, by ethnicity

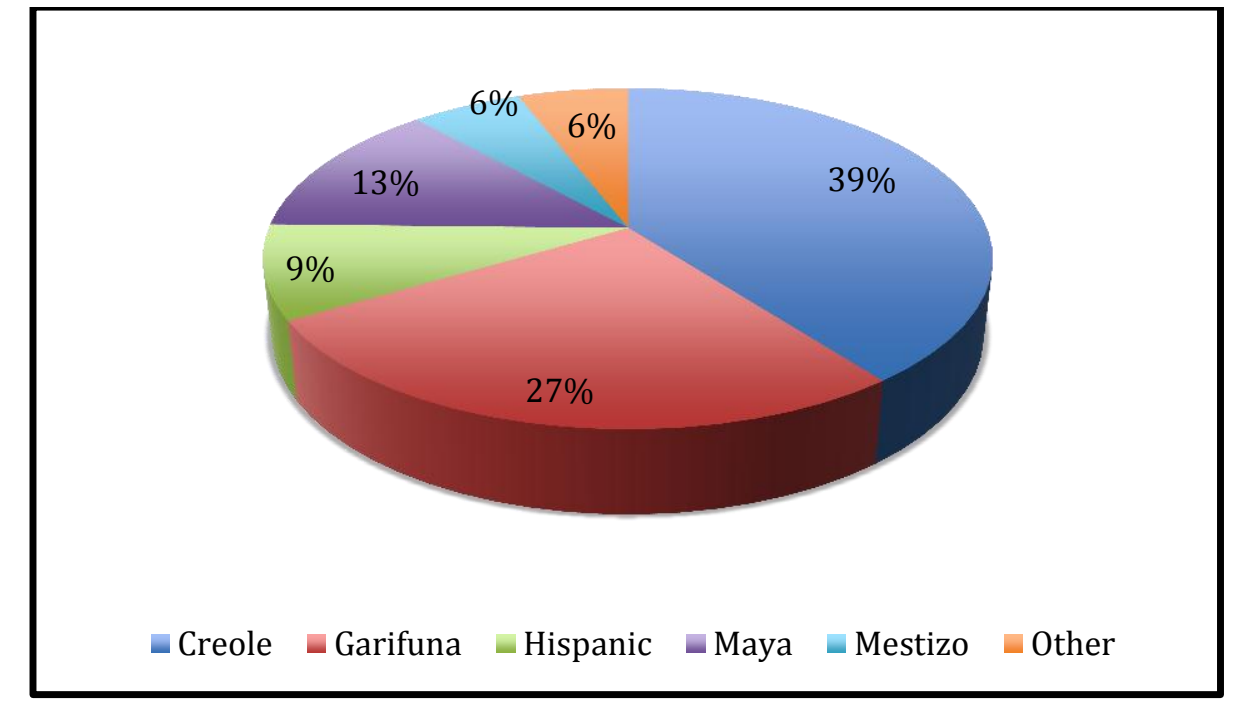

Figure 13: Distribution of female respondents of the 2011 Belize Coverage Exercise age 10-24, by ethnicity 




Tables 8-9 below show the distribution of the respondents according to their ethnicity. In Table 8 , each ethnic group is broken down by age and sex showing the distribution across the population surveyed during the CE data collection period. The ethnic group called "other" includes those who classified themselves as African, Asian, East Indian and White. Among females, the majority of each ethnic group were either adolescents (15-19) or older youth (2024). Among males, the majority were young adolescents (10-14) and adolescents (15-19) among the Creole, Garifuna and Hispanic groups and adolescents (15-19) and older youth (20-24) among the Maya, Mestizo and Other groups.

One important point to note is the relatively small percent of young adolescent (10-14) Maya females. As discussed earlier, the 10-14-year-old age group is very important to target as this is often a point in the life cycle of the girl when they are still in school and have not yet begun childbearing. This provides the opportunity to build the social and human capital necessary to ensure they stay in school and avoid early marriage and childbearing since in many cases adolescent girls age 15 and up may be already engaged in sexual relations and other high risk activities that could lead them to drop out of school. A program targeting girls age 15 and up may be too late. Across all ethnic groups, a higher proportion of male respondents were age 1014 than female respondents, suggesting that service providers may need to more actively recruit or target young adolescent females to ensure their participation in programs and access to services.

Table 8: Distribution of respondents of the 2011 Belize Coverage Exercise, by sex, development stage and ethnicity

\begin{tabular}{|lccccccc|}
\hline & Pre- & Young & & Older & Young & \\
& Adolescents & Adolescents & Adolescents & Youth & Adults & \\
Ethnicity & (less than 10) & $(10-14)$ & $(15-19)$ & $(20-24)$ & $(25+)$ & Total & $\mathrm{N}$ \\
\hline
\end{tabular}




\begin{tabular}{|llllllll|} 
Creole & 0.0 & 19.0 & 39.3 & 41.0 & 0.7 & 100.0 & 849 \\
Garifuna & 0.2 & 23.5 & 42.1 & 33.8 & 0.5 & 100.0 & 642 \\
Hispanic & 0.0 & 15.5 & 43.4 & 40.6 & 0.4 & 100.0 & 251 \\
Maya & 0.0 & 10.7 & 40.0 & 47.5 & 1.9 & 100.0 & 478 \\
Mestizo & 0.0 & 25.9 & 36.8 & 37.4 & 0.0 & 100.0 & 174 \\
Other & 0.6 & 17.4 & 40.1 & 40.1 & 1.8 & 100.0 & 167 \\
Total Females & 0.1 & 18.6 & 40.5 & 40.0 & 0.9 & 100.0 & 2,570 \\
\hline & & & Males & & & & 362 \\
\hline Creole & 0.0 & 34.3 & 37.6 & 27.6 & 0.6 & 100.0 & 362 \\
Garifuna & 0.0 & 39.0 & 42.3 & 17.9 & 0.8 & 100.0 & 246 \\
Hispanic & 0.0 & 34.6 & 42.0 & 23.5 & 0.0 & 100.0 & 81 \\
Maya & 0.0 & 16.7 & 38.3 & 43.3 & 1.7 & 100.0 & 120 \\
Mestizo & 1.9 & 29.6 & 33.3 & 35.2 & 0.0 & 100.0 & 54 \\
Other & 0.0 & 25.9 & 44.4 & 27.8 & 1.9 & 100.0 & 54 \\
Total Males & 0.1 & 32.5 & 39.4 & 27.3 & 0.8 & 100.0 & 921 \\
\hline
\end{tabular}

Table 9 shows the distribution of the respondents age 10-24 from each ethnic group by district where services were received. Not surprisingly, the majority of male and female Mayans ( $81.4 \%$ and $86.4 \%$, respectively) received services in Toledo while the majority of male and female Garifunas (69.7\% and 76.8\%, respectively) received services in Stann Creek. Among females, over $50 \%$ of Hispanics received services in Stann Creek while among males over $50 \%$ received services in Belize; similarly, over $50 \%$ of female Mestizos received services in Stann Creek while the largest group of male Mestizos received services in Belize. This may be related to male migration to Belize for purposes of work or due the types of services offered and the locations of the service delivery points in each of the districts but would require further inquiry to explain in greater detail.

Table 9: Distribution of respondents of the 2011 Belize Coverage Exercise age 10-24, by sex, ethnicity and district

\begin{tabular}{|lccccc|}
\hline Ethnicity & Belize & $\begin{array}{l}\text { Stann } \\
\text { Creek }\end{array}$ & Toledo & Total & N \\
\hline Creole & 72.8 & 22.5 & 4.5 & 100 & 841 \\
Garifuna & 18.3 & 76.8 & 4.9 & 100 & 638 \\
Hispanic & 35.9 & 59.2 & 4.9 & 100 & 245 \\
Maya & 4.3 & 9.2 & 86.6 & 100 & 468 \\
Mestizo & 32.2 & 51.1 & 16.7 & 100 & 174 \\
Other & 49.7 & 28.2 & 22.1 & 100 & 163 \\
Total Females & 38.6 & 39.6 & 21.8 & 100 & 2538 \\
& & & & &
\end{tabular}




\begin{tabular}{|lccccc|}
\hline \multicolumn{5}{c}{ Males (10-24) } \\
\hline Creole & 73.9 & 19.4 & 6.7 & 100 & 360 \\
Garifuna & 18.4 & 69.7 & 11.9 & 100 & 244 \\
Hispanic & 54.3 & 37 & 8.6 & 100 & 81 \\
Maya & 7.6 & 11 & 81.4 & 100 & 118 \\
Mestizo & 43.4 & 37.7 & 18.9 & 100 & 53 \\
Other & 58.5 & 28.3 & 13.2 & 100 & 53 \\
Total Males & 46 & 35 & 18.9 & 100 & 913 \\
\hline
\end{tabular}

The language a young person speaks at home is often their first language. This can have implications towards his/her level of understanding of complex topics and issues when discussed in a different language. Programs or services only offered in English, for example, may by default exclude large groups of people who do not speak English or are not comfortable communicating in it. Figures 14 and 15 below show the distribution of the language spoken at home for males and females age 10-24. Creole is the dominant language spoken by male and female respondents followed by English and Maya (this includes Ketchi, Mopan and Yucatec).

Figure 14: Distribution of male respondents of the 2011 Belize Coverage Exercise age 10-24, by language spoken at home



Figure 15: Distribution of female respondents of the 2011 Belize Coverage Exercise age 10-24, by language spoken at home 


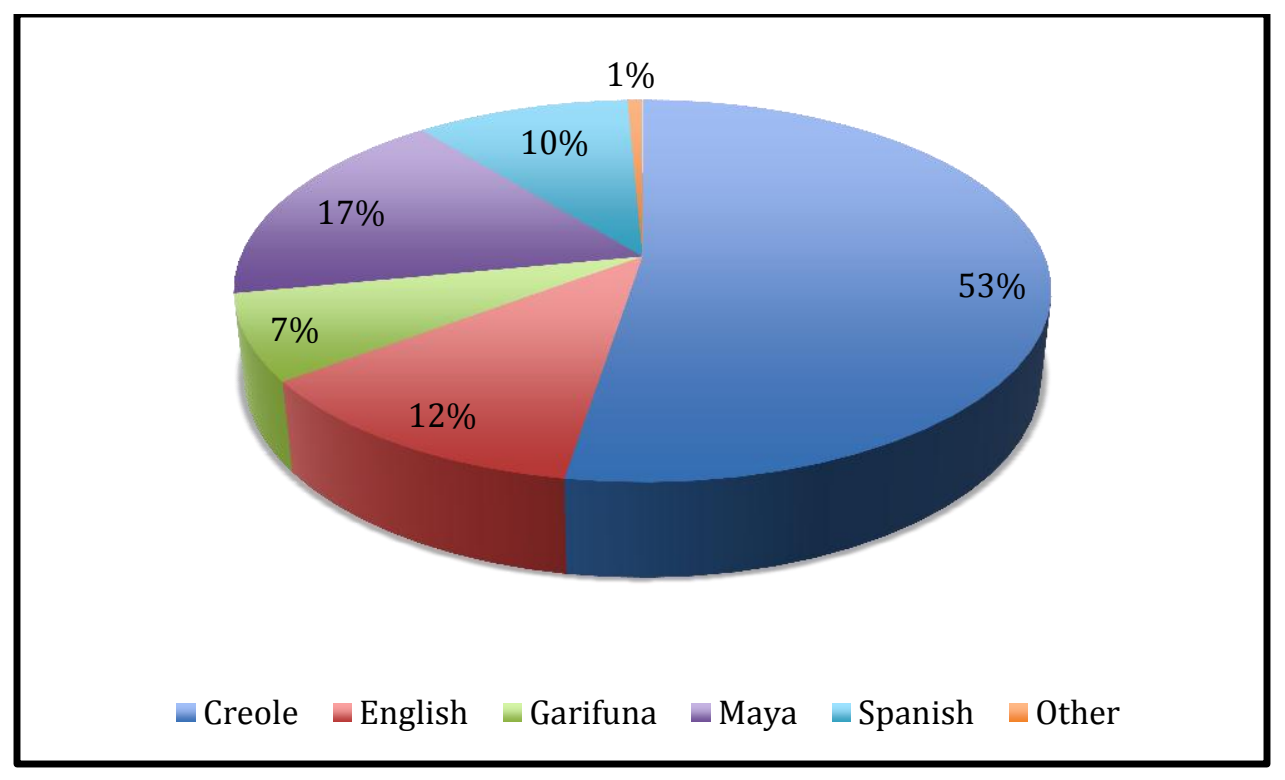

\section{Household Composition}

The household is often the context where the well-being of a young person is cared for and his/her needs are addressed. It is also the place where social and financial resources designated for young people are obtained. As a result, data on the composition of the household where a young person lives can provide important insight into the possible support mechanisms he/she can count on. A young person's relationship to the household head can have direct implications on the amount of resources available for his/her education, health care and other needs as well as the types of household chores he/she is required to take on. The overall structure of the household and the young person's position relative to other members can significantly impact his/her daily experiences and ability to participate in programs or access services. While the data collected during the $\mathrm{CE}$ are not sufficient to determine the relationship to the household head, they can serve as a proxy for understanding more about the household-level effects on social and demographic characteristics and outcomes.

The presence or absence of parents and other relatives can be a major factor in the type and level of support a young person receives. Table 10 below shows the household composition for males and females ages 10-19. Four categories of household composition were selected given the intrahousehold dynamics they suggest. The first category, "one or both parents," reports the proportion of young people living in homes with either or both of their parents. The second and third categories, "other relatives (no parents)" and "no relatives, no parents and no spouse" are used to highlight the alternative scenarios whereby young people not living with their parents may reside in households with other relatives or non-relatives. The latter is a category that suggests a young person may be living with another family, possibly as a migrant or domestic worker, or with friends. The final category is included to show the age and gender differences among the young people living with their spouses. 
According to an analysis of the $10 \%$ sample of the 2010 Belize census, approximately $93 \%$ of males and females age 10-14 live with one or both parents while approximately $88 \%$ of males and females age 15-19 live with one or both parents. Similarly, among the respondents of the $\mathrm{CE}$, the vast majority of 10-19 year old males and females live with one or both of their parents. However, the proportions of respondents in the respective sex-age cohorts living with one or both parents are lower than the national proportions - almost 18\% lower among females age 1519 - suggesting that the service providers are doing a good job reaching young people who do not reside with their parents. In many scenarios, young people not living with their parents experience many more obstacles to accessing services and are therefore under-represented in $\mathrm{CE}$ data. More in-depth research would be required to determine the extent of this issue in Belize.

Males and female respondents age 15-19 are more likely to be living with other relatives (no parents) than 10-14-year-olds. Only a small proportion of respondents do not live with their parents, relatives or spouse. This is highest among males age 15-19, which could be due to a greater tendency among males to travel for school or work or to a greater sense of autonomy males experience than females in Belize allowing them to move away from their parents' home at a younger age. Among 15-19 year olds, over 16\% of female respondents live with their spouse while slightly more than $4 \%$ of male respondents live with their spouse, data that correspond with the higher rates of females than males in some sort of union (see the next section on marital status). The data on household composition imply that those accessing services and participating in programs during the time of the $\mathrm{CE}$ were more likely to be living with their parents than in other situations. This makes senses based on the assumption that the presence of parents can help provide a protective environment whereby young people have access to the resources necessary to pursue opportunities and seek services. In order to reach more marginalized young people, program planners should explore strategies that allow them to reach even larger proportions of young people not living in homes with their parents or relatives.

Table 10: Percent of young respondents of the 2011 Belize Coverage Exercise age 10-19 living in different household compositions, by sex and development stage

\begin{tabular}{|c|c|c|c|c|}
\hline Development stage & $\begin{array}{l}\text { One or both } \\
\text { parents }\end{array}$ & $\begin{array}{l}\text { Other relatives } \\
\text { (no parents) }\end{array}$ & $\begin{array}{c}\text { No relatives, } \\
\text { no parents and } \\
\text { no spouse }\end{array}$ & Spouse \\
\hline \multicolumn{5}{|c|}{ Females } \\
\hline Young adolescents (10-14) & 84.9 & 8.6 & 2.7 & 0.4 \\
\hline Adolescents (15-19) & 70.5 & 10.1 & 3.6 & 16.4 \\
\hline \multicolumn{5}{|c|}{ Males } \\
\hline Young adolescents (10-14) & 84.9 & 7.7 & 1.0 & 1.1 \\
\hline Adolescents (15-19) & 79.9 & 11.3 & 3.9 & 4.2 \\
\hline
\end{tabular}

Note: Spouse may be present in the first two categories - one or both parents; other relatives (no parents) Rows do not sum to $100 \%$ because there are other possible household composition combinations 


\section{Marital Status}

Marriage is a life-changing experience that in a majority of cases confers a great deal of pleasure and benefit to both individuals. A marital union, whether officially sanctioned by the state or common law, helps establish a foundation for shared responsibility and resources to support a growing family, in addition to a safe and socially acceptable environment to foster a loving relationship. However, to establish and maintain a healthy marital union that is conducive to raising children in a supportive environment, a young person needs maturity and support to deal with the inevitable challenges that are part of the experience.

In many societies, one's marital status can have a direct impact on his/her socio-economic status. Through the joining of material and financial resources, a couple may be more financially stable than when single. Similarly, poverty and marital status are often interconnected since dependency on the spouse's income and labor force participation may be determined by the nature of the union and the gender norms related to the institution of marriage. For younger married females, marriage may limit opportunities to study or pursue employment due to the competing responsibilities related to the care of the household and its members that do not allow them the time required for school or work. This also means that marriage could be tied to poorer social and health outcomes for young females who experience a shrinking of opportunities after entering into a marital union. A strong understanding of the nature of the institution of marriage among young people is of critical importance to designing interventions that differentiate between the needs of single and married young people.

An analysis of the $10 \%$ sample of the 2010 census showed that among young people age 15-19, almost $75 \%$ of females were not in a union of any sort (this includes being separated, divorced or widowed) and over $86 \%$ of males were not in a union. For both males and females the rates vary only slightly between urban and rural areas but show slightly more variation between districts. In Belize district, visiting partner relationships appear to be the union of choice: over $17 \%$ of females age 15-19 and over 15\% of males age 15-19 reported being in a visiting partner relationship.

Among female respondents age 15-19, 68.9\% reported being single and 30.6\% reported being married, in a common law relationship or living with the boyfriend (the remaining $0.5 \%$ reported being separated, divorced or widowed). These data vary only slightly from the general population according to the $10 \%$ sample of the census, suggesting that service providers are seeing a group of beneficiaries that are fairly representative of the overall population.

Marital customs often vary greatly from one ethnic or cultural group to the next. Evidence for this is seen the different rates of marriage among young females and males from different groups. According to the 2010 census, among females age 15-19 in Belize, the highest rates of marriage and common law relationships are seen among Mayans (6.1\% and 18.7\%, respectively) 
while $18.2 \%$ of Creole females engage in visiting partner relations, a rate higher than all other females from the different ethnic groups. Overall, Creole, Mayan and Mestizo females reported the highest rates of being in union according to the 2010 census.

Figure 16 shows the percentage of female and male respondents in union by single year. Similar to the general population, as shown in Figure 3 above, the proportion of males and females in union increases steadily with age. Across all years, females are in union at higher rates than males; female respondents are 1.2 to 3.6 times more likely to be in union than male respondents.

Figure 16: Percent of female and male respondents of the 2011 Belize Coverage Exercise in union (married, living with boyfriend or common law), by single year



Figures 17 and 18 show the percentage of female and male respondents who are in union (married, in common law relationships, or who are living with a boyfriend or girlfriend) by development stage and ethnicity. In the adolescent stage (15-19), the data show that Hispanic, Maya, and Mestizo females are most likely to be in a union, at $40.2 \%, 36.7 \%$, and $36.0 \%$, respectively. Creole females are the least likely to be in a union in the adolescent stage, the opposite of what is seen in the census, but the percentage of Creole females in unions more than doubles in the older youth stage (20-24), from $25.7 \%$ to $62.7 \%$. Further, data from the older youth stage show that the percentage of Maya and Mestizo female respondents who are in unions more than doubles to $82.9 \%$ and $73.8 \%$, respectively. While there are slight variations in marital status by ethnicity between the respondents and the overall population, in general the data are closely matched.

Male respondents are much less likely to be in unions than females are; this is true for each ethnic category and development stage and is also seen in the census data. The gender gap in union prevalence narrows in the older youth development stage but there is a striking difference between the union rates of females and males. 
Figure 17: Percent of female respondents of the 2011 Belize Coverage Exercise in union (married, living with boyfriend or common law), by age group and ethnicity

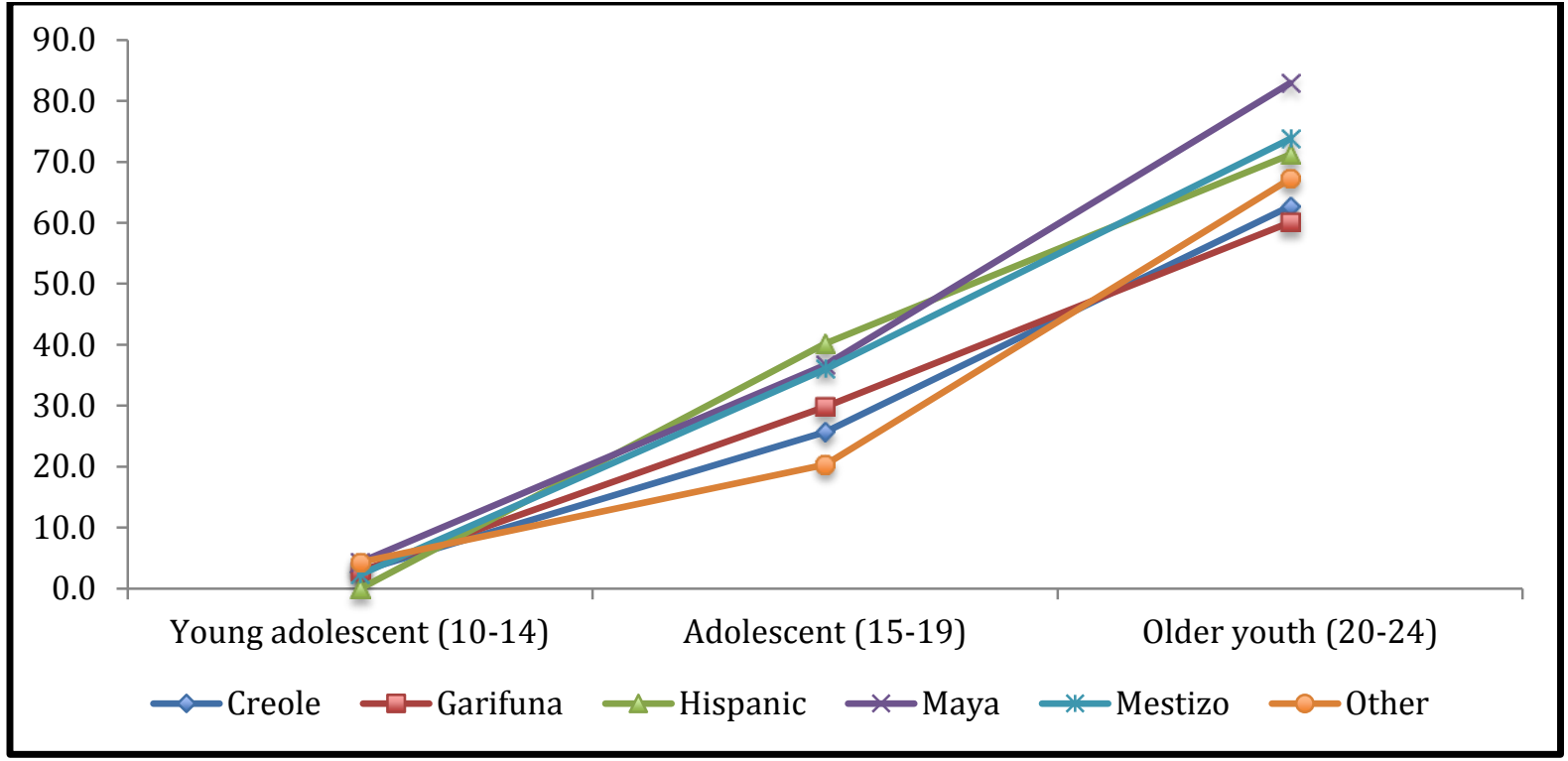

Figure 18: Percent of male respondents of the 2011 Belize Coverage Exercise in union (married, living with girlfriend or common law), by age group and ethnicity

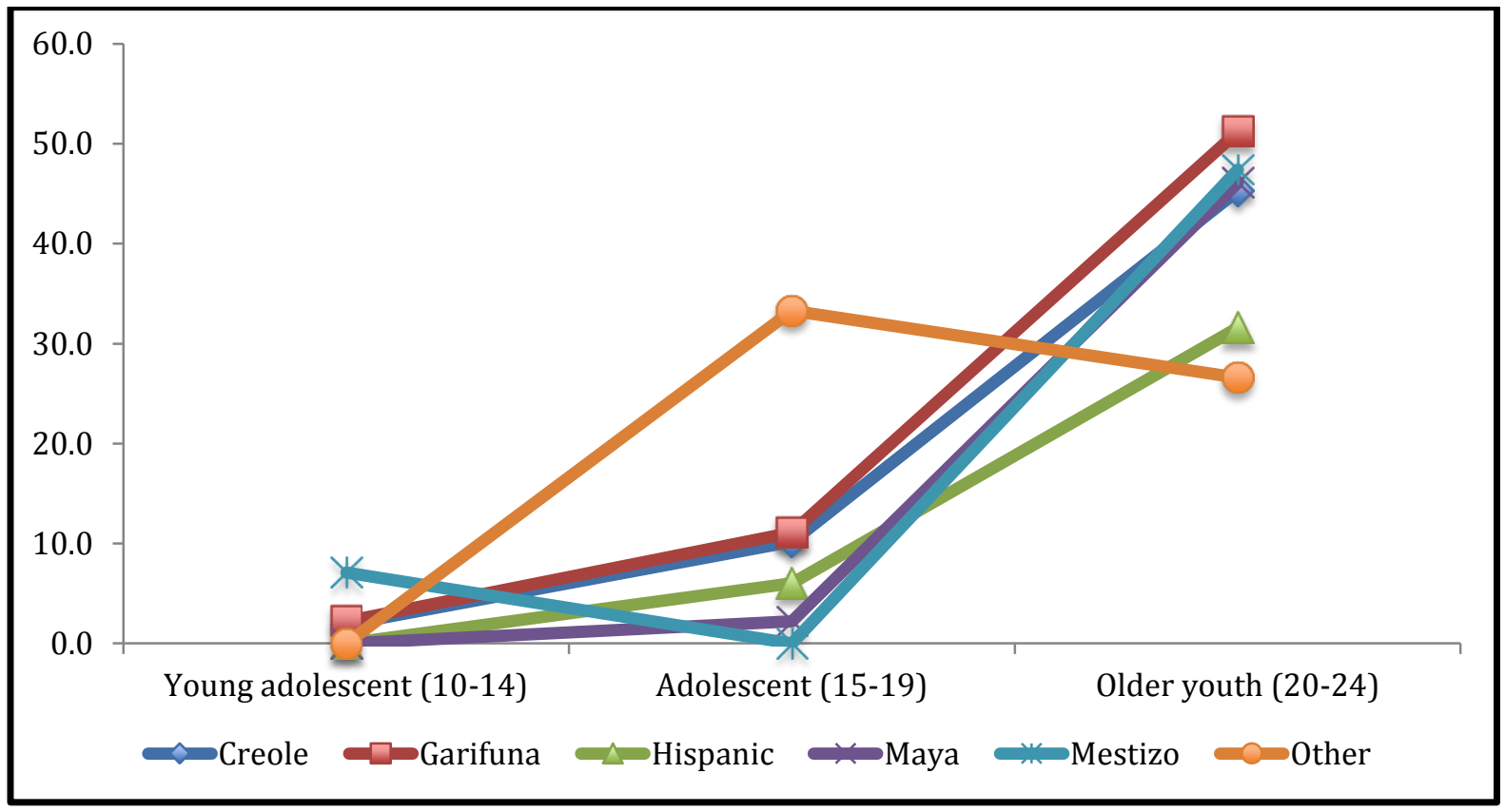

35 | P a g e 
Given the role marital status plays in shaping a young person's social, economic and health outcomes, evidence-based policies and programs that differentiate between their needs and those of their unmarried counterparts are required to support them. When issues of early or child marriage are at play, this is even more critical due to the obstacles young people, particularly girls, experience in accessing information and services when in a marital union. Services and programs that address the unique circumstances of being young and married will help build the social and human capital required to ensure their health and that of their children.

\section{Parenthood}

Childbearing among young people is particularly important because of the effects it has on the sexual and reproductive well-being of the mother and child and on the social aspects of the parents. Early childbearing can severely limit the opportunities of the parents, particularly the mother, and lead to school leaving and limited labor force participation. This will have a direct impact on the socio-economic status of the parents and level of empowerment. Young, single mothers face even greater adversity as they attempt to balance the responsibilities of childbearing with the need to acquire income to support their families.

Young, first-time mothers are at much greater risk for maternal and infant mortality. The physiological limitations of their bodies make pregnancy and childbearing particularly risky and when this occurs in low resource settings the risks are even greater (Haberland et al 2003). Data on the fertility trends within the young population and how they vary by geographic area or ethnicity are critical to establishing the programs required to delay childbirth or support expecting parents and the services that ensure the safety of the mother and her child.

In Belize, the 2010 census data show that the median age at first birth among females age 15-19 is 17. In rural areas, $17.2 \%$ of females age 15-19 have given birth at least once and in urban areas the rate is $12.6 \%$. Nationally, $15.2 \%$ of $15-19$-year-old females have given birth at least once. Figure 19 shows the proportion of females who have ever given birth by age. The data show that the rate of childbirth more than doubles each year between 15 and 17 and almost doubles between 17 and 18. A steady increase in the rates of teen pregnancy requires specialized strategies to support young mothers and help young females avoid unplanned pregnancies.

Figure 19: Proportion of female population age 15-19 that has ever given birth according to 2010 Belize Census, by age 


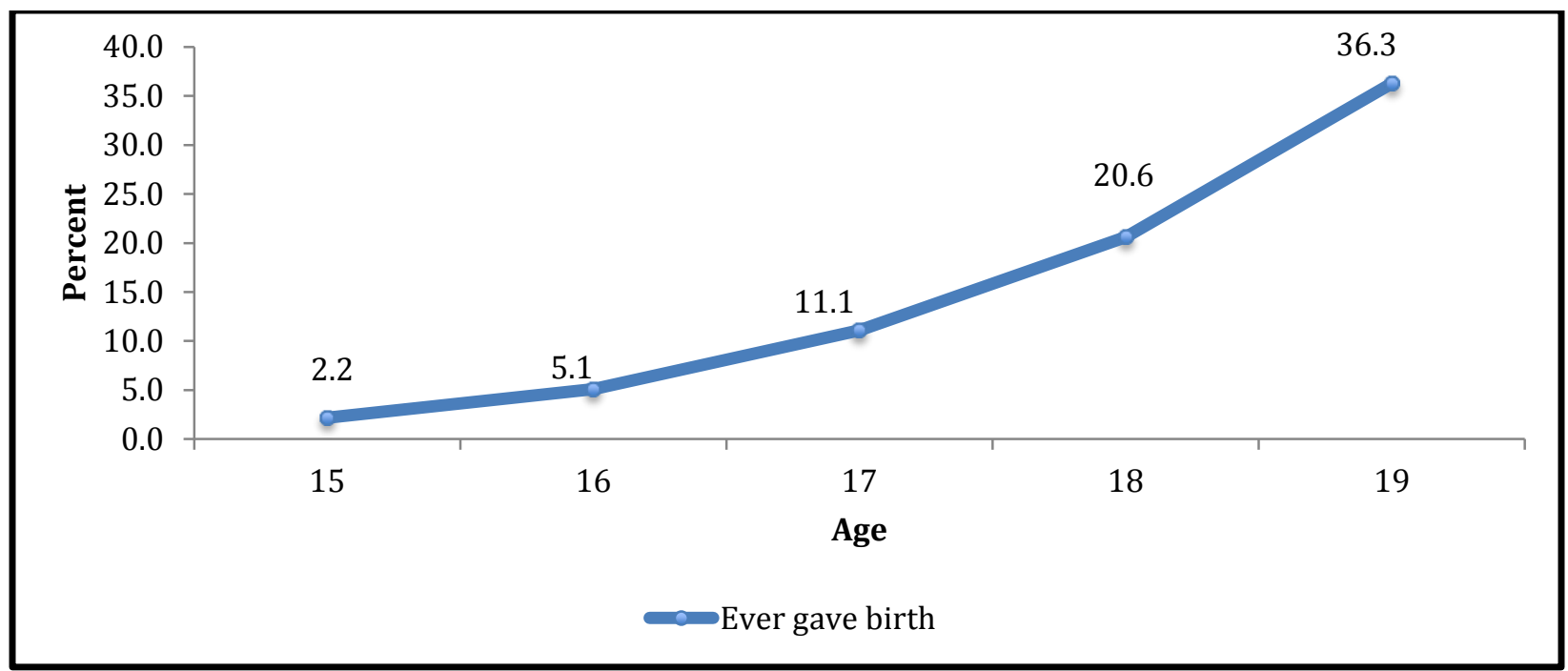

Source: 2010 Belize Census (authors' analysis of 10\% sample)

The norms and customs around childbearing differ among ethnic groups and cultures, similar to marriage. In some cultures, it is quite common for teenagers to begin childbearing early on, whether married or not, while in others it is not socially acceptable and therefore not as prevalent. In Belize, the 2010 census shows that childbirth among females age 15-19 is most common among Mayans (17.5\%) followed by Mestizos/Hispanics (17.0\%) and Creoles (14.8\%).

Table 11 below shows the percentage of female and male respondents who reported having had at least one child by development stage and ethnicity. The data show a large variation between females and males, development stages, and ethnicities in regards to parental status. In the adolescent stage (15-19), Hispanic female respondents are approximately twice as likely as Mestizo and Garifuna female respondents to have had a child, with childbearing rates at $32.1 \%$, $14.3 \%$, and $16.0 \%$, respectively, reflecting a similar scenario to that presented in the $10 \%$ sample of the 2010 Belize census. In the adolescent stage, female respondents of all ethnicities are at least twice as likely to have had a child as their male counterparts. Among the Mayan respondents, $20.2 \%$ of adolescent females have had a child as compared to $2.6 \%$ of adolescent males, a rate almost 10 times as high. Creole and Hispanic adolescent females are also much more likely than their male counterparts to have had children. The data show that adolescent Hispanic males were the most likely to have had a child, with $12.1 \%$ of males reporting that they were parents.

Table 11: Percent of respondents of the 2011 Belize Coverage Exercise who have at least one child, by sex, development stage and ethnicity

\begin{tabular}{|lcccccccc|}
\hline Development stage & Creole & Garifuna & Hispanic & Maya & Mestizo & Other & N \\
\hline Young adolescent (10-14) & 0.7 & 1.4 & 0.0 & 0.0 & 2.4 & 4.0 & 476 \\
Adolescent (15-19) & 19.1 & 16.0 & 32.1 & 20.2 & 14.3 & 11.1 & 1,035 \\
Older adolescent (20-24) & 61.1 & 61.7 & 80.2 & 68.6 & 75.0 & 59.7 & 1,026
\end{tabular}

37 | $\mathrm{P}$ a g e 


\begin{tabular}{lccccccc}
\hline \multicolumn{10}{c}{ Males } \\
\hline Young adolescent (10-14) & 0.0 & 1.1 & 0.0 & 0.0 & 0.0 & 0.0 & 298 \\
Adolescent (15-19) & 3.8 & 2.9 & 12.1 & 2.6 & 0.0 & 4.2 & 362 \\
Older adolescent (20-24) & 35.1 & 34.1 & 16.7 & 26.9 & 42.1 & 28.6 & 249 \\
\hline
\end{tabular}

Figure 20 shows the percentage of female respondents who are pregnant by development stages and ethnicity. The data show that Mayans and Mestizos are more likely to be pregnant during the adolescent stage (15-19) than female respondents of other ethnicities. In the older youth stage (20-24), Mayan female respondents are most likely to report being pregnant, with $34.1 \%$ of the Mayan females reporting they were currently pregnant. This is significantly higher than what was reported by females belonging to other ethnic categories in the older youth development stage (25.2\% of Garifuna and $24.2 \%$ of Creole females, the two next highest rates). Pregnancy can be a risk factor for young people as it often coincides with early school leaving to take care of the child or to work for pay - not to mention the physiological risks that are common among young mothers and their children - so it is of concern that there are such high percentages of females in our sample population reporting that they are currently pregnant in the adolescent stage. If service providers are not presently addressing their pregnancy-related needs then this may be an area they want to explore as a future area of intervention.

Figure 20: Percent of female respondents of the 2011 Belize Coverage Exercise who were pregnant at the time of the interview, by development stage and ethnicity 




In order to support young mothers and fathers, particularly in environments characterized by poverty and/or limited resources, all subgroups of young people require access to accurate and relevant information and services. To minimize the risks of maternal and infant mortality and equalize sexual and reproductive health outcomes throughout the population, easily accessible antenatal, delivery and postpartum care is crucial. Stakeholders will also need to target investments at programs and services that build the human capital of young people, especially girls, to provide opportunities that help them avoid early childbearing. In many cases, this will contribute to efforts that seek to break the intergenerational cycle of poverty and assist nations in tackling issues of population growth, reproductive health and poverty reduction.

\section{Education}

During childhood and adolescence, young people are ideally developing the physical and cognitive skills necessary to becoming healthy and productive adults. In addition to the obvious benefits that come from learning and interacting with peers, education is a key component of a healthy transition to adulthood. There are well-documented synergies between education and health; healthy young people are more likely to attend school and learn more effectively while educated young people, when they begin families of their own, will maintain the health of their families (Lloyd 2010). Additionally, education has been linked with delays in early sexual initiation, marriage and childbearing and is therefore a key component of any sexual and reproductive health strategy.

In Belize, school attendance rates are high, particularly among younger adolescents age 10-14. According to the 2010 census, $92.7 \%$ and $93.6 \%$ of 10-14-year-old females and males are attending school, respectively. In rural areas, $90.4 \%$ and $91.1 \%$ of $10-14$-year-old females and males are attending school, respectively, while in urban areas the rates are $96.1 \%$ and $97.0 \%$, 
respectively. Much larger differentials are seen in rural and urban areas among 15-19-year-olds: $41.2 \%$ of females and $40.9 \%$ of males in urban areas attending school while $62.3 \%$ of females and $60.6 \%$ of males attend school in urban areas. This is likely due to the fact that school attendance rates begin to decline rapidly after the age of 14 in rural areas and after age 16 among females and 17 among males in urban areas. This trend could be due to many factors, such as the limited availability of secondary schools in rural areas or the increasing need to begin working in both urban and rural areas. However, additional research would be required to determine the root causes.

Figures 21 and 22 show school attendance rates for female and male respondents age 14-19 by ethnicity. The data show that Mayan females are the least likely to be attending school at all ages represented in the chart. Mayan males are more likely to be attending school at all ages than their Mayan female counterparts (as can be seen in Table 12 below showing the female-to-male attendance ratios). Hispanic females also have much lower school attendance rates than females of other ethnicities and their male counterparts. The most significant differences can be seen during the ages of 15 and 16, where $100 \%$ and $87.5 \%$ of Hispanic male respondents attend school as compared to $6 \%$ and $58.8 \%$ of Hispanic female respondents, respectively. These data illustrate the same trends highlighted in the $10 \%$ sample of the 2010 Belize census, which show gender parity in school attendance until the age of 13, when a sharp decline begins in the level of female attendance as compared to male attendance.

Figure 21: Percent of female respondents of the 2011 Belize Coverage Exercise currently attending school, by age and ethnicity

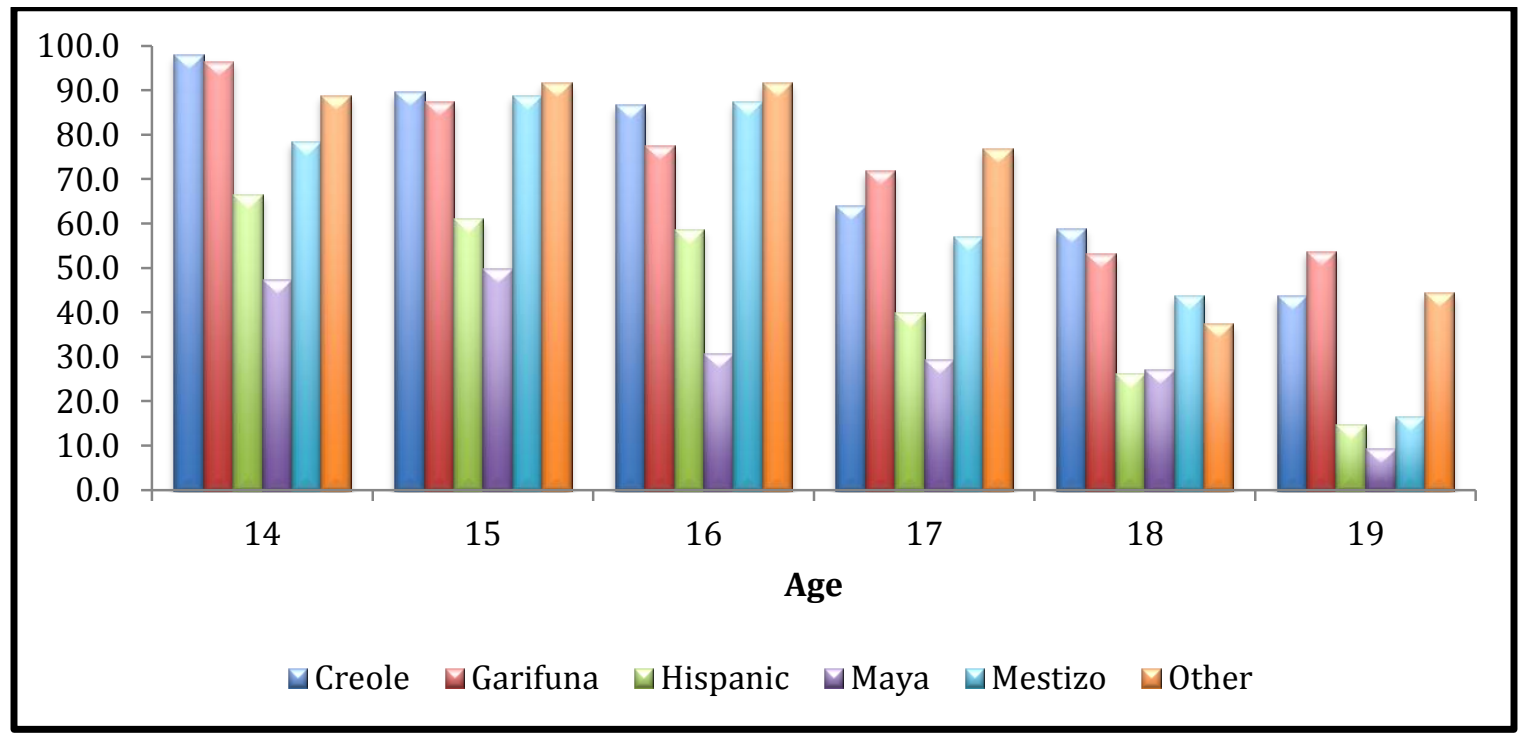


Figure 22: Percent of male respondents of the 2011 Belize Coverage Exercise currently attending school, by age and ethnicity

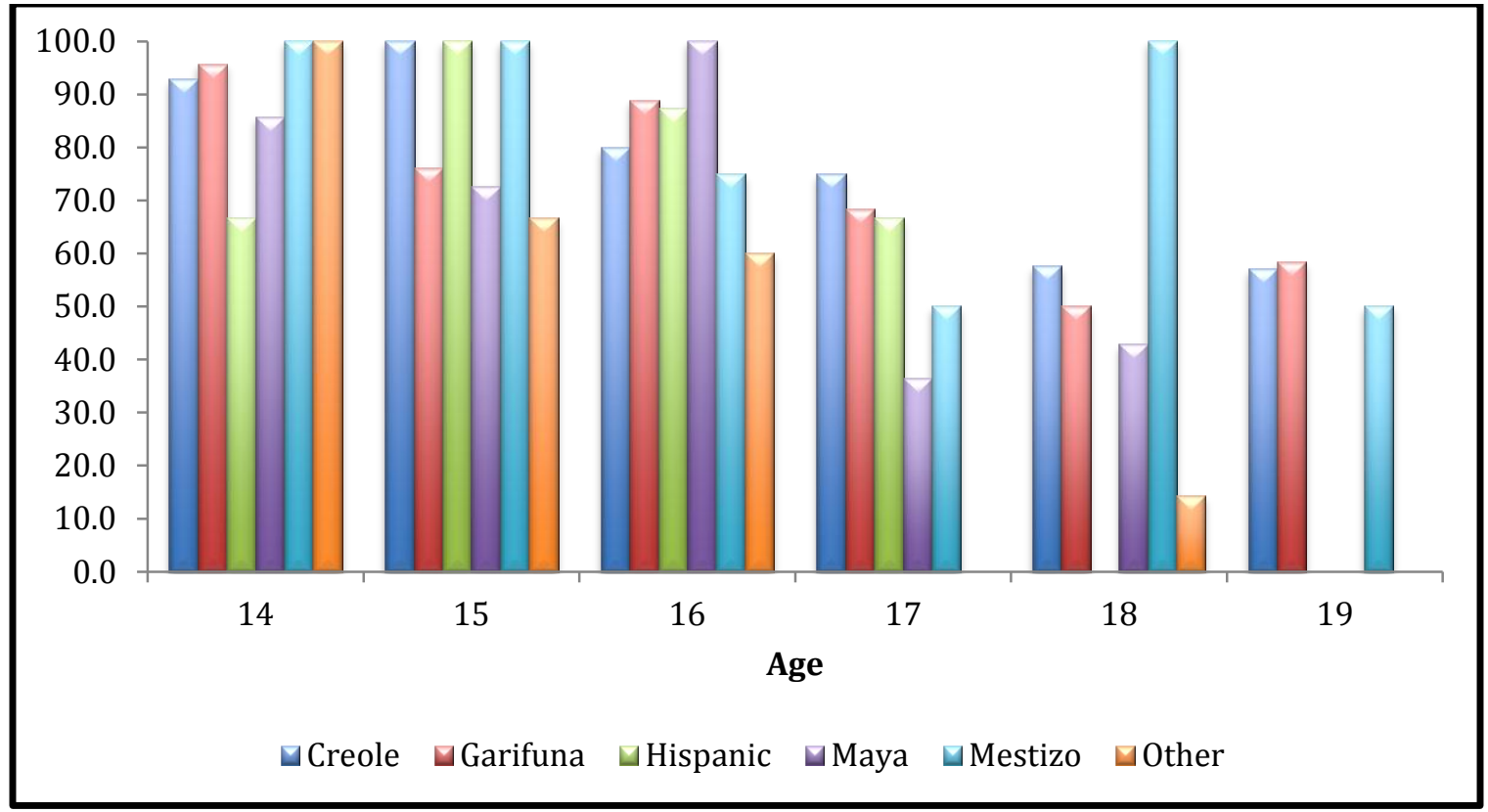

Table 12: Female-to-male school attendance ratio among respondents of the 2011 Belize Coverage Exercise, by age and ethnicity

\begin{tabular}{|ccccccc|}
\hline Age & Creole & Garifuna & Hispanic & Maya & Mestizo & Other \\
\hline 14 & 1.1 & 1.0 & 1.0 & 0.6 & 0.8 & 0.9 \\
15 & 0.9 & 1.1 & 0.6 & 0.7 & 0.9 & 1.4 \\
16 & 1.1 & 0.9 & 0.7 & 0.3 & 1.2 & 1.5 \\
17 & 0.9 & 1.1 & 0.6 & 0.8 & 1.1 & N/A \\
18 & 1.0 & 1.1 & N/A & 0.6 & 0.4 & 2.6 \\
19 & 0.8 & 0.9 & N/A & N/A & 0.3 & N/A \\
\hline
\end{tabular}

Figure 23 shows the school attendance data for two select groups of females: Creole and Mayans age 14-19. Creole female respondents have the highest rates of school attendance while Mayan female respondents have the lowest. The red area highlights the difference in school attendance rates between the two groups of females for each age; Creole females are approximately two times as likely to attend school from ages 14-18 and almost five times as likely at age 19. Data such as these are very important for service providers as they offer insight into the experiences of their beneficiaries and program participants and possible areas for new or expanded interventions. For example, those working with Mayan adolescent females can use this information to design interventions that fill the gaps in information and skills that arise from not 
attending school and work with those girls who may want to transition back into a formal or nonformal educational institution.

Figure 23: Difference in school attendance rates between Creole and Mayan female respondents of the 2011 Belize Coverage Exercise age $15-19$, by age



Figure 24 shows data that illustrate the current or last class attended by females between the ages of 10 and 19. The majority of females are in the appropriate grade-for-age: primary school for 10-14-year-olds and secondary school for 15-19-year-olds. This supports the findings from the $10 \%$ sample of the 2010 Belize census, which show that a large proportion of females age 10-14 and $15-19$ are at grade-for-age (92.0\% and $83.8 \%$, respectively). 
Figure 24: Highest school class attended among female respondents of the 2011 Belize Coverage Exercise, by age

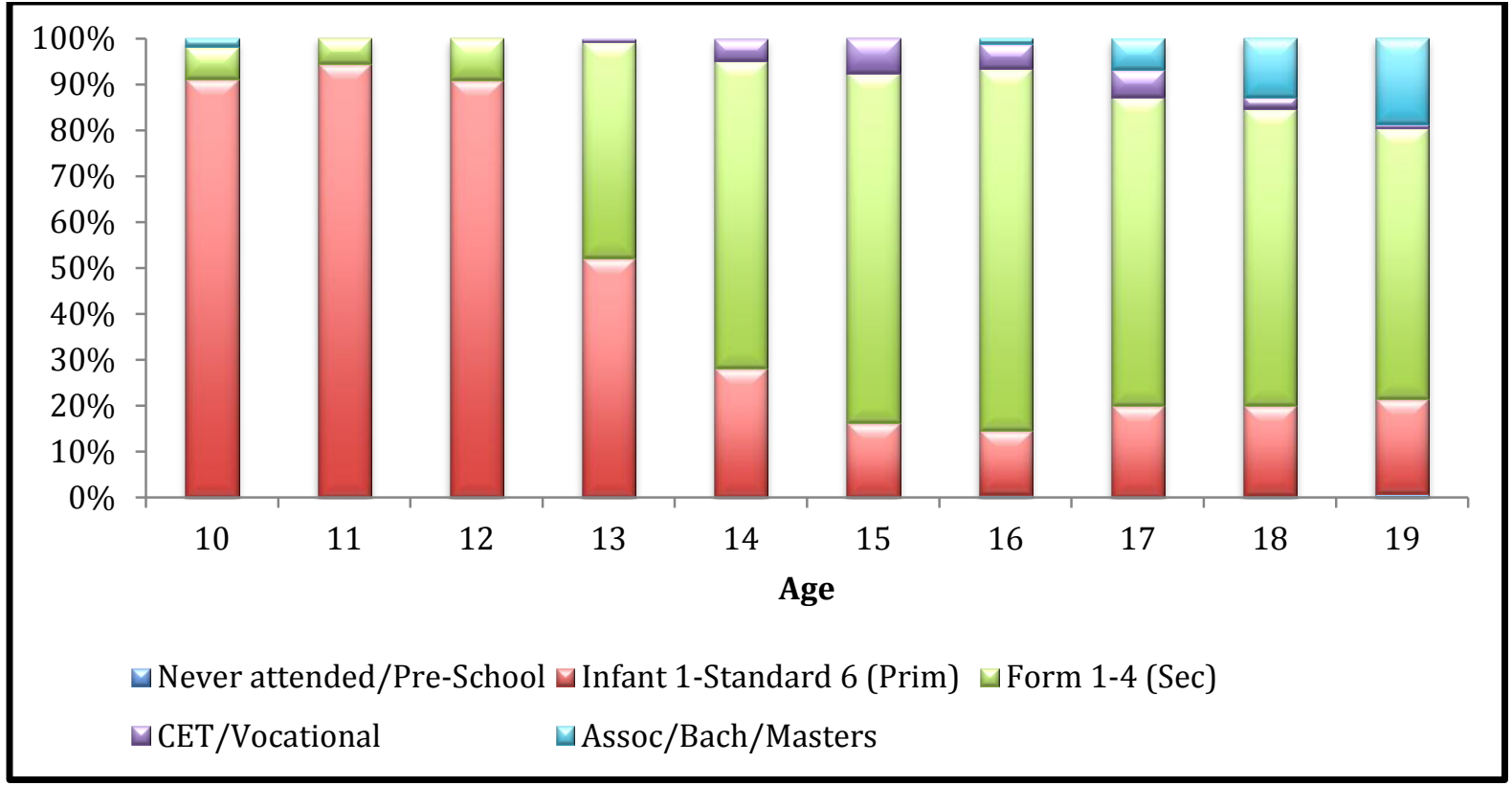

Figure 25 shows data on the current or last class attended by males between the ages of 10 and 19. The majority of males are in the appropriate grade-for-age. This supports the findings from the $10 \%$ sample of the 2010 Belize census that show that the majority of males age 10-14 and $15-19$ are at grade-for-age ( $86.7 \%$ and $73.1 \%$, respectively).

Figure 25: Highest school class attended among male respondents of the 2011 Belize Coverage Exercise, by age

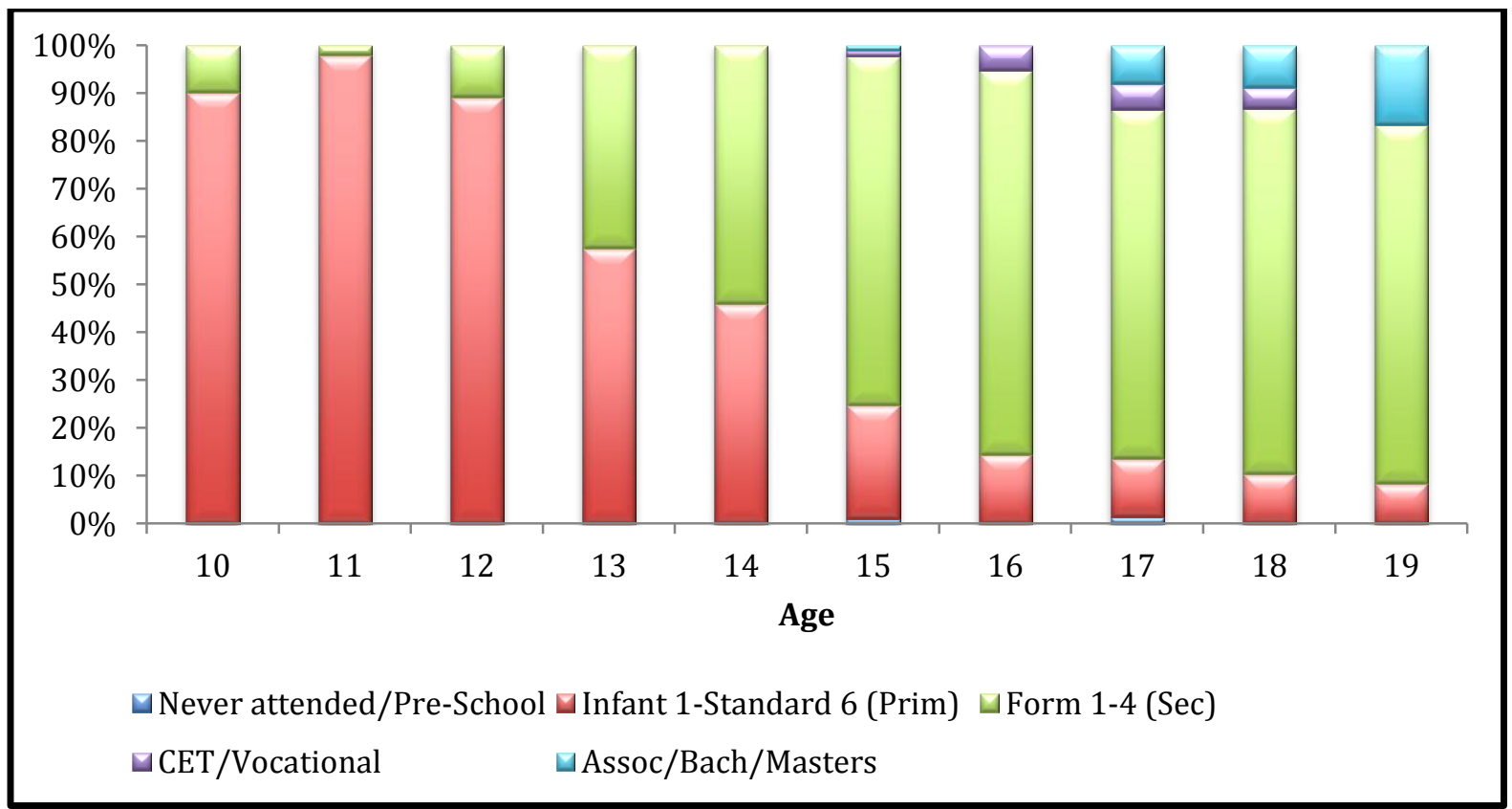


Figure 26 shows the current or last class attended for male and female respondents age 10-14, by sex and ethnicity. The data show that the majority of females and males in this age group are in the proper class for their ages. Interestingly, for each ethnicity, males are more likely than females to be attending the proper class (females appear to be in a higher class level than males across all ethnic groups), except for Hispanics where the percentage of females and males enrolled at the grade for age level is almost equal.

Figure 26: Highest school class attended among 10-14-year-old respondents of the 2011 Belize Coverage Exercise, by sex and ethnicity



Below, Figure 27 illustrates the current or last class attended among respondents between the ages of 15 and 19 by sex and ethnicity. The data show a decline in grade-for-age attendance among Maya and Hispanic females, with $49.5 \%$ and $41.5 \%$, respectively, remaining in primary school. This is on par with what is illustrated from the findings of the $10 \%$ sample of the 2010 Belize census, which shows a decline, especially for females, in grade-for-age attendance rates as age increases. It can be deduced that because of the higher number of Mayan and Hispanic female adolescent respondents still in primary school that there are fewer in secondary school, despite being at the secondary school age. The CE data confirm this: $47.4 \%$ and $44.3 \%$ of Maya and Hispanic females are attending secondary school (compared with the proportions still attending primary school cited above). 
Figure 27: Highest class attended among 15-19-year-old respondents of the 2011 Belize Coverage Exercise, by sex and ethnicity

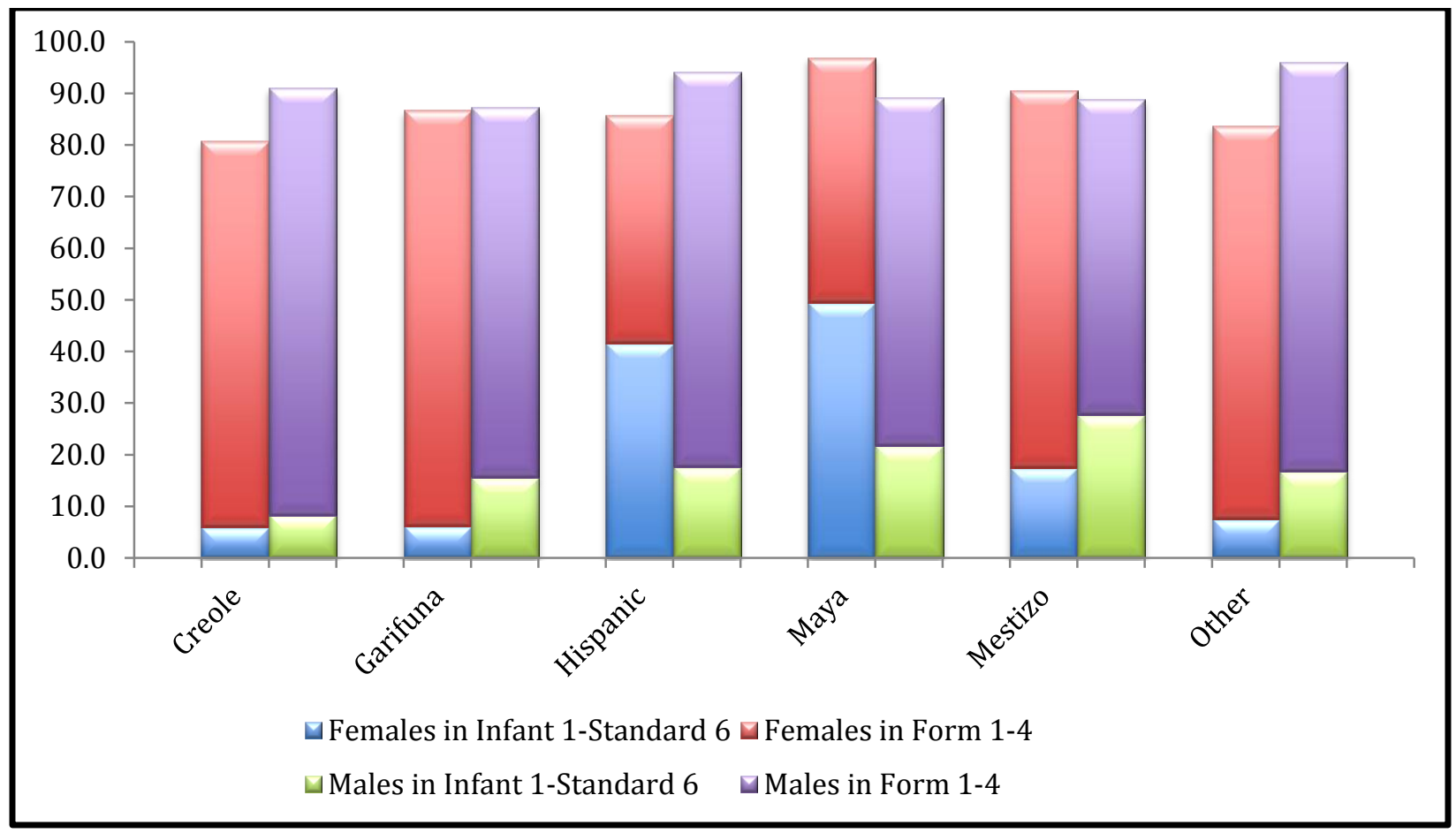

Figure 28 below shows the percentage of respondents, both in- and out-of-school, who reached the appropriate class ${ }^{3}$ that have a primary school certificate by sex and ethnicity. The data illustrate that males and females in each ethnic group have acquired a primary school certificate at similar rates. The exception to this is seen among Garifuna respondents: $84.0 \%$ of males compared to $72.7 \%$ of females possess a primary school certificate. Females from the "Other" ethnic groups and Mayan males possess a primary school certificate at rates lower than their female and male counterparts from other ethnic groups. The largest female-to-male disparity is seen among Mayan respondents: $70.8 \%$ of females and $58.2 \%$ of males possess a primary school certificate, a female-to-male ratio of 1.2

\footnotetext{
${ }^{3}$ The population under analysis is comprised of in-school respondents who are currently attending Form 1 or above plus out-of-school respondents whose last class was Standard 6 or above. This ensures that the population under analysis only includes young people who have had the opportunity to acquire a primary school certificate.
} 
Figure 28: Percent of respondents of the 2011 Belize Coverage Exercise who reached the appropriate class with a primary school certificate, by sex and ethnicity

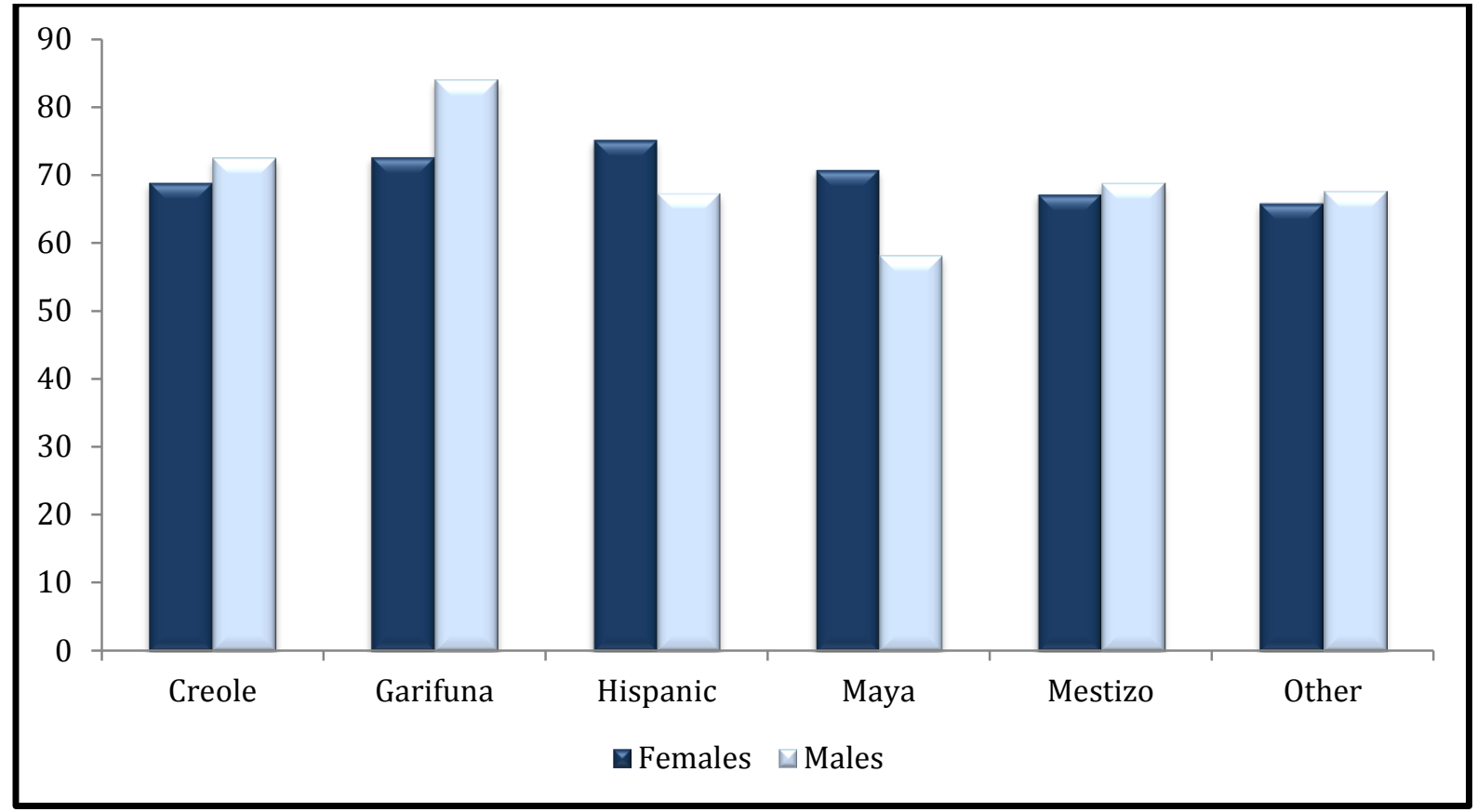

Figure 29 shows the percentage of respondents, both in- and out-of-school, who reached the appropriate class ${ }^{4}$ that have a secondary school certificate by sex and ethnicity. The figure illustrates a large disparity between the percentage of Hispanic female and male respondents who possess a secondary school certificate: $100 \%$ of Hispanic male respondents compared to $78.4 \%$ of female respondents have a secondary school certificate, a female-to-male ratio of $0.78 .^{5}$ Among all other ethnic groups, the proportion of respondents who reached the appropriate class that possess a secondary certificate is rather high.

A comparison of the proportions that possess a primary certificate versus those who possess a secondary certificate raises an interesting point. It appears that the small numbers of young people who make it past Form 4 pass the exams necessary to obtain the secondary certificate at a rate that is much higher than those trying to obtain the primary certificate. In other words, although the actual number of young people that obtain the secondary certificate is much smaller than those who obtain a primary certificate, the former are more likely to successfully complete the certificate than the latter. The select few who make it to Form 4 and beyond find more success than the others. Additional research is required to more fully understand this trend however it does suggest that until a young person passes to a certain class the chances of not

\footnotetext{
${ }^{4}$ The population under analysis is comprised of in-school respondents who are currently attending CET/Vocational school or university plus out-of-school respondents whose last class was Form 4 or above. This ensures that the population under analysis only includes young people who have had the opportunity to acquire a secondary school certificate.

${ }^{5}$ This data point should be approached with caution since only 17 Hispanic respondents were included in this analysis.
} 
completing the primary certificate is quite high. Service providers may want to target resources at supporting young people through the primary school years to ensure they acquire the primary certificate.

Figure 29: Percent of respondents of the 2011 Belize Coverage Exercise currently in school who reached the appropriate class with a secondary school certificate, by sex and ethnicity

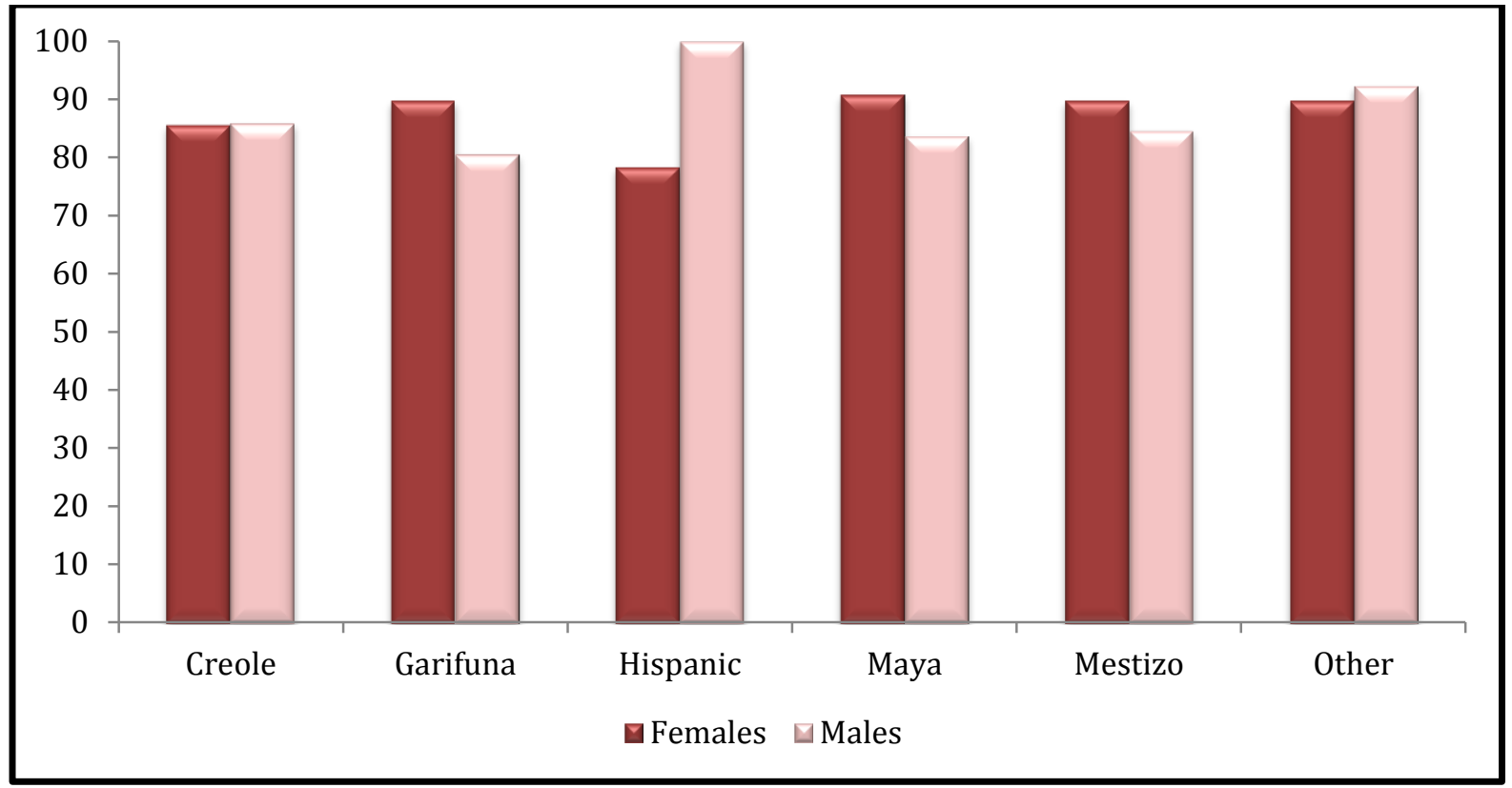

Young persons who are attending school and those who no longer attend school live very different daily experiences. In-school youth have direct access, just by being in school, to a wide range of opportunities to build their knowledge base and develop critical skills. By interacting with their peers on a regular basis they are establishing social capital (i.e., friendship networks) that often serve as critical support mechanisms, not to mention healthy outlets for socializing and recreation. Conversely, out-of-school youth, unless they participate directly in non-formal educational programs, rarely have regular access to the intellectual and social capital necessary to actualize their potential. Most out-of-school youth are not attending due to competing interests - such as the responsibilities associated with raising a child or taking care of a household - or due to limited resources that force them to transition early into work.

Educational institutions provide an excellent medium for programs designed to provide young people with important information on health, sexual and reproductive health, livelihoods and other topics. These types of programs, by virtue of taking place in the school setting, are inaccessible to out-of-school youth and therefore do not reach an important population that often experiences high levels of vulnerability and marginalization due to the socio-economic circumstances that forced them to no longer attend school. To reach both the in-school and outof-school populations of young people, decision-makers need accurate data on the trends in school attendance and educational attainment, particularly on the variations of these indicators 
between geographic areas or ethnic groups. A strong evidence-base will enable them to design policies and programs for both populations that are relevant and effective at supporting them in building the human and social capital they need to succeed.

\section{Work \& Volunteerism}

As part of the transition to adulthood, most young people will engage in either formal or informal employment at some point in time. Ideally, they will be prepared for the demands of the job, have the opportunity to learn new skills that will help them succeed and pursue their professional goals and earn sufficient income to meet their financial needs.

If the local economy is strong there will be a match between the types of skills young people possess and the types and quantities of jobs available. Yet, despite being one of the most educated generations of young people in history, many young people today find it very hard to enter the labor market and remain there over time (Matsumoto and Elder 2010). Young people and adults respond very differently to fluctuations in the labor market where the former are often the last ones to find jobs and the first ones to lose them during economic downturns. Between 2008 and 2009, the youth unemployment rate increased more than the adult unemployment rate and youth unemployment increased at the greatest rate on record from $11.8 \%$ to $12.7 \%$ (ILO 2010). The ILO estimated that there were 74 million unemployed young people in 2011 (ILO 2011), reinforcing the need for strong policies and programs that help keep young people employed when they want and need it most.

In Belize, young females are employed at a much lower rate than males; among 15-19-year-olds, $12.9 \%$ and $32.3 \%$ of females and males were employed, respectively, according to the 2010 census. Among 18-24-year-olds, 31.1\% and $63.5 \%$ of females and males were employed, respectively. However, these large differences are less likely linked with unemployment ${ }^{6}$ and more likely due to differences in labor force participation: 1.4 times as many 15-19-year-old females were not in the labor force than males (65\% vs. $49.7 \%)$ and more than 2.5 times the proportion of 18-24-year-old females were not in the labor force than males (44.7\% vs. 17.2\%). Below, Table 13 illustrates the percentage of adolescent (15-19) and older youth (20-24) respondents who have worked for pay or for their families in the last month, by the district where services were delivered. In both development stages, the percentage of males who have either worked for pay or for their families is higher than the percentage of females who have worked for pay or for their families. There is also a large variation in work participation by district. For example, in the Stann Creak district, $19.0 \%$ of adolescent females have engaged in work for pay or worked for their families during the month prior to participating in the survey as compared to $44.3 \%$ of their male counterparts. In Stann Creek there was also a large variation between work experiences for older youth, with $38.5 \%$ of females reporting that they had worked for pay or for their families during the last month, as compared to $76.5 \%$ of males in the older youth category.

\footnotetext{
${ }^{6}$ Among 15 -19-year-olds, $22.1 \%$ and $19.8 \%$ of females and males were unemployed, respectively, while among 18 24 -year-olds, $24.3 \%$ and $19.2 \%$ of females and males were unemployed, respectively.
} 
There was also a great variation between work experiences for females and males in Belize and Toledo, the other two districts in which our data was collected. The data in Table 13 show that in the adolescent and older youth development stages, regardless of district, males are more likely than females to engage in paid work and/or work for their families. The 2010 census final report shows little variation in labor force participation across the districts but larger variations in unemployment rates. Further inquiry is required to determine the reasons behind the differences seen between the $\mathrm{CE}$ and census data with respect to work.

Table 13: Percent of 15-24-year-old respondents of the 2011 Belize Coverage Exercise who have worked for pay or for their family in the last month, by development stage and district

\begin{tabular}{|llcc|}
\hline Development stage & Belize & Stann Creek & Toledo \\
\hline & Females & & \\
\hline Adolescent (15-19) & 24.5 & 19.0 & 12.9 \\
Older youth (20-24) & 49.4 & 38.5 & 20.2 \\
\hline & Males & & \\
\hline Adolescent (15-19) & 37.4 & 44.3 & 31.9 \\
Older youth (20-24) & 74.4 & 76.5 & 69.7 \\
\hline
\end{tabular}

Current and reliable data on labor force participation are necessary for designing strategies that help keep young people engaged in the labor market and ensure equitable access to safe and dignified work. These data can be used to parse out differences in other social and demographic characteristics as they vary between those young people who are employed, unemployed and not in the labor market and possibly reveal discrimination or segregation in the labor market that can affect young people in very different ways.

Volunteerism among young people is a useful proxy for civic or social participation. The act of doing volunteer work can be a great way for young people to gain important skills and meet other like-minded individuals, not to mention the benefits it confers on the local community. By measuring the level of community service or volunteer work done by young people, stakeholders can have a better idea of the potential pool of youth willing to engage in these types of acts. National level data on volunteerism are not available for Belize, but the data collected during the CE show that the respondents have volunteered in the past month at rates very similar to those who worked for pay or with their family in the past month. Table 14 below shows the proportions of young respondents who reported having volunteered in the past month. Additional research would be necessary to understand why the volunteer rates are quantitatively so close to the work data across development stages, sex and districts. 
Table 14: Percent of 15-24-year-old respondents of the 2011 Belize Coverage Exercise volunteered in the last month, by development stage and district

\begin{tabular}{|lccc|}
\hline Development stage & Belize & Stann Creek & Toledo \\
\hline \multicolumn{4}{c}{ Females } \\
Adolescent (15-19) & 24.6 & 19.2 & 13.0 \\
Older youth (20-24) & 50.4 & 38.7 & 20.6 \\
\hline \multicolumn{5}{l}{ Males } & \\
\hline Adolescent (15-19) & 38.1 & 44.6 & 32.8 \\
Older youth (20-24) & 76.3 & 77.6 & 70.8 \\
\hline
\end{tabular}

\section{Service Provision}

Types of services utilized

One of the objectives of the CE is to provide a supply-side analysis of the types of services being utilized by different subgroups of young people. The great diversity found among the youth population means there is a diversity of need for, and access to, services and programs. For example, a 15-year-old female who lives at home with her parents, is still in school and has no children has a very different set of needs than a 15-year-old single mother who no longer attends school and lives with her extended family. A careful analysis of data on the utilization of services and the variance among different subgroups within the population can assist service providers to more effectively target resources and support the local youth population in a way that is relevant to their needs.

Table 15 shows the percentage of respondents, age 10-24 who answered that they had received a certain type of service according to sex and the district where the service was delivered. The services that the respondents report accessing the most frequently are health-related services; this is true across districts and males and females. In Belize district, $62.2 \%$ of females have accessed health-related services, as compared with only $8.2 \%$ sports, $8.0 \%$ sexual and reproductive health (SRH), $6.3 \%$ education and $6.1 \%$ livelihoods, the next four highest service types. The percentages of females accessing health-related services in Stann Creak and Toledo are very similar to that of Belize at $58.2 \%$ and $62 \%$, respectively. Stann Creak has the highest percentage of females and males who reported accessing SRH services at $25.6 \%$ and $27.5 \%$, respectively. This is markedly higher than what the respondents reported in the other districts. For example, in Belize only $4.3 \%$ of males reported having received SRH services.

An interesting and important story the data tell is illustrated by examining the percentages of respondents reporting having received livelihoods, life skills and education services. These types of services can be used as a proxy for those that build the human capital necessary to help young people develop into informed, autonomous decision-makers with the ability to earn a living. In 
all districts except $\mathrm{Cayo}^{7}$, the proportion of females and males who reported receiving these types of services is relatively low, particularly compared with health and SRH. For example, in Stann Creek and Toledo, less than one percent of females age 10-24 reported having received livelihoods services while less than one percent and almost eight percent received life skills services in Stann Creek and Toledo, respectively. Among males, approximately one percent in Stann Creek and Toledo reported receiving livelihoods services while almost seven percent in each district reported receiving life skills services.

Table 15: Percent of respondents of the 2011 Belize Coverage Exercise age 10-24 who answered that they received a certain type of service, by sex and district

\begin{tabular}{|c|c|c|c|c|c|c|c|c|c|}
\hline District & Health & $\mathrm{SRH}$ & $\begin{array}{c}\text { Mental } \\
\text { health }\end{array}$ & Livelihoods & $\begin{array}{l}\text { Life } \\
\text { skills }\end{array}$ & Education & Sports & Food & Other \\
\hline \multicolumn{10}{|c|}{ Females } \\
\hline Belize & 62.2 & 8.0 & 4.2 & 6.1 & 4.6 & 6.3 & 8.2 & 1.6 & 6.7 \\
\hline Stann Creek & 58.2 & 25.6 & 3.1 & 0.9 & 7.9 & 1.8 & 0.0 & 0.0 & 7.9 \\
\hline Toledo & 62.0 & 16.1 & 6.7 & 0.4 & 0.4 & 1.1 & 0.0 & 0.0 & 8.7 \\
\hline \multicolumn{10}{|c|}{ Males } \\
\hline Belize & 51.2 & 4.3 & 4.8 & 5.5 & 8.8 & 13.6 & 10.5 & 4.5 & 19.5 \\
\hline Stann Creek & 48.8 & 27.5 & 4.7 & 0.6 & 6.9 & 2.2 & 0.0 & 0.0 & 7.8 \\
\hline Toledo & 42.2 & 8.7 & 16.2 & 1.2 & 6.4 & 2.9 & 0.0 & 0.0 & 20.2 \\
\hline
\end{tabular}

Table 16 shows the percentage of respondents age 10-24 who reported that they received a certain type of service by sex and ethnicity. Females of all ethnic groups except "Other" reported receiving health and SRH services at a higher rate than their male counterparts. Mayan females were almost twice as likely to report having accessed SRH services as their males counterparts. Less than 10 percent of male and female respondents reported receiving livelihoods and life skills services, except for $10.2 \%$ and $11.5 \%$ of Garifuna males and females who received life skills, respectively. Garifuna females and males were the most likely to report having accessed life skills services. Conversely, Mayan females and males reported the lowest rates of receiving livelihoods and life skills services among all other groups. Lastly, Creole males were more than twice as likely to access education-related services as their female counterparts: $11.4 \%$ and $4.7 \%$, respectively.

\footnotetext{
${ }^{7}$ The two programs from Cayo were selected because they specifically focus on these types of services for adolescent girls. Therefore the data for Cayo are skewed towards livelihoods, life skills, education and sports.
} 
Table 16: Percent of respondents of the 2011 Belize Coverage Exercise age 10-24 who answered that they received a certain type of service, by sex and ethnicity

\begin{tabular}{|c|c|c|c|c|c|c|c|c|c|}
\hline Ethnicity & Health & SRH & $\begin{array}{l}\text { Mental } \\
\text { health }\end{array}$ & Livelihoods & $\begin{array}{l}\text { Life } \\
\text { skills }\end{array}$ & Education & Sports & Food & Other \\
\hline \multicolumn{10}{|c|}{ Females } \\
\hline Creole & 60.6 & 10.7 & 3.8 & 5.1 & 5.5 & 4.7 & 6.8 & 1.3 & 8.4 \\
\hline Garifuna & 48.4 & 26.0 & 3.9 & 2.0 & 10.2 & 4.2 & 1.4 & 0.2 & 9.4 \\
\hline Hispanic & 75.2 & 10.8 & 2.4 & 3.2 & 3.2 & 3.6 & 4.0 & 0.8 & 7.6 \\
\hline Maya & 65.7 & 19.4 & 6.2 & 0.2 & 0.6 & 1.5 & 0.2 & 0.2 & 4.3 \\
\hline Mestizo & 65.5 & 17.8 & 5.7 & 2.3 & 2.3 & 2.3 & 1.7 & 0.0 & 4.0 \\
\hline Other & 63.8 & 11.0 & 3.7 & 1.8 & 4.9 & 2.5 & 1.8 & 0.6 & 9.8 \\
\hline \multicolumn{10}{|c|}{ Males } \\
\hline Creole & 50.3 & 7.8 & 5.3 & 3.6 & 9.2 & 11.4 & 8.1 & 3.1 & 16.9 \\
\hline Garifuna & 37.3 & 23.8 & 6.1 & 4.5 & 11.5 & 7.0 & 3.7 & 2.9 & 17.2 \\
\hline Hispanic & 70.4 & 9.9 & 3.7 & 1.2 & 1.2 & 1.2 & 0.0 & 0.0 & 7.4 \\
\hline Maya & 47.5 & 11.9 & 15.3 & 0.0 & 2.5 & 1.7 & 0.0 & 0.0 & 14.4 \\
\hline Mestizo & 58.5 & 9.4 & 9.4 & 3.8 & 7.5 & 5.7 & 5.7 & 0.0 & 7.5 \\
\hline Other & 50.9 & 13.2 & 5.7 & 0.0 & 1.9 & 7.5 & 3.8 & 0.0 & 22.6 \\
\hline
\end{tabular}

Table 17 shows the percentages of respondents age 10-24 who reported that they had accessed a certain type of service by sex and relationship status. The table shows, similar to those above, that females and males are most likely to access health related services, followed by sexual and reproductive health related services. This is illustrated across relationship categories. Females in a marital union of some type are the most likely to have reported being the recipient of health services but the least likely to have reported being the recipient SRH services. The data show the same outcomes for their male counterparts. One very important finding is that among females, those in a marital union were the least likely to receive livelihoods, life skills and education services. Among males, those in a marital union were also less likely to receive these types of services than their single counterparts. ${ }^{8}$ This is worth further inquiry as it reveals a potential bias in participation in these types of programs towards single males and females, something seen in the CE data from other countries as well.

\footnotetext{
${ }^{8}$ The clustering of a large proportion of males who are separated, divorced or widowed in the health and SRH services and not in other areas is due to the fact that only three males age 10-24 have this relationship status.
} 
Table 17: Percent of respondents of the 2011 Belize Coverage Exercise age 10-24 who answered that they received a certain type of service, by sex and relationship status

\begin{tabular}{|c|c|c|c|c|c|c|c|c|c|}
\hline $\begin{array}{l}\text { Relationship } \\
\text { Status }\end{array}$ & Health & SRH & $\begin{array}{l}\text { Mental } \\
\text { health }\end{array}$ & Livelihoods & $\begin{array}{l}\text { Life } \\
\text { skills }\end{array}$ & Education & Sports & Food & Other \\
\hline \multicolumn{10}{|c|}{ Females } \\
\hline Single & 48.3 & 18.0 & 4.7 & 4.1 & 8.1 & 5.3 & 5.1 & 1.0 & 9.5 \\
\hline In Union & 77.3 & 14.6 & 3.7 & 1.1 & 1.1 & 1.0 & 0.8 & 0.0 & 4.8 \\
\hline \multicolumn{10}{|l|}{ Sep, Div, } \\
\hline Widowed & 58.3 & 33.3 & 4.2 & 8.3 & 8.3 & 8.3 & 12.5 & 8.3 & 4.2 \\
\hline \multicolumn{10}{|c|}{ Males } \\
\hline Single & 46.8 & 13.9 & 7.2 & 3.2 & 8.4 & 8.9 & 5.7 & 2.5 & 16.7 \\
\hline In Union & 56.0 & 12.0 & 7.3 & 1.3 & 3.3 & 2.7 & 1.3 & 0.7 & 11.3 \\
\hline \multicolumn{10}{|l|}{ Sep, Div, } \\
\hline Widowed & 33.3 & 33.3 & 0.0 & 0.0 & 0.0 & 0.0 & 0.0 & 0.0 & 0.0 \\
\hline
\end{tabular}

Table 18 shows the percentage of female respondents reported accessing a certain type of service by pregnancy status. Of respondents who reported being currently pregnant and those who reported that they were not currently pregnant, both groups were more likely to report accessing a health related service than any other service. An interesting point is that females who reported not being pregnant at the time of the survey were more likely than females who reported being pregnant to report accessing SRH services. Pregnant females reported receiving livelihoods, life skills and education services at rates much lower than their non-pregnant counterparts: pregnant respondents accessed those types of services at scant rates of $0.2 \%$ and $0.7 \%$ as compared to non-pregnant respondents who accessed livelihoods and life skills services at rates of $3.4 \%$ and $6.4 \%$, respectively. Further, non-pregnant respondents were also more likely to access education services at a rate of $4.1 \%$ as compared to pregnant respondents who reported accessing education services at a rate of $1.0 \%$. This reflects a trend seen in CEs from other countries whereby pregnant females mostly receives services related to health and SRH while other programs that build human capital are utilized by non-pregnant females. This bias could be due to the inaccessible nature of human capital services so that pregnant females are largely underrepresented there. In-depth research is required to more fully explain this issue. 
Table 18: Percent of female respondents of the 2011 Belize Coverage Exercise age 10-24 who answered that they received a certain type of service, by pregnancy status

\begin{tabular}{|lccccccccc|}
\hline $\begin{array}{l}\text { Currently } \\
\text { pregnant }\end{array}$ & Health & SRH & $\begin{array}{c}\text { Mental } \\
\text { health }\end{array}$ & Livelihoods & $\begin{array}{c}\text { Life } \\
\text { skills }\end{array}$ & Education & Sports & Food & Other \\
\hline No & 54.6 & 18.9 & 4.8 & 3.4 & 6.4 & 4.1 & 3.8 & 0.8 & 8.4 \\
Yes & 88.5 & 7.5 & 1.9 & 0.2 & 0.7 & 1.0 & 0.7 & 0.2 & 2.9 \\
\hline
\end{tabular}

Table 19 shows the reporting of services by school attendance status. Among males and females, out-of-school youth are much less likely to have reported receiving livelihoods, life skills and education services than those who are in school. The data show that females who were attending school at the time of the survey were more likely than females who were not attending school when the survey was conducted to report accessing livelihoods- and life skills-related services at rates of $6.0 \%$ and $8.6 \%$ as compared to $0.5 \%$ and $1.0 \%$, respectively. These rates suggest that there may be a slight correlation between school attendance and accessibility of livelihoods and life skills services. This is of particular concern as these young people are less likely to be acquiring the knowledge and skills needed to transition smoothly to both work and adulthood and are therefore in need of specialized attention in this area.

Table 19: Percent of respondents of the 2011 Belize Coverage Exercise age 10-24 who answered that they received a certain type of service, by sex and school attendance status

\begin{tabular}{|c|c|c|c|c|c|c|c|c|c|}
\hline $\begin{array}{l}\text { Currently } \\
\text { attending } \\
\text { school }\end{array}$ & Health & $\mathrm{SRH}$ & $\begin{array}{c}\text { Mental } \\
\text { health }\end{array}$ & Livelihoods & $\begin{array}{l}\text { Life } \\
\text { skills }\end{array}$ & Education & Sports & Food & Other \\
\hline \multicolumn{10}{|c|}{ Female } \\
\hline No & 75.4 & 15.0 & 3.8 & 0.5 & 1.0 & 0.5 & 0.1 & 0.0 & 4.3 \\
\hline Yes & 45.5 & 18.3 & 4.7 & 6.0 & 8.6 & 6.6 & 6.9 & 1.0 & 11.5 \\
\hline \multicolumn{10}{|c|}{ Male } \\
\hline No & 60 & 12.8 & 8.6 & 1.0 & 2.1 & 1.7 & 0.3 & 0.3 & 10.0 \\
\hline Yes & 47.1 & 11.7 & 6.2 & 3.9 & 9.1 & 9.7 & 6.8 & 2.5 & 17.3 \\
\hline
\end{tabular}

Access to services and frequency of use

In settings where services and programs are inaccessible to many young people, the same people utilize resources repeatedly. The "repeat users" are often participating in a program that meets regularly or taking advantage of the multiple services available. But for other young people, those who experience obstacles to accessing the services or attending programs and might not be getting their needs met, the possibilities are limited and their frequency of use is very low. By 
examining the frequency of use of services across different social and demographic characteristics, program planners can get a better understanding of the types of young people that may be over- or under-represented.

Table 20 shows how often female and male respondents accessed services by the district where services were delivered. We can see that the majority of females and males access services every few months. The proportion of first time users of services is also fairly high among females and males, particularly among males in Stann Creek and Toledo and females in Stann Creek. Another interesting point illustrated by the data is that in both Belize and Toledo males are more likely to report accessing certain services at the daily rate than females.

Table 20: Frequency of use of services among respondents of the 2011 Belize Coverage Exercise age $10-24$, by sex and district

\begin{tabular}{|lccccccccc|}
\hline District & Daily & Weekly & $\begin{array}{c}\text { Once per } \\
\text { month }\end{array}$ & $\begin{array}{c}\text { Every few } \\
\text { months }\end{array}$ & $\begin{array}{c}\text { First } \\
\text { time }\end{array}$ & DK & Total & N \\
\hline Belize & 9.5 & 12.4 & 12.2 & 40.8 & 10.6 & 14.5 & 100.0 & 968 \\
Stann Creek & 1.2 & 19.9 & 21.0 & 35.4 & 15.0 & 7.5 & 100.0 & 1,005 \\
Toledo & 2.7 & 17.8 & 18.3 & 38.2 & 11.8 & 11.2 & 100.0 & 552 \\
\hline & & \multicolumn{7}{c}{ Females } \\
\hline Belize & 17.5 & 7.7 & 7.2 & 39.9 & 10.5 & 17.2 & 100.0 & 401 \\
Stann Creek & 2.5 & 12.5 & 20.9 & 34.4 & 20.3 & 9.4 & 100.0 & 320 \\
Toledo & 7.5 & 10.4 & 9.2 & 41.0 & 19.7 & 12.1 & 100.0 & 173 \\
\hline
\end{tabular}

Table 21 below shows data that represent the frequency of use of certain services by gender and ethnicity. The table illustrates that females and males from most ethnic groups access certain services most frequently on a basis of every few months. Overall, there is little significant variation in the frequency of use of services between ethnic groups and males and females. 
Table 21: Frequency of use of services among respondents of the 2011 Belize Coverage Exercise age $10-24$, by sex and ethnicity

\begin{tabular}{|lccccccccc}
\hline Ethnicity & Daily & Weekly & $\begin{array}{c}\text { Once per } \\
\text { month }\end{array}$ & $\begin{array}{c}\text { Every few } \\
\text { months }\end{array}$ & $\begin{array}{c}\text { First } \\
\text { time }\end{array}$ & DK & Total & N \\
\hline Creole & 7.5 & 14.4 & 13.9 & 40.7 & 10.8 & 12.8 & 100.0 & 836 \\
Garifuna & 3.9 & 22.4 & 17.2 & 31.7 & 14.0 & 10.9 & 100.0 & 635 \\
Hispanic & 2.8 & 9.3 & 23.1 & 43.7 & 13.0 & 8.1 & 100.0 & 247 \\
Maya & 2.8 & 18.8 & 18.1 & 40.7 & 11.3 & 8.3 & 100.0 & 469 \\
Mestizo & 1.7 & 9.2 & 25.3 & 32.8 & 20.1 & 10.9 & 100.0 & 174 \\
Other & 3.7 & 17.8 & 11.7 & 38.7 & 11.0 & 17.2 & 100.0 & 163 \\
\hline & & & & Males & & & & \\
\hline Creole & 14.0 & 10.5 & 7.6 & 38.1 & 11.6 & 18.3 & 100.0 & 344 \\
Garifuna & 10.2 & 12.7 & 18.9 & 29.1 & 17.6 & 11.5 & 100.0 & 244 \\
Hispanic & 0.0 & 5.1 & 19.0 & 46.8 & 17.7 & 11.4 & 100.0 & 79 \\
Maya & 5.1 & 6.8 & 12.7 & 50.8 & 17.8 & 6.8 & 100.0 & 118 \\
Mestizo & 13.2 & 9.4 & 5.7 & 39.6 & 20.8 & 11.3 & 100.0 & 53 \\
Other & 7.7 & 9.6 & 11.5 & 40.4 & 19.2 & 11.5 & 100.0 & 52 \\
\hline
\end{tabular}

The accessibility of services depends on many different factors ranging from the distance one needs to travel and the cost of transportation to the proximity of the services to dangerous areas. Any of these factors, or the combination of them, can severely limit a young person's ability to access services regularly or find the possibility to participate in a program with other youth. Asking questions in surveys, exit interviews or daily registers about issues pertaining to accessibility can provide key insight into the types of challenges or obstacles young people experience that may inhibit their ability to arrive at the service delivery point.

Below, Figures 30 and 31 show the amount of time it takes female and male respondents between the ages of 10 and 24 to get from their point of origin to arrive at the point of service delivery (where data were collected) by district. The data show some variation in the amount of time that females have to travel to their respective points of service delivery by district. For example, in the district of Toledo, $47.3 \%$ of female respondents reported traveling 30 minutes or more to a point of service delivery as compared to $18.2 \%$ and $28.9 \%$ of females in the Stann Creek and Belize, respectively, who reported traveling 30 minutes or more to points of service delivery (among male respondents, the trend is the same only the values vary slightly). These large distances can easily deter a young person from accessing services given the time and resources needed to arrive. 
Figure 30: Travel time (one way) to arrive at the point of service delivery among female respondents of the 2011 Belize Coverage Exercise age 10-24, by district

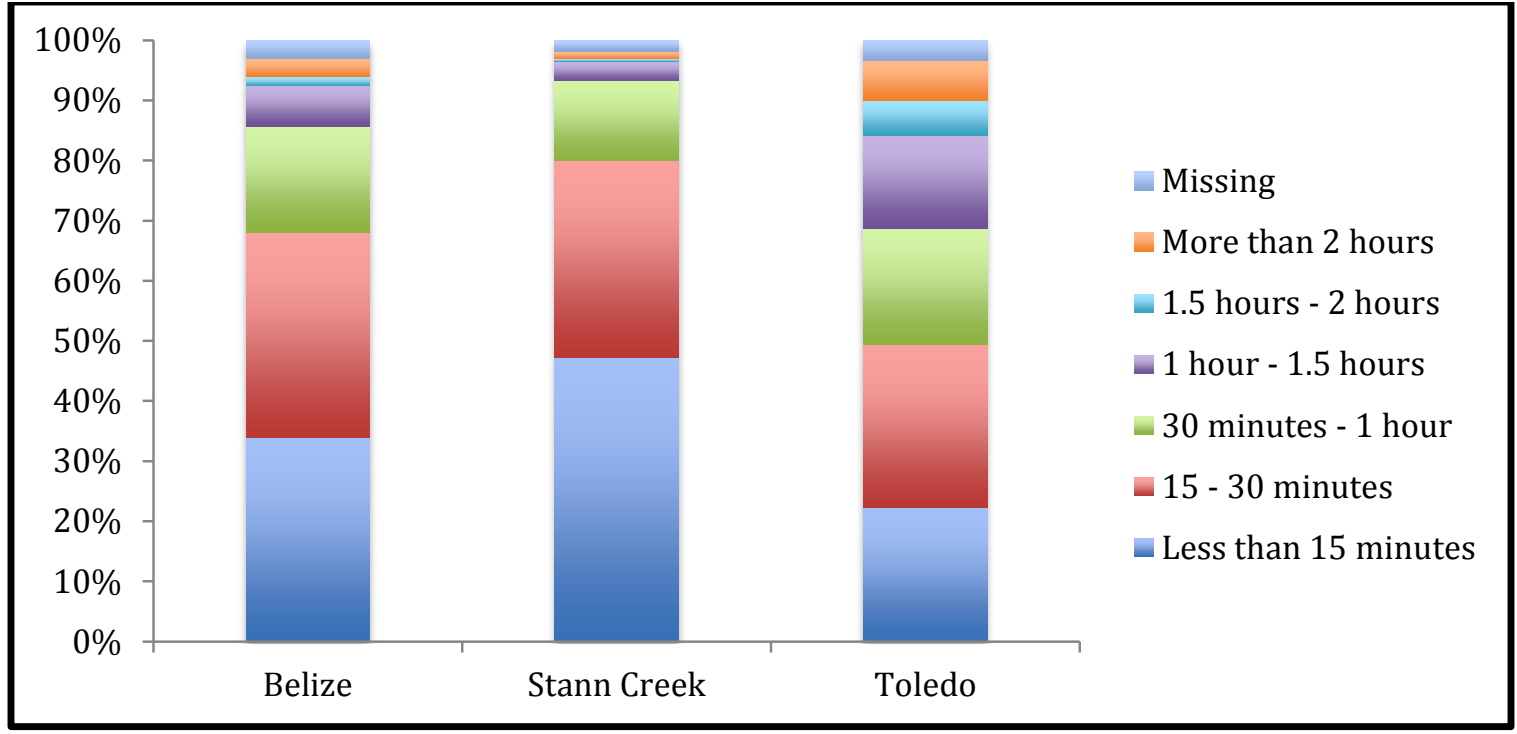

Figure 31: Travel time (one way) to arrive at the point of service delivery among male respondents of the 2011 Belize Coverage Exercise age 10-24, by district

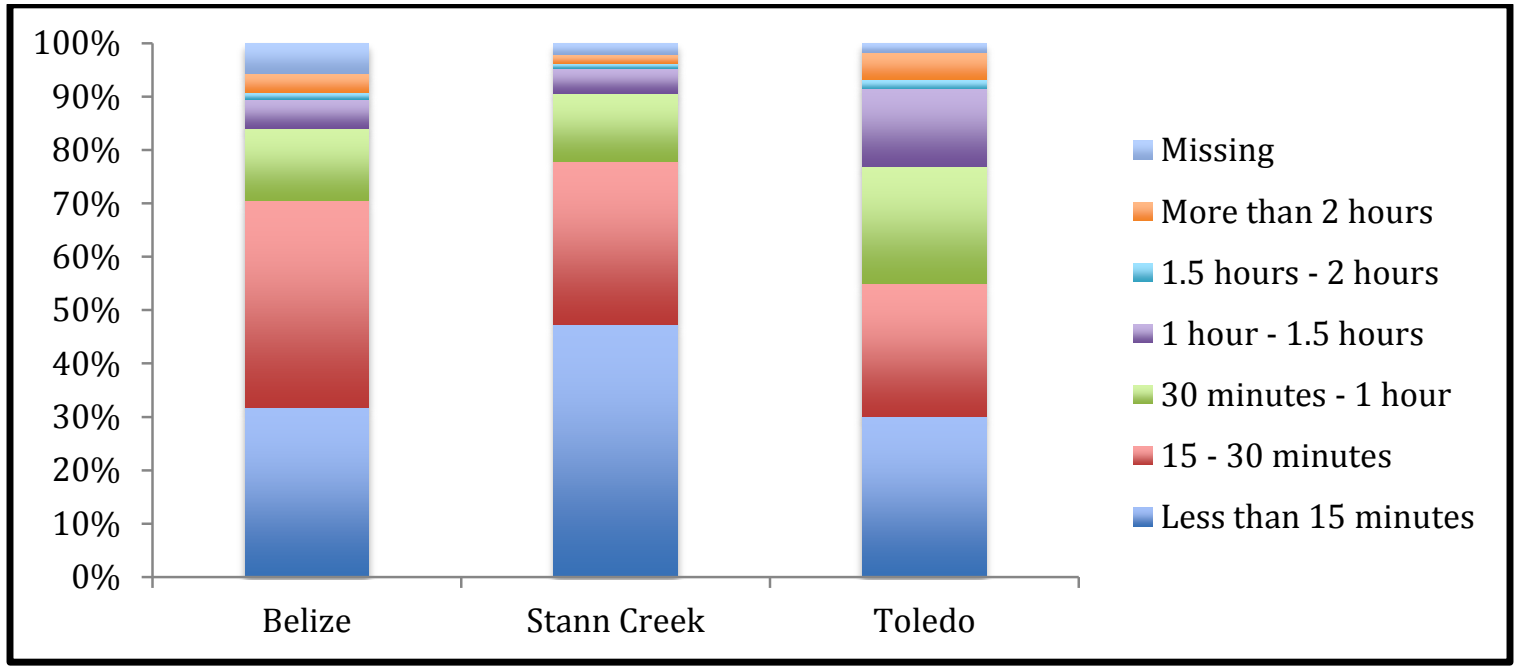

Table 22 presents data on the perceptions of safety when traveling to the point of service delivery among female and male respondents aged 10 to 24 by the districts where services were received. Overall, data show that the vast majority of females and males reported feeling safe during their travel to receive services or participate in programs and that there is very little variation of perceptions of safety between sexes. However, females in Belize district were the group that reported the highest percentage of feeling unsafe, always or sometimes, at $13.8 \%$ as compared to $8.4 \%$ of males in Belize district who reported feeling unsafe. Females in Belize district are 
approximately twice as likely to have reported feeling unsafe than females in Stann Creek and Toledo.

Table 22: Perception of safety when traveling to the point of service delivery among respondents of the 2011 Belize Coverage Exercise age 10-24, by sex and district

\begin{tabular}{|c|c|c|c|}
\hline District & Feel safe & $\begin{array}{c}\text { Don't feel } \\
\text { safe } \\
\text { (always or } \\
\text { sometimes) }\end{array}$ & $\mathrm{N}$ \\
\hline \multicolumn{4}{|c|}{ Females } \\
\hline Belize & 79.3 & 13.8 & 981 \\
\hline Stann Creek & 90.1 & 7.7 & 1,005 \\
\hline Toledo & 90.6 & 6.5 & 552 \\
\hline Total Females & 85.8 & 9.8 & 2,538 \\
\hline \multicolumn{4}{|c|}{ Males } \\
\hline Belize & 82.9 & 8.4 & 420 \\
\hline Stann Creek & 90.6 & 7.8 & 320 \\
\hline Toledo & 91.9 & 7.5 & 173 \\
\hline Total Males & 87.3 & 8.0 & 913 \\
\hline
\end{tabular}

\section{Identifying Vulnerable Subgroups of Young Service}

\section{Users}

Young people are a highly diverse population with different capabilities and opportunities that vary according to their age, sex, area of residence, educational attainment, marital status and household composition, among others. Data disaggregated by these characteristics will help policy-makers and program planners to identify the vulnerable and marginalized young people who are under-represented at youth services and programs. These data will also help to highlight the key points in the lives of young people that lead them towards or away from vulnerability. Understanding this aspect of their lives will assist in the design of interventions that support them before life-changing events occur that are difficult or impossible to reverse, such as early childbearing and HIV.

More extensive household surveys, such as the DHS and MICS, that collect important data on sexual and reproductive health, domestic violence and other indicators related to fertility, maternal and infant health and labor force participation, allow for a fine disaggregation of data to study the interactions of different indicators. Additionally, this permits analysts to identify and locate vulnerable populations of young people who may be suffering from multiple disadvantages, such as an out-of-school, disabled male living with a foster family. Due to the limitations related to the number and range of questions included, the CE data analysts selected 
one key indicator, school attendance, and analyzed it as it differs according to other social and demographic indicators.

A young person's ability to attend school can be directly impacted by many different factors, either endogenous to the individual, exogenous to his/her surroundings or both. The responsibilities of parenting, restrictions on mobility due to gender norms, lack of schooling options and the need to work can, among other trap doors on the road to adulthood, derail a young person and take him/her off course for finishing school. Reversing this trend by reenrolling in school is very challenging and unlikely to happen unless the proper support mechanisms are in place to serve as a bridge between the out-of-school and school-going experiences.

Raising a child is a significant responsibility that may require too much of a young person's time to allow for school attendance. It is very common for females to drop out of school before or right after childbirth, an issue that can be seen in variations in school attendance by parental status. In many settings, girls who become pregnant are not permitted to attend school and are only allowed to return after the birth of their child. However, given the level of responsibility required to rear a child and the changing priorities that accompany being a young parent, the likelihood they return is often quite low. In Belize, very large differences are seen in school attendance rates between those females who have had a child and those who have not (according to the analysis of the $10 \%$ sample of the 2010 census). Figure 32 below shows school attendance rates among 15-19-year-old females by children ever born. More than 20 times the proportion of females without children attend school than their counterparts who have had at least one child. This large differential is evidence that females with children have a difficult time staying in school once they become mothers. To remedy this situation, service providers need to tailor interventions so that they address the young mothers' unique needs and, if they so desire, get them back into school or in a non-formal education program to ensure they do not fall too far behind their peers. 
Figure 32: Percent attending school among females age 15-19 according to 2010 Belize Census, by parental status

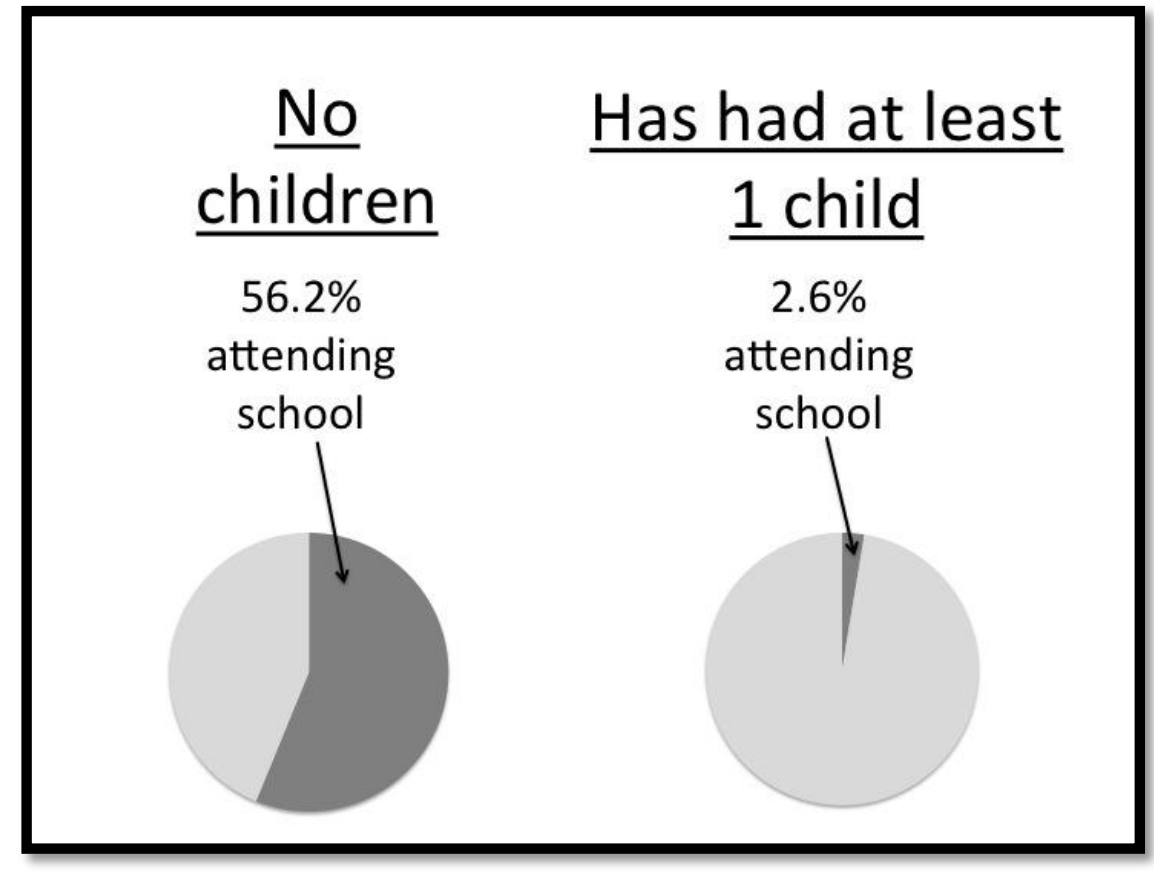

Source: 2010 Belize Census (authors' analysis of $10 \%$ sample)

Figure 33 illustrates the percentage of female respondents age 15-19 who were attending school when the survey was administered by parental status. For all ages, female respondents without a child were much more likely to be attending school than those with a child. The data show that from age 15-19, 2.3-4 times as many female respondents who are not mothers are in school than those who are mothers. Although the proportion of female respondents with children who are in school is significantly higher than in the general population (see Figure 32 above), the trend is still the same in that far fewer of these females attend school than those without children. Given the high rates of teen pregnancy in Belize, out-of-school young mothers will likely make up large segments of population accessing services and will therefore need specific types of attention to help them overcome the obstacle of this double disadvantage. 
Figure 33: Percent of female respondents of the 2011 Belize Coverage Exercise currently attending school, by age and parental status

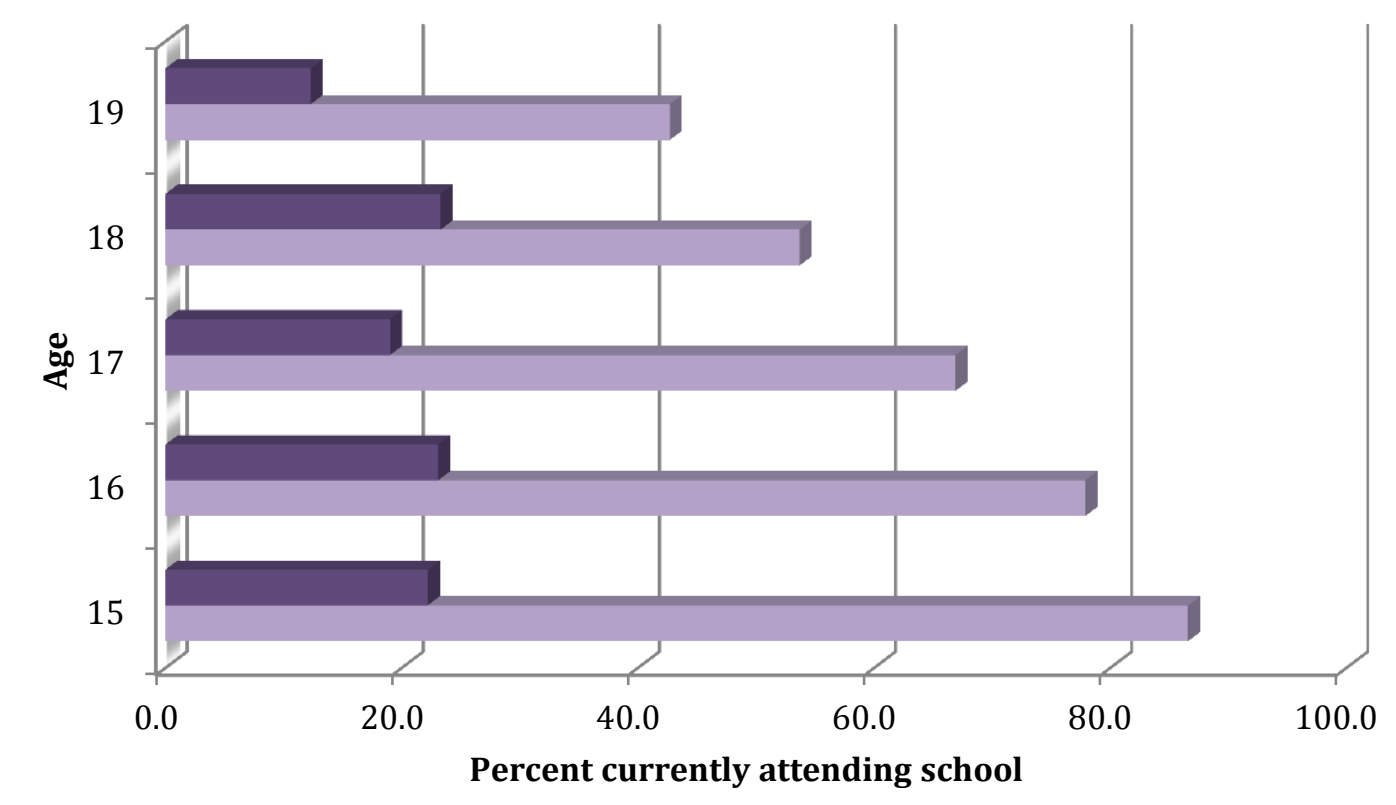

- Females who have a child $\quad$ Females who do not have a child

The data presented in Figure 34 show the percentage of female respondents who were attending school when the survey administered by their age and their pregnancy status. The data show that, similar to what occurs among young mothers, large proportions of pregnant females are not attending school compared to those who are not pregnant. Between the ages of 15 and 19, 1.7-4.4 times as many non-pregnant female respondents were attending school than their pregnant counterparts. Similar to those who have children, young pregnant females will need specialized support tailored to their unique needs to help them overcome the challenges they may encounter during pregnancy so that they do not fall far behind their peers. 
Figure 34: Percent of female respondents of the 2011 Belize Coverage Exercise currently attending school, by age and pregnancy status

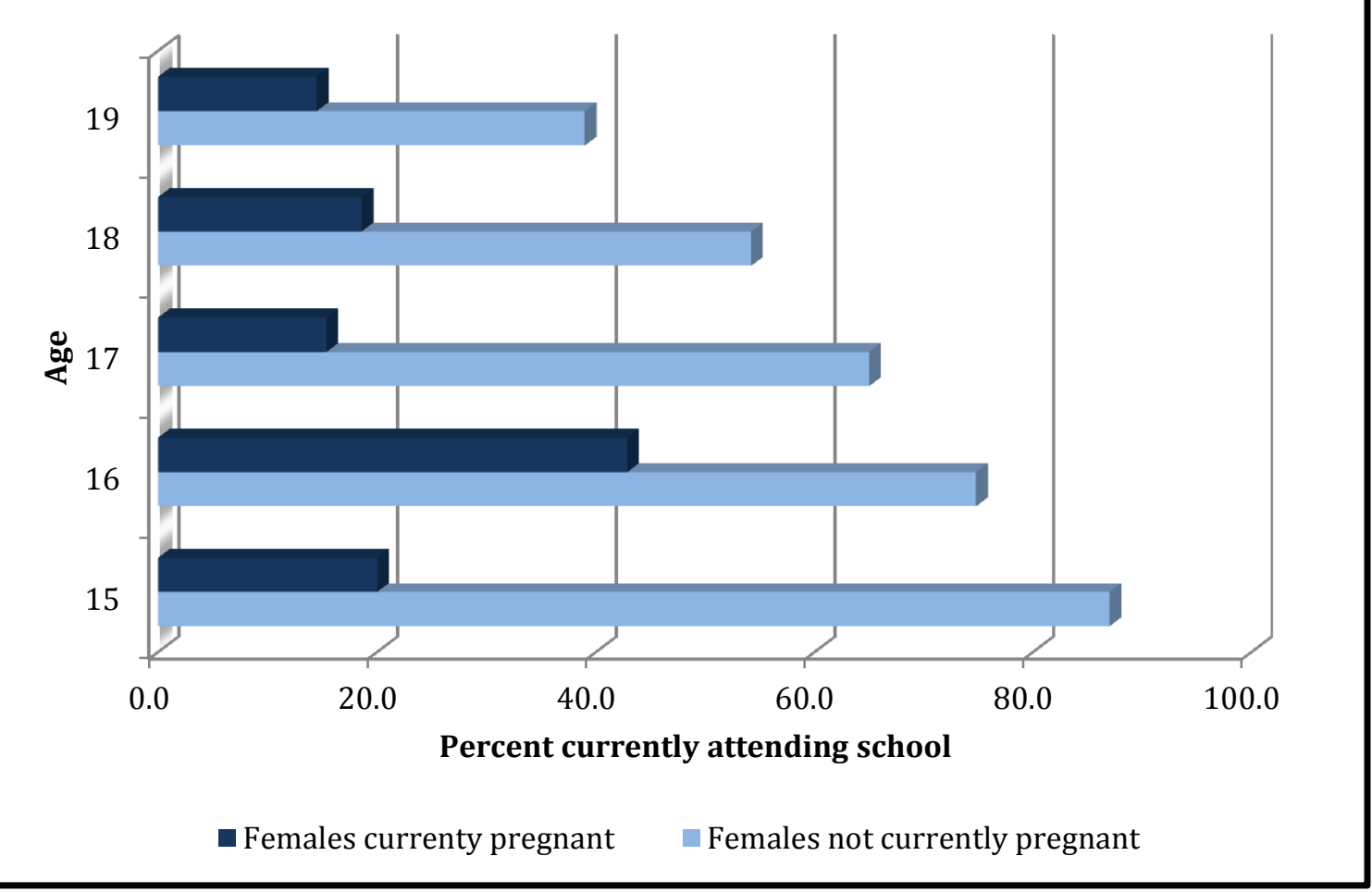

Similar to childbearing, the dynamics of marriage can lead to early school leaving, particularly among females. In many settings, the gender norms surrounding marriage and the restrictions placed on young married females may prohibit them from attending school or participating in programs. In Belize, major differences are seen in school attendance rates between those who are single and those who are in a marital union. Figure 35 below shows the different school attendance rates as they differ between single and married/in union 15-19-year-old females. More than 12 times the percent of single females age 15-19 attend school than their married/in union counterparts of the same age. In rural areas (data not shown in graphic), $51.2 \%$ of single females age 15-19 attend school while only $1.8 \%$ of married/in union females attend school; in urban areas $73.3 \%$ and $11.0 \%$ of single and married/in union 15-19-year-old females attend school, respectively. These very large differentials suggest that married females experience significant obstacles to attending school that their single counterparts either do not experience or can overcome. Service providers can assist married girls by designing programs that address their unique circumstances. 
Figure 35: Percent attending school among females age 15-19 according to 2010 Belize Census, by marital status

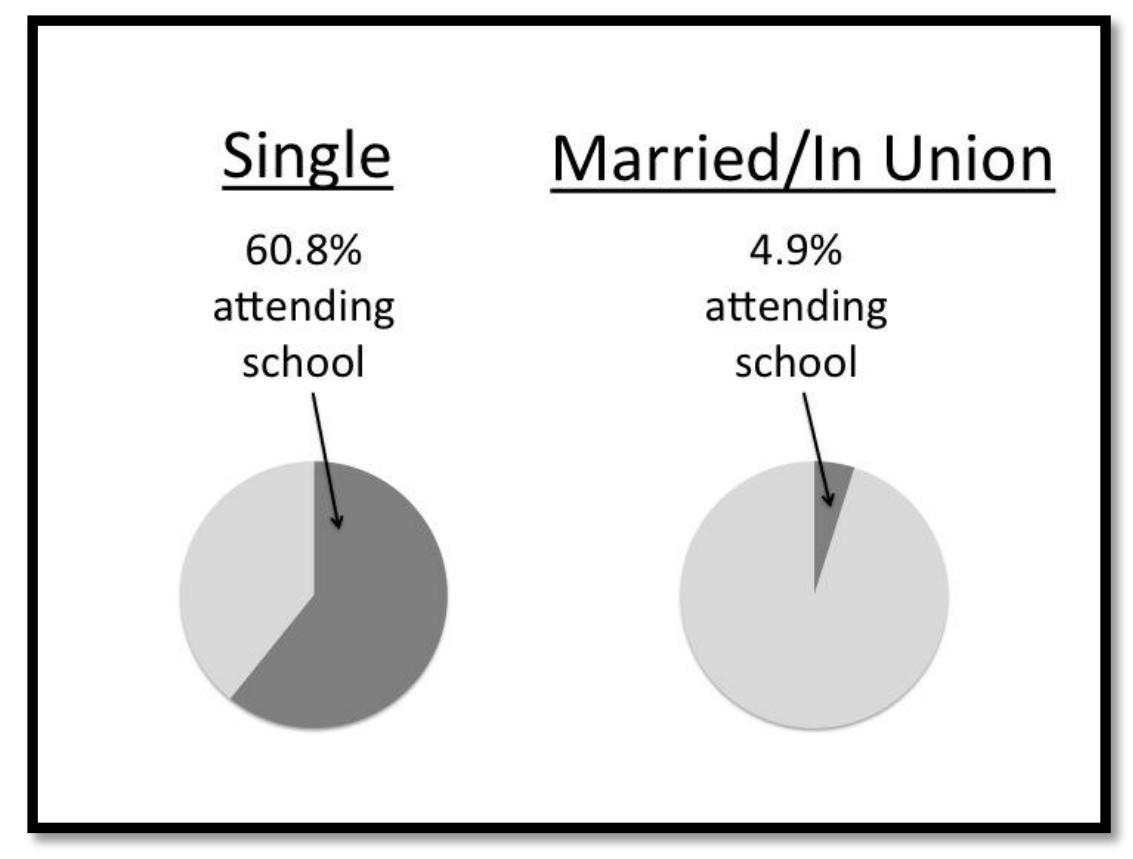

Source: 2010 Belize Census (authors' analysis of 10\% sample)

Figure 36 shows the percentage of females age 15-19 attending school when the survey was administered by their relationship status. The data show that females who are single are more likely to attend school than those who are in unions at all ages, suggesting a correlation between age, relationship status and school attendance. The decrease in school attendance rates with age seems to accelerate much more quickly for females in unions so that by age 16 less than $50 \%$ of female respondents attended school compared to more than $75 \%$ of single respondents. There was also a significant gap reported between the school attendance rates of single respondents and those in unions who are aged 18 and 19, with reported school attendance rates for those in unions at $22.5 \%$ and $17.9 \%$, respectively. While the data are not representative of Belize as a whole or of program participants throughout Belize, they highlight the relationship between being in a marital union and low school attendance rates among adolescent females. The data show that being in a union is a risk factor for adolescent females with respect to their educational attainment, thus, being in a union has the potential to increase lifelong vulnerability of females. 
Figure 36: Percent of female respondents of the 2011 Belize Coverage Exercise currently attending school, age and relationship status

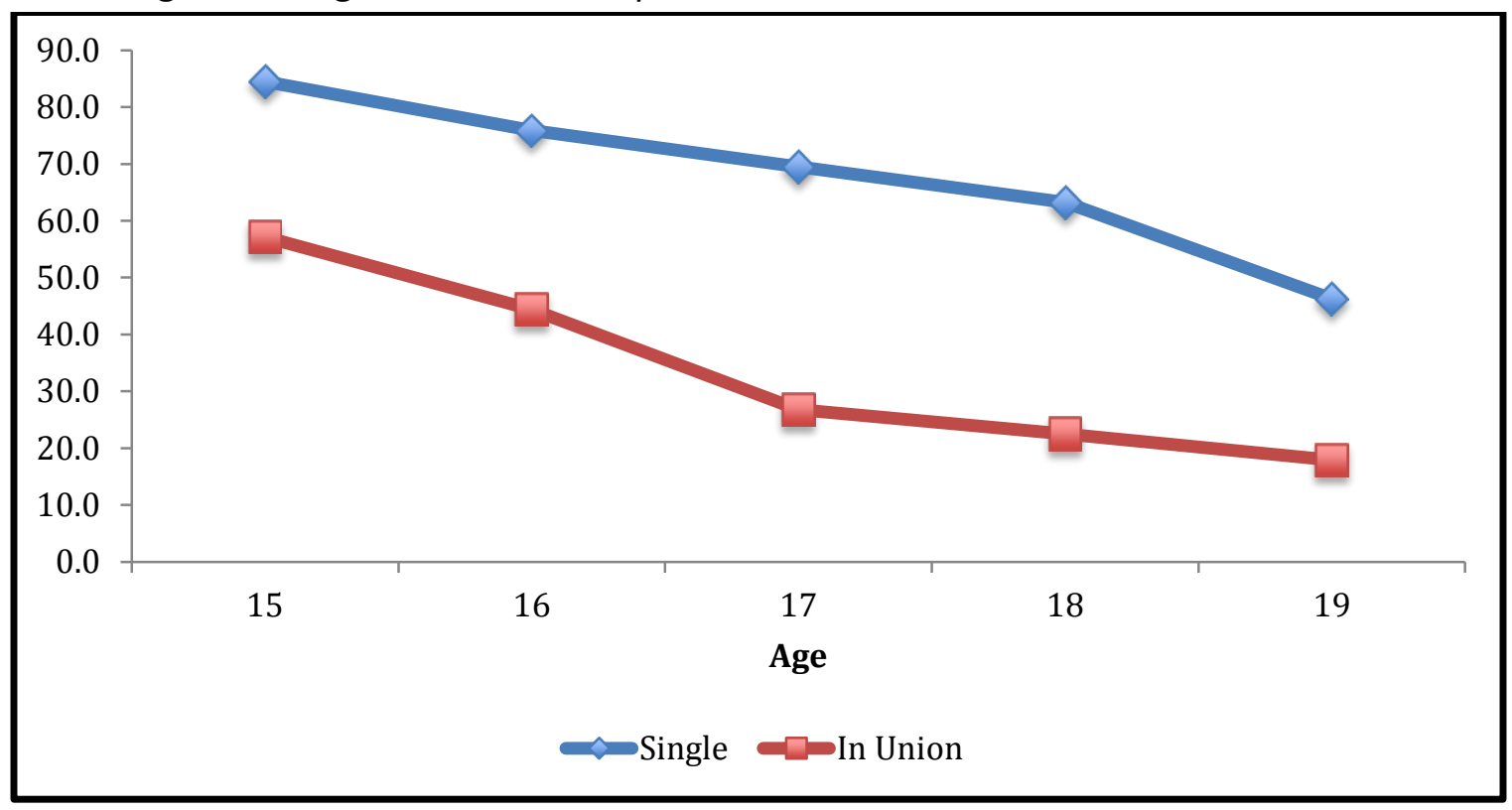

Table 23 presents data on the relationship between school attendance and work status among male and female respondents age 15-19. Work and school are often two competing interests and therefore may not permit a young person to participate fully in both. In Belize, the 2010 census shows that only $16.2 \%$ of females age $15-19$ and $9.2 \%$ of males age 15-19 who were employed were also attending school compared with $70.1 \%$ and $90.5 \%$ of unemployed females and males, respectively. Similarly, for all ages among male and female respondents (except at age 15 where $100 \%$ of females who worked reported being in school, a data point likely due to the very small sample size of this population), those young people who worked attended school at lower rates than those who did not. In some cases, such as among 17-year-old female respondents and 19year-old male respondents, the difference in school attendance rates was approximately 2-3 times. Service providers will benefit from these data as evidence to justify the need for services that support working young people to ensure they stay in school and can manage the responsibilities of both. 
Table 23: Percent of respondents of the 2011 Belize Coverage Exercise currently attending school, by age, sex and work status (worked for pay or for the family in the last month)

\begin{tabular}{|c|c|c|}
\hline Age & $\begin{array}{c}\text { Did not } \\
\text { work }\end{array}$ & Worked \\
\hline \multicolumn{3}{|c|}{ Females } \\
\hline 15 & 80.9 & 100.0 \\
\hline 16 & 74.5 & 61.9 \\
\hline 17 & 61.5 & 34.4 \\
\hline 18 & 48.8 & 36.2 \\
\hline 19 & 33.1 & 32.4 \\
\hline \multicolumn{3}{|c|}{ Males } \\
\hline 15 & 96.8 & 58.8 \\
\hline 16 & 87.2 & 78.3 \\
\hline 17 & 78.8 & 46.7 \\
\hline 18 & 53.3 & 37.9 \\
\hline 19 & 66.7 & 22.2 \\
\hline
\end{tabular}

\section{SECTION 4: CONCLUSIONS \& RECOMMENDATIONS}

\section{CONCLUSIONS}

The data presented in this report are an important evidence base for policy analysis and decision-making around program design and resource allocation. They provide a

1 snapshot in time of both the supply side (i.e., the demographic profile of beneficiaries at select service provision sites where data were collected for the $\mathrm{CE}$ ) and the demand side (i.e., population-based statistics from the 2010 Belize Population and Housing Census) of the lives of adolescents and youth in Belize. Through the cross-referencing of these distinct sources of data, a process referred to as triangulation when three or more sources are used in conjunction, stakeholders can begin to identify the subgroups of young people who are under-represented at service provision sites but, due to their unique circumstances, are in need of attention.

Data from the 2010 census, particularly the authors' analysis of the $10 \%$ sample, underscore some of the important issues young people in Belize face: early parenthood, low secondary school attendance and high unemployment, among others. Each of these play a significant role in limiting young people's ability to access the information and resources necessary for a healthy transition to adulthood and to ultimately realize their dreams. Additionally, each subgroup of young people - either from certain geographic areas or ethnic groups - experience these issues differently as evidenced by the variance in their outcomes. For example, Mayan females experience the highest rates of teen pregnancy and the lowest levels of school attendance (both primary and secondary) among females while Mayan males show the lowest grade-for-age rates. 
Similarly, Creole males and females age 18-24 have some of the highest unemployment rates among their peers.

The CE data from the respondents who were surveyed during the data collection period reflect what is happening in the general population although they are not a representative sample and should not be used to make generalized statements about young people who utilize youth services in Belize. Data show that, similar to what occurs in the general population, Mayan female and male respondents have the lowest school attendance rates while Mayan female respondents have some of the highest rates of childbearing and pregnancy. Female respondents who have had at least one child or are in a marital union attend school at very low rates relative to those who do not have children and those who are single, respectively, an issue also seen among the general population in Belize.

Service providers and their government, UN and donor partners are encouraged to use the information presented here to assess how well they are reaching the target population of young people and if the target population is actually the one with the greatest or most severe needs. This provides an opportunity to review how interventions are targeted and if considerations are being made to ensure that programs and services are relevant to the lives of the young participants. Decision-makers and program planners must do everything in their power to ensure equitable access to the resources offered by the youth service provider community of Belize if marginalized young people are to receive their fair share of these resources. Given the large size of the youth population in Belize and their role in the country's social and economic growth, it is crucial to ensure their full participation in all areas and to break down barriers they may experience on this path.

\section{Recommendations}

In order to more effectively reach the most marginalized and vulnerable populations of young people, stakeholders must base decisions on reliable and up-to-date evidence. The data presented in this report can form the cornerstone of the evidence base that informs the design and implementation of targeted polices and programs but will not help bring about the change necessary without intentional action. Below are a number of recommended areas and action items to guide practitioners through the evidence gathering and analysis, advocacy, capacity building and implementation phases. These areas are meant for a wide range of stakeholders, from local CBOs and civil society groups to government ministries, UN agencies, donors and research institutions.

\begin{tabular}{|l|l|}
\hline \multicolumn{2}{|c|}{ Area 1: Gathering and Analyzing Evidence } \\
\hline \multicolumn{1}{|c|}{ Action Items } & \multicolumn{1}{|c|}{ Relevant Actors } \\
\hline $\begin{array}{l}\text { Research the availability of data and information on young people } \\
\text { or other target populations in Belize or the region to serve as a } \\
\text { foundation of evidence }\end{array}$ & CBOs/Civil society groups \\
UN agencies \\
Government ministries
\end{tabular}

$66 \mid \mathrm{P}$ a g e 


\begin{tabular}{|c|c|}
\hline & Research institutions \\
\hline $\begin{array}{l}\text { Identify the vulnerable or marginalized subgroups of young people } \\
\text { within the population through careful review of data, paying close } \\
\text { attention to differences in outcomes along the lines of sex, } \\
\text { ethnicity, education, marital status, childbearing and area of } \\
\text { residence, among others }\end{array}$ & $\begin{array}{l}\text { CBOs/Civil society groups } \\
\text { UN agencies } \\
\text { Government ministries } \\
\text { Research institutions }\end{array}$ \\
\hline $\begin{array}{l}\text { Design and implement adolescent surveys to fill information gaps } \\
\text { and highlight the individual-level, daily experiences of young } \\
\text { people from priority areas or groups }\end{array}$ & $\begin{array}{l}\text { Research institutions } \\
\text { UN agencies } \\
\text { Government ministries } \\
\text { Donors }\end{array}$ \\
\hline $\begin{array}{l}\text { Expand daily program or service registers to include more } \\
\text { demographic data on the young people (see CE questionnaire } \\
\text { below) }\end{array}$ & CBOs/Civil society groups \\
\hline $\begin{array}{l}\text { Work with well-respected and informed community members to } \\
\text { deepen the scope of the information on the lives of the local youth } \\
\text { and adolescent population }\end{array}$ & $\begin{array}{l}\text { CBOs/Civil society groups } \\
\text { Research institutions }\end{array}$ \\
\hline \multicolumn{2}{|l|}{ Area 2: Advocacy } \\
\hline Action Items & Relevant Actors \\
\hline Select target population(s) for the focus of advocacy campaign & $\begin{array}{l}\text { CBOs/Civil society groups } \\
\text { UN agencies } \\
\text { Donors }\end{array}$ \\
\hline $\begin{array}{l}\text { Utilize available data when making arguments for justifying the } \\
\text { need to focus on the select population(s) and seeking resources to } \\
\text { support the campaign }\end{array}$ & $\begin{array}{l}\text { CBOs/Civil society groups } \\
\text { UN agencies }\end{array}$ \\
\hline $\begin{array}{l}\text { Link advocacy campaign, policy and programmatic goals with } \\
\text { national Millennium Development Goals and poverty reduction } \\
\text { strategy goals and objectives }\end{array}$ & $\begin{array}{l}\text { CBOs/Civil society groups } \\
\text { UN agencies } \\
\text { Government ministries }\end{array}$ \\
\hline \multicolumn{2}{|l|}{ Area 3: Building Local Capacity } \\
\hline Action Items & Relevant Actors \\
\hline $\begin{array}{l}\text { Select local partners interested in designing and implementing } \\
\text { targeted programs for vulnerable young people }\end{array}$ & $\begin{array}{l}\text { CBOs/Civil society groups } \\
\text { UN agencies } \\
\text { Government ministries } \\
\text { Donors }\end{array}$ \\
\hline $\begin{array}{l}\text { Work with mentors to build institutional capacity of these partners } \\
\text { to design a targeted program }\end{array}$ & $\begin{array}{l}\text { CBOs/Civil society groups } \\
\text { UN agencies } \\
\text { Government ministries } \\
\text { Donors }\end{array}$ \\
\hline $\begin{array}{l}\text { Develop project proposal for targeted program and share with } \\
\text { partners/donors }\end{array}$ & CBOs/Civil society groups \\
\hline $\begin{array}{l}\text { Develop individual-level outcome indicators that focus on the skills } \\
\text { and information the program/service will help to build in the young }\end{array}$ & CBOs/Civil society groups \\
\hline
\end{tabular}




\begin{tabular}{|c|c|}
\hline participants & \\
\hline $\begin{array}{l}\text { Expand portfolios and annual work plans to include funding for } \\
\text { targeted interventions for adolescent girls and other vulnerable } \\
\text { populations of young people }\end{array}$ & $\begin{array}{l}\text { UN agencies } \\
\text { Government ministries } \\
\text { Donors }\end{array}$ \\
\hline \multicolumn{2}{|l|}{ Area 4: Program Implementation } \\
\hline Action Items & Relevant Actors \\
\hline $\begin{array}{l}\text { Focus interventions on building the social and human capital of } \\
\text { participants }\end{array}$ & $\begin{array}{l}\text { CBOs/Civil society groups } \\
\text { UN agencies } \\
\text { Government ministries } \\
\text { Donors }\end{array}$ \\
\hline $\begin{array}{l}\text { Target programs at subgroups of vulnerable young people identified } \\
\text { through an analysis of available evidence }\end{array}$ & $\begin{array}{l}\text { CBOs/Civil society groups } \\
\text { UN agencies } \\
\text { Government ministries } \\
\text { Donors }\end{array}$ \\
\hline $\begin{array}{l}\text { Provide technical support and funding for innovative, holistic } \\
\text { programs based on evidence }\end{array}$ & $\begin{array}{l}\text { CBOs/Civil society groups } \\
\text { UN agencies } \\
\text { Government ministries } \\
\text { Donors }\end{array}$ \\
\hline $\begin{array}{l}\text { Designate resources for programs that support adolescent girls and } \\
\text { young women }\end{array}$ & $\begin{array}{l}\text { CBOs/Civil society groups } \\
\text { UN agencies } \\
\text { Government ministries } \\
\text { Donors }\end{array}$ \\
\hline
\end{tabular}




\section{References}

Bruce, Judith. 2007. "The Girls Left Behind: Outside the Box and Out of Reach," AIDSLink (101) <http://www.globalhealth.org/publications/article.php3?id=1597>.

Economic Commission for Latin America and the Caribbean (ECLAC). 2005. Objetivos de desarrollo del milenio: Una mirada desde América Latina y el Caribe. Santiago: United Nations.

Haberland, Nicole, Chong, Erica and Bracken, Hillary. 2003. "Married Adolescents: An Overview." Paper prepared for the WHO/UNFPA/Population Council Technical Consultation on Married Adolescents (9-12 December 2003). Geneva: WHO. Paper can be found at <www.popcouncil.org/pdfs/MA-Overview.pdf>

Hallman, Kelly. 2007. "Nonconsensual sex, school enrollment and educational outcomes in South Africa," Africa Insight 37(3): 454-472.

International Labour Organization (ILO). 2011. Global Employment Trends for Youth: 2011 Update. Geneva: ILO.

Lloyd, Cynthia B. 2010. "The role of schools in promoting sexual and reproductive health among adolescents in developing countries." In: Malarcher, Shawn (Ed.). Social determinants of sexual and reproductive health: informing future research and programme implementation. Geneva: World Health Organization; 113-131.

Matsumoto, Makiko and Elder, Sara. 2010. Characterizing the school-to-work transitions of young men and women: Evidence from the ILO School-to-work transition surveys. Employment Sector Working Paper No. 51. Geneva: International Labour Organization.

Statistics Institute of Belize (SIB). 2011. Main Results of 2010 Population and Housing Census. Belmopan: SIB.

United Nations. 2007. Principles and Recommendations for Population and Housing Censuses, revision 2. New York, UN Statistics Division, Statistical Papers, Series M, No. 67/Rev.2.

United Nations High Commissioner for Refugees (UNHCR). 2012. World Directory of Minorities and Indigenous Peoples - Mexico : Indigenous peoples.

<http://www.unhcr.org/refworld/topic,463af2212,469f2e812,49749ce423,0,,,html> Accessed 11 February 2012.

Weiner, Adam. 2011. "Assessing equity of access in youth programs," Promoting Healthy, Safe, and Productive Transitions to Adulthood Brief (no. 28). New York: Population Council.

World Bank. 2012. Fertility rate, total (births per woman).

<http://data.worldbank.org/indicator/SP.DYN.TFRT.IN〉. Accessed 14 March 2012.

69|P a g e 


\section{SECTION 5: APPENIDICES}

\section{APPENDIX 1: PARTICIPATING ORGANIZATIONS PROFILES}

Table 1: Belize District

\begin{tabular}{|l|c|l|c|}
\hline \multicolumn{1}{|c|}{ Site Name } & Received Questionnaires & \multicolumn{1}{c|}{ Site Name } & Received Questionnaires \\
\hline Cleopatra White & 348 & YES & 18 \\
\hline Matron Roberts & 492 & Dorothy Menzies & 32 \\
\hline Youth for The Future & 142 & Yabrough Girl Guides & 33 \\
\hline BFLA & 8 & $\begin{array}{c}\text { Samuel Haynes Institute of } \\
\text { Excellence }\end{array}$ & \\
\hline BFLA - NHI & 254 & & \\
\hline BFLA -YAM & 14 & & $\mathbf{9 1}$ \\
\hline YWCA & 43 & & \\
\hline Total & $\mathbf{1 3 0 1}$ & & \\
\hline
\end{tabular}

Table 2: Stann Creek District

\begin{tabular}{|l|c|}
\hline Site Name & Received Questionnaires \\
\hline Dangriga Polyclinic & 430 \\
\hline Pomona Polyclinic & 238 \\
\hline Hopkins Polyclinic & 145 \\
\hline POWA & 388 \\
\hline Women's Department & 108 \\
\hline Little Sisters Club & 42 \\
\hline Total & $\mathbf{1 3 5 1}$ \\
\hline
\end{tabular}

Table 3: Toledo District

\begin{tabular}{|l|c|}
\hline \multicolumn{1}{|c|}{ Site Name } & Received Questionnaires \\
\hline Punta Gorda Polyclinic & 214 \\
\hline Santa Teresa Polyclinic & 103 \\
\hline San Antonio Polyclinic & 133 \\
\hline Big Falls Polyclinic & 123 \\
\hline Youth for the Future - PG & 67 \\
\hline Toledo Maya Women's Council & 95 \\
\hline
\end{tabular}

$70 \mid \mathrm{P}$ a g e 


\begin{tabular}{|l|c|}
\hline Women's Department - PG & 10 \\
\hline Girl Guides - PG & 20 \\
\hline Total & $\mathbf{7 6 5}$ \\
\hline
\end{tabular}

\section{Appendix 2: Questionnaire}

71 | $\mathrm{P}$ a g e 


\section{Belize Youth \& Adolescent Program Coverage Survey}

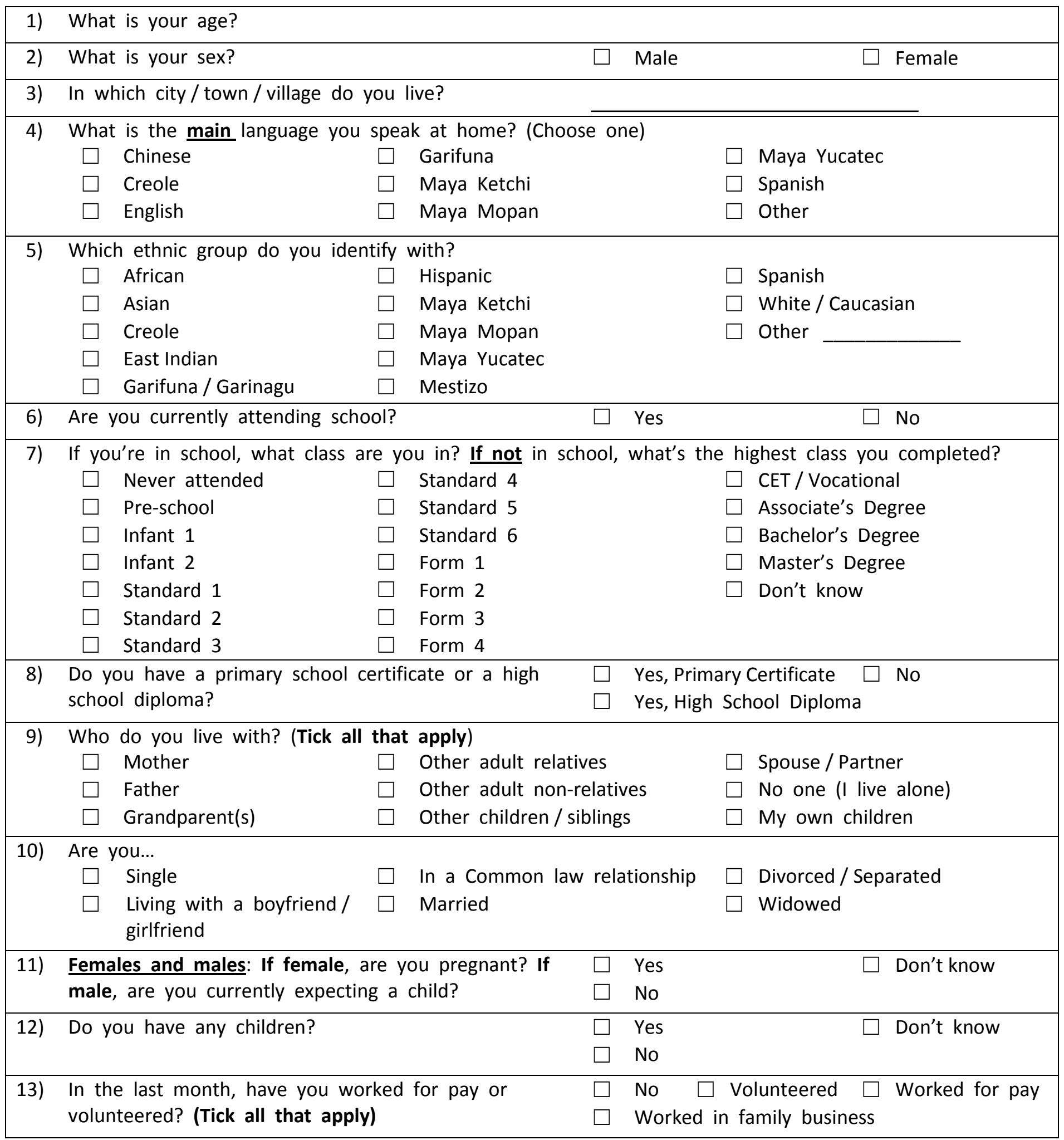




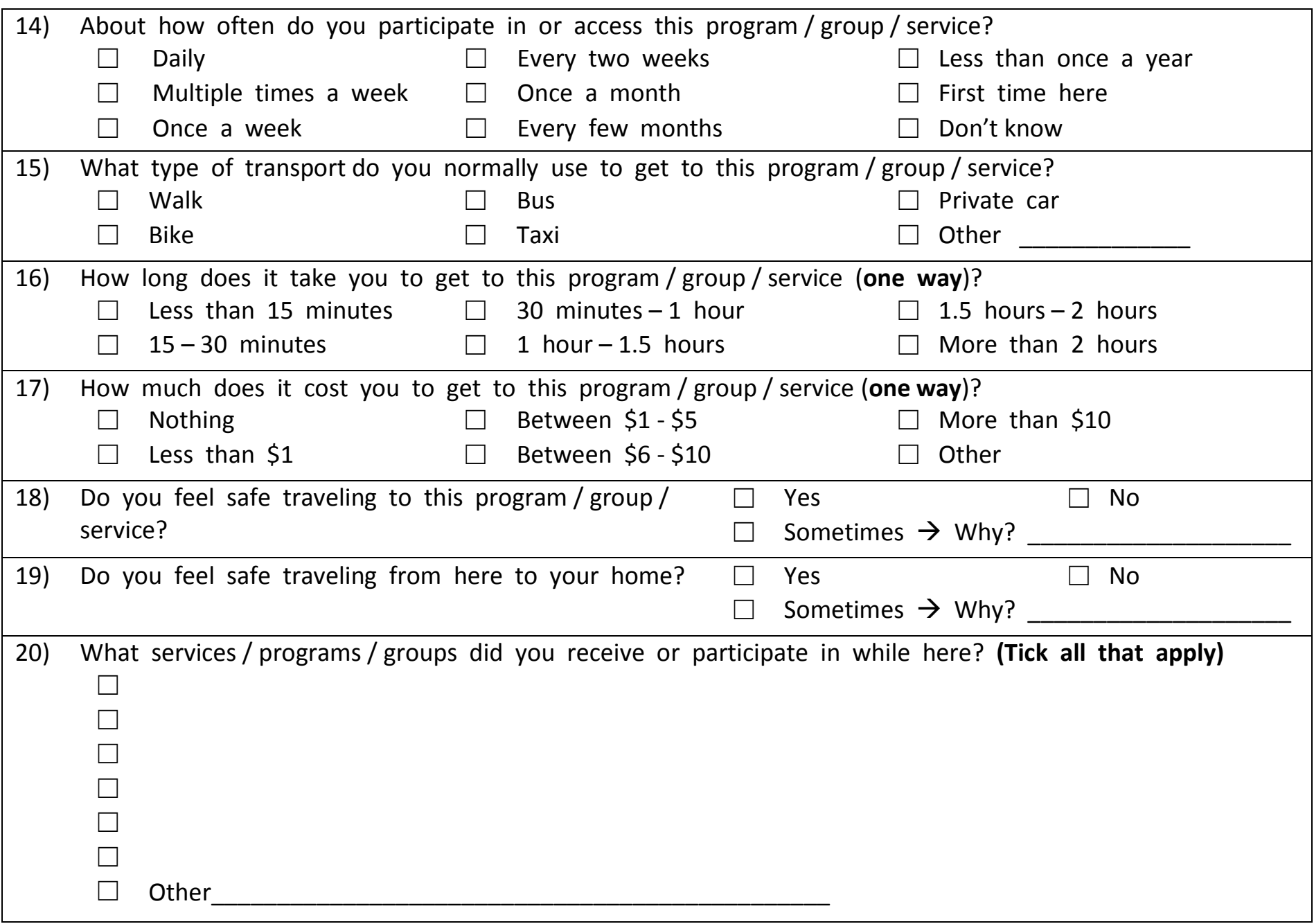




\section{JoINT UN PROGRAMME}

OF

Adolescent GiRls

BELIZE COVERAGE EXERCISE STUDY:

ASSESSING THE STATUS TO BUILD A PORTFOLIO OF TARGETED INTERVENTIONS FOR VULNERABLE GIRLS
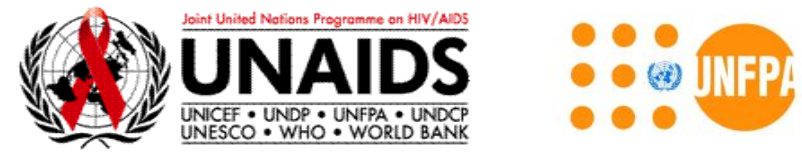